PATRICIA RZEZAK

\title{
Avaliação das funções executivas e mnésticas de crianças e adolescentes com epilepsia de lobo temporal
}

\author{
Tese apresentada à Faculdade de Medicina da \\ Universidade de São Paulo para obtenção do título \\ de Doutor em Ciências
}

Área de concentração: Psiquiatria Orientador: Dra. Kette Dualibi Ramos Valente

São Paulo 2009 


\title{
PATRICIA RZEZAK
}

\section{Avaliação das funções executivas e mnésticas de crianças e adolescentes com epilepsia de lobo temporal}

\author{
Tese apresentada à Faculdade de Medicina da \\ Universidade de São Paulo para obtenção do título \\ de Doutor em Ciências \\ Área de concentração: Psiquiatria \\ Orientador: Dra. Kette Dualibi Ramos Valente
}

São Paulo 2009 
Dados Internacionais de Catalogação na Publicação (CIP)

Preparada pela Biblioteca da

Faculdade de Medicina da Universidade de São Paulo

\section{Creprodução autorizada pelo autor}

Rzezak, Patricia

Avaliação das funções executivas e mnésticas de crianças e adolescentes com epilepsia de lobo temporal / Patricia Rzezak. -- São Paulo, 2009.

Tese(doutorado)--Faculdade de Medicina da Universidade de São Paulo.

Departamento de Psiquiatria.

Área de concentração: Psiquiatria.

Orientadora: Kette Dualibi Ramos Valente.

Descritores: 1.Neuropsicologia 2.Funções executivas 3.Atenção 4.Memória 5.Epilepsia do lobo temporal 6.Criança 7.Adolescente

USP/FM/SBD-314/09 
Esta tese é especialmente dedicada às pessoas com as quais convivi que me ensinaram a importância da boa formação, da aprendizagem, do esforço e do conhecimento ou que propiciaram meios para que eu os adquirisse.

Meus pais, Lea e Moyses Rzezak, sem os quais não teria aprendido o valor do trabalho e a importância de persistir apesar das adversidades. Obrigada pela força, carinho e incontáveis ajudas nos momentos mais difíceis.

Meu marido, Richard Tencer, pela lógica e objetividade, mas sempre com muito carinho.

Minha Orientadora, Dra. Kette Dualibi Ramos Valente, com quem aprendi imensamente sobre a epilepsia e sobre a vida. Obrigada por abrir as portas do conhecimento com tanta generosidade e por ter depositado tamanha confiança em minha capacidade e trabalho.

Dr. Daniel Fuentes, quem me apresentou a neuropsicologia e compartilhou seu entusiasmo e raciocínio clínico. Obrigada pelas inúmeras discussões, as antigas, as atuais e as futuras.

Aos amigos neuropsicólogos Juliana Góis, Pedro Zuccolo e Sylvie Paes Moschetta pelo apoio constante e amizade em todos os momentos.

A todos os profissionais envolvidos, direta ou indiretamente, no processo de elaboração e execução deste trabalho.

Às Dras. Sigride Thomé-Souza, Evelyn Kuczynski, Lia Fiore, Silvia de Vincentiis, Tatiane Pradines e Adriana Pereira.

Aos membros do Laboratório de Neurofisiologia do Instituto de Psiquiatria do Hospital das Clínicas da Faculdade de Medicina da USP. 
Sumário

$\begin{array}{ll}\text { Lista de Abreviaturas } & \\ \text { Lista de Tabelas } & \\ \text { Lista de Figuras } & 1 \\ \text { Resumo } & 24 \\ \text { Summary } & 27 \\ \text { Introdução } & 27 \\ \text { Justificativa } & 28 \\ \text { Objetivos } & 37 \\ \text { Casuística e Métodos } & 58 \\ \text { Resultados } & 74 \\ \text { Discussão } & 75 \\ \text { Conclusões } & 85 \\ \text { Anexos } & 75 \\ \text { Referências } & \end{array}$ 


\section{Lista de Abreviaturas}

$\mathrm{AH}$ : atrofia hipocamapal

CPF: Córtex pré-frontal

DAE: droga antiepiléptica/drogas antiepilépticas

DD: Dígitos Diretos

DE: Disfunção Executiva

DI: Dígitos Indiretos

ELT: epilepsia do lobo temporal

EMT: esclerose mesial temporal

EEG: eletrencefalograma

FE: funções executivas

FV: Fluência Verbal

ILAE: International League Against Epilepsy (Liga Internacional Contra a Epilepsia)

J: Janelas Digitais

LT: lobo temporal

DMn: Déficits de Memória/ Déficits Mnésticos/ Disfunção de Memória

MFFT: Matching Familiar Figures Test

NL: Memória para Número e Letra

PET: Tomografia por Emissão de Pósitrons

QI: Quociente Intelectual

RM: Ressonância Magnética

SD: Standard Desviation (Desvio Padrão)

SPECT: Tomografia Computadorizada por Emissão de Fóton único

TMT: Trail Making Test

Vídeo-EEG: vídeo-eletrencefalograma ou vídeo-eletrencefalografia

TCG: crises tônico-clônicas

WCST: Wisconsin Card Sorting Test

WISC: Wechsler Intelligence Scale for Children (Escala de Inteligência de Wechsler para crianças). 


\section{STA DE TABELAS}

Tabela 1 Caracterização dos Pacientes

Tabela 2 Caracterização intragrupo de Pacientes com ELT Sintomática e Criptogênica

Tabela 3 Tabela descritiva das variáveis clínicas da Epilepsia

Tabela 4 Comparação do desempenho de Pacientes e Controles nos testes de Memória

Tabela 5 Comparação do desempenho de Pacientes com lesão à direita e à esquerda nos testes de Memória

Tabela 6 Comparação do desempenho de Pacientes e Controles nos testes de Funções Executivas

Tabela 7 Comparação do desempenho de Pacientes Sintomáticos e Criptogênicos nos testes de Memória

Tabela 8 Comparação do desempenho de Pacientes com Atrofia Hipocampal e demais Pacientes com ELT nos testes de Memória

Tabela 9 Comparação do desempenho de Pacientes Sintomáticos e Controles nos testes de Funções Executivas

Tabela 10 Comparação do desempenho de Pacientes com Atrofia Hipocampal e demais Pacientes com ELT nos testes de Funções Executivas

Tabela 11 Influência das Variáveis Clínicas da Epilepsia no desempenho de Pacientes testes de Memória

Tabela 12 Influência das Variáveis Clínicas da Epilepsia no desempenho de Pacientes testes de Funções Executivas

Tabela 13 Comparação do Desempenho de Pacientes segundo a idade no momento da testagem nos Testes de Memória

Tabela 14 Comparação do Desempenho de Pacientes segundo a idade de início da epilepsia nos Testes de Memória

Tabela 15 Comparação do Desempenho de Pacientes segundo a idade no momento da testagem nos Testes de Funções Executivas

Tabela 16 Comparação do Desempenho de Pacientes segundo a idade de início da epilepsia nos Testes de Funções Executivas

Tabela 17 Gravidade da Disfunção Executiva e de Memória em Pacientes e Pacientes Sintomáticos e Criptogênicos

Tabela 18 Correlação entre os testes de Funções Executivas e Memória dos pacientes com ELT

Tabela 19 Correlação entre os testes de Funções Executivas e Memória dos controles

Tabela 20 Correlação entre o Desempenho em Testes Executivos e de Memória 


\section{LISTA DE FI GURAS}

Figura 1 Ressonância Magnética do lobo temporal 2

Figura 2 Formação Hipocampal 4

$\begin{array}{lll}\text { Figura } 3 & \text { Conexões internas do Hipocampo } & 17\end{array}$

Figura 4 Conexões do lobo temporal mesial e estruturas pré-frontais 18

Figura $5 \quad$ Atrofia Hipocampal no Lobo Temporal Esquerdo evidenciada por hipersinal 30 em imagens pesadas em T2

Figura $6 \quad$ Gravidade da Disfunção de Memória em pacientes com ELT 51

Figura $7 \quad$ Gravidade da Disfunção de Executiva em pacientes com ELT 52 
RESUMO

Rzezak P. Avaliação das funções executivas e mnésticas em crianças e adolescentes com epilepsia de lobo temporal [tese]. São Paulo: Faculdade de Medicina, Universidade de São Paulo; 2009.

Os objetivos deste estudo foram investigar a presença e gravidade de disfunção mnéstica e executiva em crianças com epilepsia do lobo temporal; verificar a influência das variáveis clínicas da epilepsia e o impacto da disfunção executiva sobre a memória. Para tal, comparou-se o desempenho de 32 crianças com epilepsia do lobo temporal e 21 crianças saudáveis com paradigmas de memória, funções atencionais e executivas. Pacientes tiveram pior desempenho do que os controles, em atividades de atenção, memória e funções executivas. Observou-se disfunção mnéstica e executiva grave em $56,25 \%$ e $71,88 \%$ dos pacientes, respectivamente. A presença de atrofia hipocampal, idade de início precoce, duração e politerapia influenciaram negativamente o desempenho executivo e mnéstico.

Descritores: Neuropsicologia, Funções executivas, Atenção, Memória, Epilepsia do lobo temporal, criança, adolescente. 


\section{SUMMARY}

Rzezak P. Evaluation of executive and memory functions in children and adolescents with temporal lobe epilepsy [thesis]. Faculty of Medicine, University of São Paulo, SP (Brazil); 2009.

The present study aimed to investigate the presence and severity of memory and executive dysfunction in children with temporal lobe epilepsy; evaluate the influence of epilepsy clinical variables and the impact of executive dysfunction in memory. For this purpose, performance on attentional, executive and memory function tests of 32 children with temporal lobe epilepsy were compared to 21 healthy children. Patients had a worse performance than controls in tasks of attention, memory and executive functions. Severe memory and executive dysfunction were demonstrated in $56.25 \%$ and $71.88 \%$ of patients, respectively. The presence of hippocampus atrophy, early seizure onset, duration, and politherapy negatively influenced executive and mnestic performance.

Descriptors: Neuropsychology, Executive functions, attention, memory, Temporal lobe epilepsy, children, adolescents. 


\section{Epilepsia do Lobo Temporal}

A epilepsia afeta aproximadamente 1 a 3\% da população, o que a torna um dos distúrbios neurológicos mais freqüentes. Segundo os dados da OMS, a epilepsia representa a segunda maior causa de procura por centros de Saúde Mental, depois da depressão.

Estima-se que 2.700.000 pessoas vivam com epilepsia nos EUA. Esta população tem um custo para o Sistema de Saúde de U\$12,5 bilhões /ano (Begley et al., 2000). Este custo varia, sendo de U\$ 4272 nos pacientes com remissão após o diagnóstico para U\$ 138602 nos pacientes com crises freqüentes e intratáveis (Begley et al., 1994). O custo elevado é referente predominantemente às despesas indiretas $(67,2 \%)$ causadas pela incapacitação observada no grupo de pacientes com epilepsia refratária ou epilepsia de difícil controle (Begley et al., 1994). Deste grupo, destaca-se a epilepsia de lobo temporal (ELT) por ser a causa mais freqüente de epilepsia refratária no adulto com remissão de $90 \%$ das crises após a cirurgia, quando diagnosticada adequada e precocemente.

Nos países em desenvolvimento as taxas de incidência anual da epilepsia são de 122 a 190/100 000 indivíduos (Placencia et al., 1992). As principais causas da maior taxa de incidência em países em desenvolvimento são atribuíveis a doenças parasitárias (principalmente neurocisticercose), infecções intracranianas virais ou bacterianas, traumatismo crânio encefálico (TCE) e doenças cerebrovasculares (Gomes, 2000; Li et al., 1985; Scott et al., 2001; Senanayake et al., 1993).

Os estudos epidemiológicos da epilepsia no Brasil, entretanto, ainda são escassos. Além disso, os estudos existentes demonstraram diferentes taxas de prevalência em diversas cidades brasileiras. Desta forma, Almeida Filho (1980) demonstrou a prevalência de 0,1\% de indivíduos com epilepsia ativa na cidade de Salvador, Marino Jr. et al. (1986) encontraram a prevalência de 1,19\% em São Paulo, Fernandes et al. (1992) mostraram 1,65\% de sujeitos com epilepsia ativa e 2,03\% com epilepsia inativa em Porto Alegre e Borges et al. (2002) encontraram 1,2\% de epilepsia ativa e 0,6\% inativa nos índios Bakari, residentes no rio Paranatinga, afluente do rio Xingu. 
O estudo de Noronha et al. (2007) demonstrou que a prevalência ao longo da vida de epilepsia no Brasil é de 9,2/1000 e de epilepsia ativa é de 5,4/1000 indivíduos e que a prevalência era maior entre as classes sociais mais baixas (7,5/1000 comparado a 1,6/1000 em classes mais altas) e entre a população idosa (8,5/1000). Além disso, 38\% dos pacientes com epilepsia ativa receberam tratamento inadequado (19\% sem medicação) o que parece ser semelhante em diferentes grupos socioeconômicos. Estes achados são similares a outros, demonstrados em países em desenvolvimento.

Assim, demonstrou-se que a epilepsia é mais prevalente entre as classes socioeconômicas mais baixas e entre os idosos, revelando a necessidade de educar e orientar a população brasileira de que a epilepsia é uma condição tratável e possível de ser prevenida.

A ELT é a epilepsia focal mais comum em adolescentes e adultos, na qual as crises são originadas em um ou ambos os lobos temporais (LT) (Stafstrom, 2006). (Figura 1)

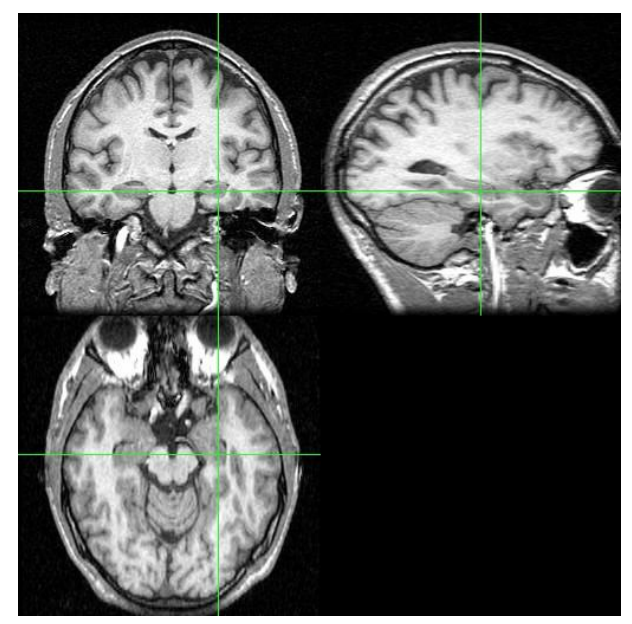

Figura 1 - Ressonância Magnética do lobo temporal.

A necessidade de ampliar os estudos sobre a ELT encontra-se em sua alta prevalência e pelo fato de pacientes refratários ao tratamento medicamentoso responderem bem ao tratamento cirúrgico, obtendo uma remissão de crises em 80 a 90\% dos casos (Cendes \& Kobayashi, 2000). 
Estas crises podem originar-se nas regiões lateral, inferior e mesial do LT e o distúrbio, por sua vez, varia dependendo da etiologia, idade de início da epilepsia, tipo de crise epiléptica, gravidade e duração da epilepsia (Sauerwein et al., 2005).

Estudos neurofisiológicos como a monitorização vídeo-eletroencefalográfica (vídeo-EEG) associados ao uso de técnicas de neuroimagem estrutural permitiram o diagnóstico adequado das ELT assim como um melhor delineamento eletroclínico, possibilitando a definição de duas entidades clínicas distintas: a ELT mesial e a lateral (Saygi et al., 1994; Burgerman et al., 1995; Fish, 1996; O'Brien et al., 1996; Pacia et al., 1996; Sanah et al., 1996).

Desta forma, as manifestações clínicas e comportamentais da ELT são heterogêneas, bem como as disfunções que são mediadas por muitas estruturas anatômicas e seus componentes límbicos. Fenômenos ictais como respostas autonômicas, automatismos, sensações viscerais, respostas emocionais, alucinações auditivas e visuais, distúrbios transitórios de memória e episódios psicóticos costumam estar relacionados com descargas originadas em estruturas mesiais, principalmente no hipocampo, giro parahipocampal e amígdala (Sauerwein et al., 2005).

As manifestações interictais e de longo-prazo, por sua vez, costumam ser complexas e dependem de um grande número de fatores, tais como: localização do foco epileptogênico, tipo de crise predominante e duração da epilepsia (Sauerwein et al., 2005).

Entre os fatores etiológicos envolvidos na ELT encontram-se: Atrofia Hipocampal (AH), processos neoplásicos, distúrbios do desenvolvimento cortical, cistos e mal-formações vasculares, lesões atróficas, além da ELT familiar benigna. Em adultos, a AH é a causa mais freqüente de ELT (Sheibel, 1991; Jackson et al., 1993).

Em adultos, as manifestações clínicas das crises do LT com origem mesial tendem a seguir uma seqüência previsível de eventos (Delgado-Escueta et al., 1982; Kotagal, 1993; Jorge et al., 1996): aura, parada das atividades com mudança de atitudes e, geralmente, fixação do olhar, automatismos ipsilaterais e alterações motoras contralaterais - distonias e/ou paresias ao foco epileptogênico. 
Estas crises duram, em média, de 90 a 180 segundos e estes eventos são seguidos de confusão mental pós-ictal que pode durar até 30 minutos. A generalização secundária pode ocorrer (Wieser et al., 1992).

Há menos estudos e informações sobre a ELT lateral quando comparada à ELT mesial. No entanto, a ocorrência de ilusões ou alucinações auditivas, de pseudovertigens ou um bloqueio súbito da fala no início da crise sugerem um envolvimento do córtex temporal lateral (Erickson et al., 2006; Villanueva et al., 2005). Posteriormente, as crises decorrentes desta região podem apresentar manifestações motoras que muitas vezes se confundem com as crises hipermotoras do lobo frontal (Manford et al., 1996).

A ELT determinada por AH (Figura 2) é reconhecida como uma das formas mais comuns de desordem epileptogênica em humanos, sendo responsável por, aproximadamente, $60 \%$ dos casos de ELT (Engel, 1996; 2001). Além disso, a AH é encontrada em 50 a $70 \%$ dos casos de ELT mesial refratária ao tratamento clínico (Babb \& Brown, 1986; Leite et al., 2005).

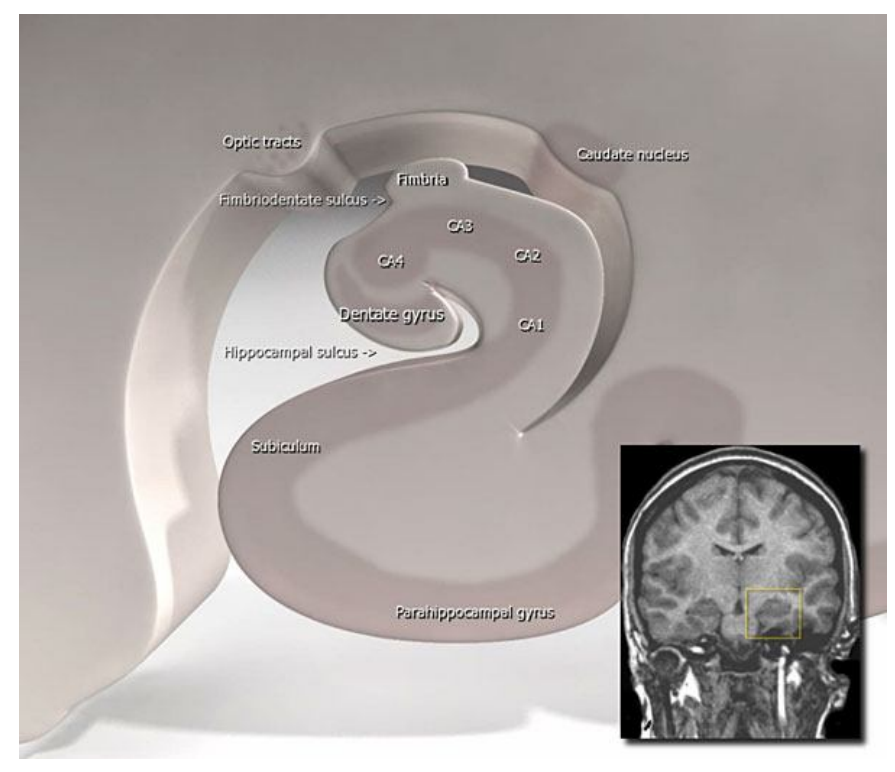

Figura 2 - Formação Hipocampal

Com a utilização de diversas técnicas de neuroimagem - tomografia por emissão de pósitrons (PET), tomografia computadorizada por emissão de fóton único (SPECT) e a ressonância magnética (RM) - foi possível demonstrar que as anormalidades cerebrais da AH não 
estão limitadas à região epileptogênica, como era esperado. Assim, evidenciou-se o espraiamento para regiões extrahipocampais e extratemporais, incluindo os lobos frontal e parietal, região neocortical do LT, gânglios da base, tálamo, estruturas límbicas e cerebelo (Kim et al., 2003). Nas $\mathrm{AH}$, as ressecções cirúrgicas possibilitaram a análise do tecido envolvido, demonstrando a presença de três componentes: a perda de células nervosas, a gliose e a reorganização (Spencer et al., 2001).

Portanto, os achados anatomopatológicos são: perda neuronal ou gliose do hillus denteado e células piramidais do tecido do hipocampo (Stafstrom, 2006). Estudos recentes apontam para morte celular em áreas límbicas extrahipocampais como o complexo subicular, córtex entorrinal e amígdala (Bernasconi et al., 2003; Schwarcz et al., 2002).

Apesar de ter-se constatado a alta incidência de crises febris complicadas em pacientes com AH, a causa destas crises ainda é desconhecida. Cendes \& Kobayashi (2000) sugerem que insultos cerebrais nas primeiras fases do desenvolvimento sejam as principais causas de AH. Assim a AH teria início nos primeiros anos de vida, mas poderia ser agravada pela presença de crises tônico-clônico generalizadas freqüentes e de estado de mal focal. Além disso, a maior incidência de história familiar de epilepsia, entre estes pacientes, sugere uma predisposição genética (revisão em Stafstrom et al., 2006).

Assim, por um lado a lesão em idade precoce desencadearia uma série de reações em cascata: molecular, fisiopatológica, alterações cerebrais estruturais, que podem resultar na clássica AH e por outro exames genéticos em pacientes com ELT apontam para uma mutação do gene EPITEMPIN ou LCI1 (leucin-rich glioma-inactivated 1), originalmente relacionado com gliomas, em casos de crises do LT lateral (Ottman et al., 2004). No entanto, a função normal deste gene, sua predileção para a ELT lateral e como ele altera o balanço excitação/inibição para originar a epilepsia ainda estão sendo investigados (revisão em Stafstrom et al., 2006).

Por fim, estudos longitudinais de volumetria em pacientes com ELT demonstraram que existe uma tendência à diminuição progressiva do volume do hipocampo relacionada ao número de crises epilépticas (Briellmann et al., 2002; Fuerst et al., 2003; Liu et al., 2003). Estes estudos 
demonstram que mesmo pacientes sem lesões iniciais podem desenvolver lesões progressivas no LT mesial em decorrência da freqüência de crises (revisão em Stafstrom et al., 2006).

\section{Epilepsia do Lobo Temporal na I nfância}

Apesar da alta incidência e prevalência de epilepsia na faixa-etária pediátrica, estudos que abordem as diferenças entre os pacientes que tiveram início da epilepsia na infância, adolescência e idade adulta são escassos (Arzimanoglou, 2005).

O diagnóstico topográfico preciso de epilepsias parciais não-idiopáticas na infância pode ser difícil por um grande número de razões relacionadas com a idade (Kahane et al., 2005) como veremos a seguir.

A coleta de informações concretas das manifestações clínicas e sua análise podem ser de difícil acesso, particularmente em relação à presença ou ausência de alterações da consciência e a descrição de sintomas subjetivos. Assim, a descrição de sinais e sintomas costuma ser muito menos detalhada do que nos adultos, especialmente referente à presença de alucinações. Este fato pode apenas refletir a menor habilidade expressiva da criança e as diferentes interpretações que elas fazem de seus sintomas subjetivos (Kahane et al., 2005) ou a pobreza de instrumental para avaliá-las.

As crises parciais em crianças, especialmente nas mais novas, podem manifestar-se clinicamente de forma diferente daquelas dos adultos. Num grande número de casos a semiologia pode passar despercebida, enquanto em outros pode ser mais evidente, provavelmente devido à rápida propagação das descargas ictais. Desta forma, crises parciais em crianças muito pequenas costumam apresentar semiologia motora global que mascaram as características próprias das crises parciais, ou que precedem as crises parciais mais comuns. Sintomas envolvendo um hemicorpo também são freqüentes. No entanto, crises parciais típicas dos adultos também podem ser observadas em crianças pequenas (Kahane et al., 2005).

As expressões clínicas das crises modificam com o tempo, devido a muitos fatores: a evolução do processo maturacional, aumento da capacidade da criança em descrever seus sintomas subjetivos e a medicação empregada (Minotti et al., 1998). 
Além disso, as anormalidades observadas no eletroencefalograma (EEG) interictal tendem a ser mais difusas, o que implica no fato de que o EEG precisa ser repetido mais vezes em busca de anormalidades focais que podem aparecer ou tornarem-se mais evidentes durante a evolução do quadro (Kahane et al., 2005).

Por fim, a visualização de lesões epileptogênicas, especialmente os distúrbios do desenvolvimento cortical - displasias - através de exames de RM depende da qualidade das imagens, com a necessidade da obtenção de exames dirigidos a uma área de interesse. Além disso, em crianças muito pequenas, as mudanças na aparência dos exames devido à dinâmica de mielinização cerebral podem tornam a identificações de anormalidades corticais um trabalho árduo (Kahane et al., 2005).

Assim, a ELT em crianças pode iniciar-se em qualquer idade, mas o seu diagnóstico pode ser tardio até o aparecimento da primeira generalização secundária. A expressão semiológica das crises pode ser um fator de confusão, principalmente quando ela revela manifestações viscerais autonômicas ou manifestações psicológicas e sensoriais, podendo ser confundida com queixas gastro-intestinais ou problemas de comportamento de natureza não epiléptica (Arzimanoglou, 2005).

De uma forma geral, as crises das crianças com ELT tendem a ser prolongadas (1-2 minutos), iniciarem-se com sintomas autonômicos, psíquicos ou alucinações olfativas. A presença de alteração da consciência é menos comum, aparecendo normalmente após o início das crises, embora em alguns casos as crises iniciem-se com comportamento de parada súbita ou de fixação do olhar. Automatismos tornam-se mais complexos com a idade, sendo os mais comuns os oroalimentares (mastigatório) ou gestos simples. A fase pós-ictal costuma ser prolongada. Sono pósictal é freqüente, particularmente nas crianças pequenas e a total amnésia do evento não é incomum (Arzimanoglou et al., 2004; Kahane et al., 2005).

Diversos autores discorreram a respeito dos fatores etiológicos mais freqüentes na faixa etária pediátrica, mas não há concordância entre eles (Davidson \& Falconer, 1975; Lindsay et al., 1984; Adams et al., 1990; Mizrahi et al., 1990; Hopkings \& Klug, 1991; Duchowny et al., 1992; Wyllie et al., 1993; Brockhaus \& Elger, 1995; Blume et al., 1997). Nestas diferentes séries 
pediátricas foram encontradas as seguintes etiologias, em ordem decrescente de ocorrência: processos expansivos, $\mathrm{AH}$, distúrbios do desenvolvimento cortical e outras causas como as malformações vasculares, cistos, etc (Spencer et al., 2001).

O início das crises dá-se entre três meses e 15 anos, com um curto período de latência das crises. Antes do início das crises, há história de crise febril ou de outros antecedentes em 15 a 75\% dos estudos. Na revisão realizada por Spencer et al. (2001), as crianças com mais de seis anos possuem crises semelhantes às dos adultos, exceto pelos automatismos que são mais simples, enquanto que aquelas com menos de seis anos têm mais manifestações motoras e clônicas. A incidência de generalização secundária varia de 10 a 50\% em diferentes estudos

Estudos retrospectivos sobre tratamento cirúrgico demonstraram alta incidência de fatores precipitadores iniciais, como por exemplo, crises febris, trauma, hipóxia e infecções intracranianas, normalmente, mas não somente, antes dos cinco anos de idade. Schmidt et al. (2004) revisaram 13 estudos retrospectivos e cinco prospectivos publicados a partir de 1980 que continham dados sobre o controle de crises de longo-prazo, sem a utilização de drogas antiepilépticas (DAE), num total de 1658 pacientes. Segundo sua análise, após submeter-se a cirurgias do LT, aproximadamente um em cada quatro adultos e um em cada três crianças e adolescentes tiveram controle de crises por até cinco anos após a cirurgia. A taxa de controle de crises parece permanecer estável após dois anos de follow-up.

\section{Maturação Cerebral, Epilepsia e Cognição}

A neuropsicologia clínica é uma ciência aplicada envolvida na relação da expressão comportamental com a disfunção cerebral (Lesak, 1995), tendo como objetivo a investigação do papel de sistemas cerebrais individuais em formas complexas de atividade mental (Luria, 1984).

A precisão e a sensibilidade das medidas neuropsicológicas tornam-nas instrumentos valiosos para a investigação de pequenas e, às vezes, súbitas alterações comportamentais, como aquelas que se seguem a certos procedimentos neurocirúrgicos ou a mudanças metabólicas (Lezak, 1995). 
As funções cognitivas, ou seja, a capacidade de processar adequadamente as informações e de programar o comportamento adaptativo, dependem do processamento cortical e envolvem inúmeras funções, entre elas: a habilidade de resolver problemas, memorizar informações e focar a atenção. Além disso, as funções cognitivas estão relacionadas à capacidade de lidar, de forma criativa, com situações complexas, transcendendo a situação imediata e antecipando a ação futura (ILAE, 2003).

De forma esquemática, o desenvolvimento dos processos cognitivos emerge em uma fase de interação da organização neuronal com a estimulação ambiental. Dessa interação resulta uma nova organização neuronal que vai, por sua vez, novamente, ser influenciada pelo ambiente, gerando, desta forma, um processo cíclico de contínua reorganização neural. Se nada de errado ocorrer neste período de formação, este processo será responsável pela especialização funcional cerebral, que é normalmente semelhante em todos os indivíduos (Laurent \& Arzimanoglou, 2006).

Em crianças com epilepsia, a atividade ictal e interictal ocorre em um córtex que ainda está em maturação. A atividade elétrica anormal vai estimular redes neuronais num período em que está ocorrendo o maior crescimento de dendritos e sinapses. Desta forma, o processo patológico poderia interferir no desenvolvimento cerebral normal da atividade de redes neuronais envolvidas em um ou em muitos processos cognitivos (Laurent \& Arzimanoglou, 2006).

Estudos recentes sugerem que a epilepsia que se inicia em idade precoce pode ter um efeito maior sobre a estrutura neuronal do que a epilepsia com início na idade adulta. Assim, exames de RM sugerem redução da conectividade cerebral, demonstrada pela redução volumétrica da substância branca de todo o cérebro, do corpo caloso em particular, de pacientes com epilepsia de início precoce. Nestes pacientes, há uma associação entre a redução volumétrica e piores performances em alguns domínios cognitivos, porém, não em todos (Hermann et al., 2002; 2003)

Assim, tipo, grau e curso do déficit cognitivo na epilepsia seriam determinados por três fatores, segundo Helmstaedter \& Kockelmann (2006): I. a disfunção epileptogênica ou a lesão primária que origina as descargas epileptogênicas, II. as crises crônicas não controladas e as 
lesões cerebrais secundárias às crises e III. o impacto do tratamento medicamentoso sobre a cognição.

Portanto, os déficits cognitivos serão dinâmicos e reversíveis dependendo de sua causa: a lesão, o atraso do desenvolvimento, a disfunção epileptogênica ou o tratamento medicamentoso (Helmstaedter \& Kockelmann, 2006).

Em uma criança com ELT, as conseqüências da lesão, da disfunção epiléptica e do tratamento ocorrem em um cérebro ainda em desenvolvimento, sendo responsáveis, muitas vezes, por atraso do desenvolvimento neuropsicomotor e retardo mental (Helmstaedter \& Kockelmann, 2006). Ainda assim, embora o início precoce da ELT interfira significativamente no desenvolvimento cerebral, este ocorre num período de maior plasticidade funcional do cérebro, o que poderá permitir compensações e restituição de funções prejudicadas. Este fato é evidenciado pela alta incidência de distribuições atípicas das funções cognitivas intra e inter-hemisféricas em pacientes com ELT de início precoce. Desta forma, Janszky et al. (2003), demonstraram que 30\% dos pacientes com ELT apresentaram algum padrão atípico de lateralização da linguagem, quando avaliados com o teste de amobarbital intracarotídeo (Teste de WADA).

\section{Epilepsia do Lobo Temporal e Avaliação Neuropsicológica}

Alguns déficits cognitivos específicos são observados em pacientes com epilepsia. Particularmente naqueles com ELT são esperados déficits mnésticos, nas habilidades verbais (Jokeit \& Ebner, 2002), dificuldades no processamento de números (Delazer et al., 2004), de reconhecimento de emoções faciais (Meletti et al., 2003) e das funções intelectuais. Os déficits mais freqüentemente estudados são os de memória, que será detalhado a seguir.

\subsection{Funções Mnésticas e a ELT no Adulto}

A memória declarativa, ou seja, a aquisição e o acesso posterior de informações novas é

uma das funções cognitivas mais importantes para o homem. É a memória declarativa que permite o estabelecimento de uma sensação de continuidade em um mundo em constante 
transformação, provendo, desta forma, a base de uma biografia pessoal, identidade e o desenvolvimento cognitivo e comportamental (Helmstaedter, 2005).

Na ELT esta memória está comprometida quando estruturas mesiais, associadas às neocorticais adjacentes, estão lesionadas ou disfuncionais, sob efeito de atividade elétrica anormal e/ou de efeitos indesejados de tratamentos. Assim, Helmstaedter (2002), em um estudo com 100 pacientes com ELT refratária, avaliados desde 1988, demonstrou que 70 a $80 \%$ destes pacientes apresentavam comprometimentos mnésticos verbal ou visual.

Helmstaedter (2002) afirma que os déficits de memória (DMn) episódica (informações adquiridas dependentes do tempo e de um contexto) são aqueles mais evidentes em pacientes com ELT. No entanto, DMn semântica também podem ser encontrados, mas de forma menos consistente. Além disso, Blume (2003) afirma que DMn são comuns quando a zona epileptogênico encontra-se em ambos os LT ou quando está localizado no LT dominante para a linguagem.

Existem evidências de que os pacientes com ELT unilateral apresentam déficits neuropsicológicos lateralizados (Grammaldo et al., 2006; Nolan et al., 2004). Foi postulado que tais déficits podem ser causados pela perda de células associadas à lesão ou pela interferência das descargas epileptiformes interictais na cognição (Akanuma et al., 2003).

Desta forma, alguns autores demonstraram que pacientes com ELT esquerda costumam apresentar prejuízos de memória verbal enquanto aqueles com ELT direita têm DMn não-verbal (Helmstaedter, 2001; Elger et al., 2004). No entanto, falsas lateralizações dos DMn (desvio da regra esquerdo versus direito e verbal versus não-verbal) são freqüentes. A falsa lateralização na ELT esquerda vem sendo atribuída a fatores como a dominância hemisférica e diferenças ligadas ao gênero, enquanto falsa lateralização na ELT direita é relacionada com uma maior organização bilateral das redes de memória não-verbal, processos de reverberações mentais ou o tipo de teste empregado para avaliação desta função (Helmstaedter, 2005).

O estudo de Grammaldo et al. (2006) demonstrou que o efeito lateralizatório dos testes neuropsicológicos de memória só pode ser observado nos pacientes com ELT secundária à AH. Os autores propuseram três hipóteses para explicar este achado: I. o efeito da duração maior das 
variáveis da epilepsia sobre a memória dos pacientes com lesão mesial em comparação àqueles com tumores e outros tipos de lesão no LT, II. as diferenças fisiológicas ligadas à neuropatologia de cada condição e III. conseqüência da heterogeneidade do grupo com ELT sem AH.

A AH é freqüentemente associada a DMn uma vez que tanto a zona epileptogênica como a lesão, localizarem-se em uma região reconhecida por ser crítica na consolidação de novas memórias (Riva et al., 2001; Kim et al., 2003). As estruturas temporais mesiais estão relacionadas com o processamento da memória declarativa de longo-prazo no período de desenvolvimento da criança. Alguns autores acreditam que uma lesão precoce nestas regiões não pode ser compensada pelo estabelecimento de regiões alternativas e que o grau de DMn é relacionado com a idade em que a criança adquiriu a lesão (Riva et al., 2001).

Estudos com RM funcional em sujeitos normais, desempenhando atividades de memória, revelaram a ativação simétrica bilateral das regiões mesiais do LT (Detre et al., 1998; Dupont et al., 2000; Jokeit et al., 2001; Powell et al., 2004). Em compensação, nos pacientes com ELT, foi observada ativação assimétrica das regiões mesiais do LT, diminuição da atividade de estruturas mesiais do LT ipsilateral ao foco epileptogênico (Bellgowan et al., 1998; Detre et al., 1998; Jokeit et al., 2001; Golby et al., 2002; Cheung et al., 2006) ou hiperativação das estruturas mesiais contralaterais ao foco da lesão (Richardson et al., 2003).

Cheung et al. (2006), em estudo com RM funcional, atribuem seus achados - redução da ativação bilateral no LT mesial com uma redução mais acentuada nas estruturas mesiais do LT ipsilateral ao foco epileptogênico - ao envolvimento patológico unilateral da região mesial do LT dos seus pacientes, que poderia resultar em diminuição funcional bilateral do processamento da memória. Estes autores (Cheung et al., 2006) encontraram, também, associação negativa entre a ativação funcional do LT e a duração da ELT. Entretanto, freqüência de crises e o volume hipocampal não se correlacionaram com a ativação mesial.

Vê-se, portanto, que lesões nas regiões mesiais do LT parecem ser suficientes para originar os DMn. No entanto, existem indícios de que não apenas a região hipocampal, mas, também, as regiões corticais temporais adjacentes estão envolvidas no processamento da 
memória. Cabe então, questionar-se se estas regiões neocorticais também são importantes para as funções de memória (Cheung \& Chan, 2003).

Em um estudo realizado por Cheung \& Chan (2003) foi possível encontrar evidências da participação do neocortex na memória, quando se estudou um grupo de pacientes com DMn após lesão bilateral no córtex temporal lateral, com preservação hipocampal. Interessantemente, os déficits desses pacientes com lesões neocorticais temporais bilaterais eram comparáveis aos daqueles com lesões hipocampais.

A maioria dos estudos que investigou a memória de pacientes com ELT teve como objetivo o estudo da memória anterógrada (recente ou explícita). Poucos estudos investigaram a memória retrógrada ou remota (dados da história pessoal ou de história em geral). No entanto, pacientes com ELT possivelmente têm dificuldades com este tipo de memória, uma vez que estão sujeitos a anos de prejuízos da memória anterógrada. Os déficits de codificação e aprendizado durante os anos devem gerar comprometimento para estes eventos com o passar do tempo (Helmstaedter, 2005).

Lah et al. (2004) investigaram as fases de recuperação e reconhecimento de conhecimento autobiográfico e público, de pacientes submetidos a lobectomia temporal anterior. Estes autores demonstraram defeitos na evocação de eventos públicos famosos tanto nos pacientes com ELT esquerda quanto direita. Além disso, estes autores demonstraram que os pacientes com ELT esquerda apresentavam maior dificuldade para recordar o nome de pessoas famosas.

\subsection{Funções Mnésticas e a ELT na Infância}

Parece bem estabelecido que pacientes adultos com ELT, com idade de início precoce, apresentam um maior risco de ter graves prejuízos de memória (Hermann et al., 2002; Lespinet et al., 2002; Strauss et al., 1995). Contudo, pouco se sabe sobre as DMn de crianças com ELT provavelmente devido a alguns fatores, tais como: porque a maturação da memória episódica na criança é relativamente tardia (Perner \& Ruffman, 1995), devido a limitações das próprias 
medidas nesta faixa-etária (Lassonde et al., 2000) e pelo relativo recente desenvolvimento de cirurgias para as epilepsias focais (Clusmann et al., 2004; Wyllie, 1998).

Além disso, as crianças com epilepsia podem referir menos problemas de memória do que os adultos. A consciência dos DMn pode ser ainda imperfeita (Piolino et al., 2007) e elas ainda dependem dos familiares para explicar suas dificuldades. Estes fatores podem explicar porque suas dificuldades podem passar desapercebidas ou gerarem um menor número de queixas.

Os DMn episódica são difíceis de identificar antes dos cinco e seis anos de idade, o que foi previamente evidenciado em pacientes com amnésia de desenvolvimento (Vargha-Khadem et al., 1997; 2001).

Ainda assim, Smith et al. (2006) relataram dificuldades significativas de memória, que afetariam as atividades diárias, de crianças mais velhas e adolescentes. Em crianças com epilepsia em idade escolar, são comuns as queixas de dificuldades de aprendizagem que sugerem DMn (Fastenau et al., 2004; Mitchell et al., 1991; Schouten et al., 2002; Williams, 2003).

Entretanto, ainda restam dúvidas quanto a presença de DMn em crianças com ELT. Assim, no estudo de Lendt et al. (1999), com 20 crianças e pré-adolescentes com ELT (idade média de 13,8 anos), as funções mnésticas estavam intactas, contradizendo o que é freqüentemente observado em adultos com ELT. Os autores creditam este achado ao menor tempo de duração da epilepsia em crianças, o que reduziria a ocorrência de déficits cognitivos.

Outros autores (Adams et al., 1990; Gonzales et al., 2007; Guimarães et al., 2008 submetido; Jambaqué et al., 1993), por outro lado, demonstraram a presença de DMn em crianças e adolescentes com ELT, principalmente aqueles com lesões mesiais.

Em crianças com ELT a relação entre o desempenho em testes neuropsicológicos de memória e a lateralização do foco epileptogênico ainda é controversa. Adams et al. (1990) observaram prejuízos iguais quanto à memória verbal e visual em crianças com foco à direita e à esquerda. Por outro lado, Jambaqué et al. (1993) demonstraram DMn verbal em crianças com ELT à esquerda e de memória visual nas com ELT à direita, equivalente ao encontrado nos adultos com esta síndrome. 
No estudo de Szabó et al. (1998), 14 pré-adolescentes com ELT (idade média de 9,4 anos), foram submetidos a avaliações neuropsicológicas pré e pós-operatórias e apresentaram a estabilidade do Quociente Intelectual (QI) e diminuição da memória verbal após ressecção do LT. A relativa estabilidade das medidas de QI em pré-adolescentes, indica que a habilidade intelectual geral não é afetada pela ressecção do LT. Segundo estes mesmos autores, poucos estudos avaliaram os efeitos da ELT e da lobectomia temporal na cognição de crianças com epilepsia. Em sua revisão, notaram que a maior parte das séries abordando este tópico apresentam resultados semelhantes aos dos estudos com adultos. Os autores justificam este achado pelo fato da população estudada, predominantemente composta por adolescentes, limitar as conclusões sobre as DMn em crianças pós-cirurgia do LT.

No estudo realizado pelo nosso grupo (Guimarães et al., 2008 submetido), no qual o desempenho em testes de memória e aprendizado de 25 crianças com ELT com lesões em estruturas mesiais e neocorticais do LT, foi comparado ao de 25 crianças voluntárias saudáveis, observamos um pior desempenho das primeiras em testes avaliadores das habilidades atencionais, mnésticas verbais e visuais e de aprendizagem verbal e visual, corroborando o previamente relatado (Fedio \& Mirsky, 1969; Adams et al., 1990; Jambaqué et al., 1993; Lendt et al., 1999; Nolan et al., 2004). Em nosso estudo, não foram observados déficits específicos relativos à lateralidade da lesão. Assim, crianças com lesão em hemisfério esquerdo não tiveram piores desempenhos em testes de memória e aprendizagem verbal do que aquelas com lesão à direita.

Observamos, ainda, que a literatura sobre a ELT na infância também é inconsistente quanto a presença de prejuízos de memória não verbal nestas crianças. Em partes este fato ocorre, pois alguns estudos enfatizaram a relação entre memória verbal e o LT esquerdo e não incluíram em sua metodologia crianças com ELT à direita (Jambaqué et al., 1993). Além disso, a memória não verbal pode ser um processo mais complexo do que a memória verbal, uma vez que abrange processos específicos como a memória alocêntrica (aprendizado independente de pistas relacionadas com a própria história do indivíduo), memória de localização de objetos e figuras e para figuras geométricas, não contextualizadas (Gonzáles et al. 2007). 


\subsection{Funções Executivas e a ELT no Adulto}

Para compreender as funções executivas (FE) basta considerar a seqüência de eventos necessária para cada comportamento propositado. Primeiro o comportamento deve ser iniciado, o objetivo deve ser identificado e a meta da ação formulada. Em seguida, um plano de ação deve ser traçado para a obtenção do objetivo estabelecido e as formas de realizar o plano devem ser selecionadas numa seqüência temporal. Assim, os vários passos do plano devem ser executados numa ordem apropriada com uma passagem de um passo a outro imperceptível. Por fim, uma comparação deve ser feita entre o objetivo traçado e as conseqüências da ação propriamente dita. Estas são funções dos lobos frontais e por esta razão que as funções atribuídas aos lobos frontais são chamadas de executivas (Goldberg, 2001).

Portanto, o termo FE refere-se a um conceito abrangente utilizado para descrever uma série de habilidades complexas relacionadas a um comportamento orientado para uma meta (Hart et al., 2003). As FE permitem ao indivíduo (i) escolher e renegar comportamentos de forma flexível, em resposta às demandas ambientais, (ii) regular estes comportamentos através de processos de auto-monitoramento e (iii) sustentar planos de ações durante um período de tempo.

As definições de FE designam uma coleção de habilidades, que embora estejam relacionadas entre si, são distintas. Estas funções são responsáveis pela organização e controle do funcionamento cognitivo, comportamental e emocional direcionados a metas (Gioia et al., 2002). Esta função está relacionada com a habilidade do indivíduo em realizar ações independentes, intencionais e auto-direcionadas, de forma bem sucedida.

Assim, as FE incluem: antecipação, planejamento e organização, iniciação de planos de ações, inibição de distratores e interferências, auto-monitoramento do processo, flexibilidade para alterar novas ações quando necessário, ao mesmo tempo em que se mantém o processo e a meta numa memória de operacional ativa (Lezak, 1995; Doval et al., 2001; Gioia et al., 2002).

Portanto, indivíduos com disfunções executivas (DE) apresentam dificuldades no planejamento de ações visando conseqüências futuras, controle de impulsos espontâneos e modulação da expressão emocional (Capilla et al., 2004). 
Damásio (1996), postulou que estas disfunções do lobo frontal estariam relacionadas a mecanismos de sinalização neural disfuncionais que, quando funcionando adequadamente, integram os aspectos afetivo-motivacionais com a cognição no processo de tomada de decisões integradas ao contexto das esferas pessoais e interpessoais.

O orquestramento cognitivo frontal opera através de conexões recíprocas entre as estruturas pré-frontais e límbicas, córtices de associação têmporo-parieto-occipital e regiões motoras corticais e subcorticais (Gazzaniga et al., 2006), conforme demonstrado nas Figuras 3 e

4.

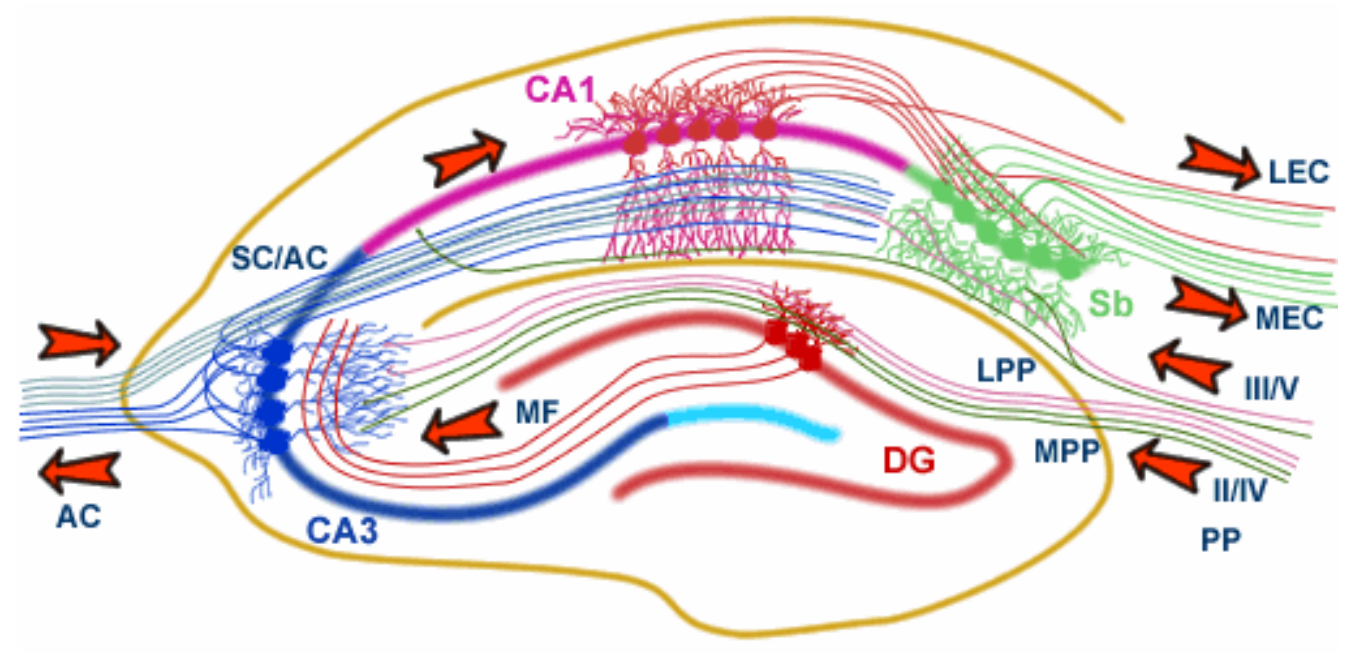

Figura 3 - Conexões internas do Hipocampo. Legenda: A rede hipocampal: o Hipocampo forma principalmente uma rede uni-direcional com input do Córtex Entorrinal (EC) que forma conexões com o Giro Denteado (DG) e com os neurônios piramidais CA3 através da Via Perfurante (PP - que se divide na via medial e na lateral). Os neurônios CA3 também recebem input do DG pelas mossy fibers (MF). Eles enviam para as células piramidais CA1 pela Via Colateral de Schaffer (SC), assim como para as células CA1 no Hipocampo contralateral através da via da Comissura Associativa (AC). Os neurônios CAl também recebem input diretamente da Via Perfurante e envia axônios para o Complexo Subicular (Sb). Estes neurônios por sua vez formam o output principal do Hipocampo redirecionando fibras de volta ao EC, formando um loop. 


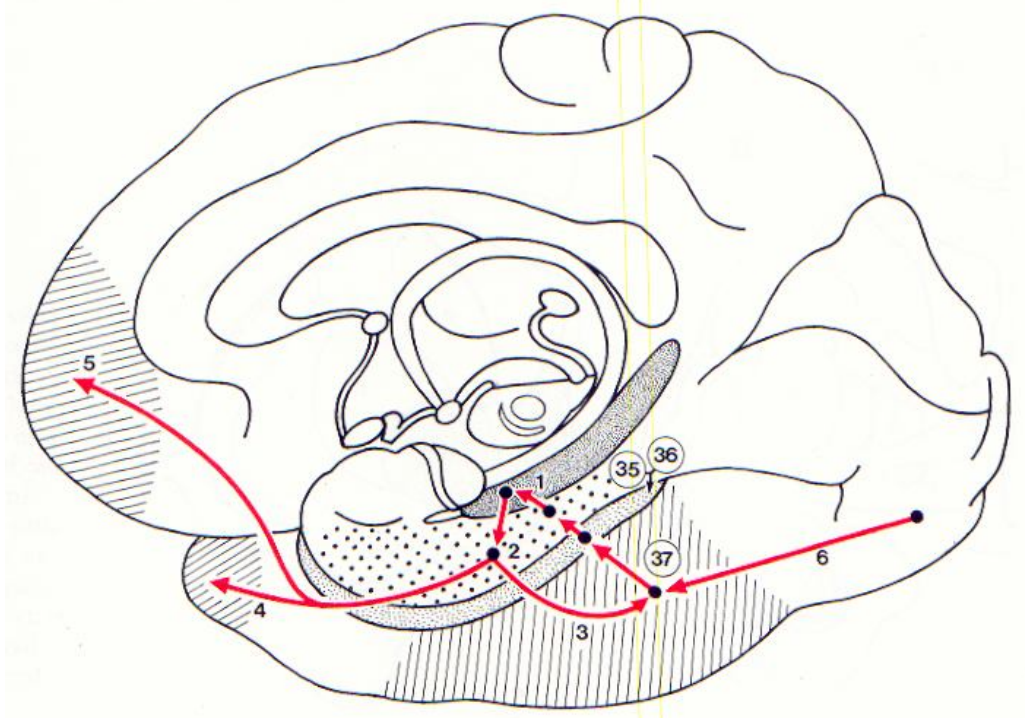

Figura 4 - Conexões do lobo temporal mesial e estruturas pré-frontais. Conexões corticais da via intra-hipocampal direta. 1. Circuitaria intra-hipocampal. Fibras de saída do hipocampo para o córtex: das camadas profundas do Córtex Entorrinal (2), as fibras alcançam o córtex de associação do lobo temporal inferior (3), o pólo temporal (4) e o córtex pré-frontal (5). Fibras de entrada do córtex para o hipocampo: a origem principal destas fibras é o córtex de associação temporal inferior (área 37) em relação ao sistema visual inferior (6), alcançando o córtex entorrinal através do córtex perirrinal (áreas 35 e 36$)$.

Os lobos frontais ocupam aproximadamente $1 / 3$ do córtex cerebral e podem ser subdivididos em algumas estruturas anátomo-funcionais distintas: opérculo, córtex pré-frontal (CPF) ventromedial e dorsolateral e cíngulo. Cada uma destas estruturas é responsável por componentes das FE distintos (Devinsky et al., 1995; Goldberg, 2001):

> Córtex órbito-frontal: inibição de ações inapropriadas e impulsivas, coordenação de comportamentos que levam a gratificações futuras e duradouras.

> Córtex dorsolateral: iniciação da ação, capacidade de planejamento e flexibilidade mental.

> Córtex ventromedial: habilidade de obedecer a regras socialmente determinadas, aprendizagem com experiências novas, interpretação de emoções complexas e organização da tomada de decisões. 
Estudos com pacientes adultos com ELT vêm evidenciando a presença de DE, além daquelas de memória e aprendizagem amplamente reconhecidas na literatura. No momento, existem duas hipóteses para explicar esta disfunção em pacientes com ELT, que serão detalhadas a seguir.

Segundo Corcoran \& Upton (1993), a presença de AH em hemisfério direito estaria associada a um pior desempenho em teste avaliador de flexibilidade mental (Wisconsin Card Sorting Test - WCST) o que foi demonstrado pelo pior desempenho destes pacientes do que daqueles com ELT lateral ou, até mesmo, de pacientes com epilepsia do lobo frontal. Portanto, esta DE seria explicada pela lesão hipocampal per se e estaria relacionada com a memória operacional (working memory). Em concordância ao achado de Corcoran \& Upton (1993), o estudo de Hermann et al. (1988) demonstraram um pior desempenho no WCST dos pacientes com foco no LT direito.

Por outro lado, Hermann \& Seidenberg (1995) propuseram que a atividade epiléptica anormal do LT espraiava-se para estruturas extra-temporais responsáveis pelas habilidades executivas, hipótese essa baseada nos seus achados de correlação do funcionamento executivo com controle de crises e não com etiologia da ELT.

Contudo, não existe ainda um consenso quanto ao desempenho no WCST e a lateralização da lesão e etiologia da ELT. Assim, enquanto Horner et al. (1989) não encontraram diferenças significativas entre pacientes com foco no LT direito ou no esquerdo, Hermann \& Seidenberg (1995) não encontraram associação entre a presença de AH e o desempenho no WCST.

\subsection{Funções Executivas e a ELT na Infância}

Como mencionado anteriormente, o estudo do funcionamento executivo de pacientes com ELT ainda é escasso, principalmente no que tange a faixa etária pediátrica.

As hipóteses de Corcoran \& Upton (1993) da participação do hipocampo como um modulador do funcionamento executivo e de Hermann \& Seidenberg (1995) da conectividade 
entre os lobos temporal e frontal e do espraiamento das descargas epileptogênicas entre as regiões como justificativa para estes comprometimentos, têm uma variável de confusão no estudo com adultos. Isto ocorre uma vez que estes têm uma longa história de crises focais complexas e generalizações secundárias que influenciam tanto o lobo temporal per se quanto as regiões corticais adjacentes.

No estudo sobre DE em crianças com ELT, Igarashi et al. (2002) relataram que crianças com $\mathrm{AH}$ têm maiores déficits de execução/planejamento do que aquelas com lesões neocorticais temporais ou frontais quando avaliadas pelo WCST.

Hernandez et al. (2002) avaliaram as FE através de testes que investigavam as habilidades de planejamento, memória operacional, controle de impulsos, atenção e alguns aspectos da coordenação motora em crianças com epilepsia de lobo frontal utilizando crianças com ELT, epilepsia generalizada idiopática (ausências típicas) e controles como grupos de comparação. As crianças com epilepsia de lobo frontal apresentaram prejuízos de planejamento, controle de impulsos e maiores problemas de coordenação motora do que as demais crianças. Um outro estudo (Culhane-Shelburne et al., 2002), com características similares ao primeiro, corrobora estes achados, demonstrando que crianças com epilepsia de lobo frontal tem pior performance nas $\mathrm{FE}$, enquanto àquelas com ELT apresentavam somente problemas de memória.

A avaliação neuropsicológica é de grande importância nos programas de cirurgia para epilepsia ao estudar pacientes antes e após a intervenção cirúrgica, tendo um papel primordial ao predizer resultados neuropsicológicos pós cirúrgicos e oferecer um prognostico (Orozco-Giménez et al., 2002). Esta avaliação ganha uma importância ainda maior quando se trata de epilepsia em faixa etária pediátrica. Isso porque, nesta fase, ainda é possível a mudança do prognóstico, através da reabilitação neuropsicológica. Além disso, auxilia na escolha de um tratamento mais efetivo, prevenindo assim, o prolongamento de disfunções cognitivas secundárias à epilepsia e uma vida adulta com possibilidades ocupacionais restritas (ILAE, 2003). 


\section{Variáveis da Epilepsia e Funções Cognitivas}

O estudo das funções cognitivas de pacientes com ELT ficaria incompleto sem a interpretação do efeito das variáveis clínicas da epilepsia sobre a cognição destes pacientes.

No entanto, na literatura, as variáveis clínicas estudadas variam imensamente de estudo para estudo. Desta forma, foram investigadas a atuação de variáveis diferentes, como será abordado a seguir.

I. Número de DAE utilizadas (Donati et al., 2007; López-Gonogora et al., 2008; Hermann et al., 2002; Hernandez et al., 2002; Igarashi et al., 2002),

II. Idade dos pacientes (Baxendale et al., 2006; Martin et al., 2000; Hernandez et al., 2002),

III. Lateralização da lesão (Jambaqué et al., 1997; Lendt et al., 1999; Gonzáles et al., 2007; Grammaldo et al., 2006; Nolan et al., 2004; Corcoran \& Upton, 1993; Hermann et al., 1997; Martin et al., 2000; Hernandez et al., 2002; Igarashi et al., 2002; Keiski et al. 2006),

IV. Nível de escolaridade (Martin et al., 2000),

V. Idade de início da epilepsia (Baxendale et al., 2008; Thompson \& Duncan, 2005; Martin et al., 2000; Hermann et al., 2002; Igarashi et al., 2002; Keiski et al. 2006),

VI. Duração da epilepsia (Baxendale et al., 2008; Martin et al., 2000; Igarashi et al., 2002),

VII. História de status epilepticus (Hermann et al., 2002; Igarashi et al., 2002),

VIII. Generalização secundária (Martin et al., 2000; Hermann et al., 2002),

IX. Transtorno depressivo (Hermann et al., 2002),

X. Outras comorbidades físicas (Hermann et al., 2002),

XI. Volume do hipocampo (Martin et al. 2000; Keiski et al., 2006).

Como conseqüência das diferenças metodológicas que dizem respeito à bateria neuropsicológica, variáveis clínicas e população estudada, observamos que não há concordância quanto às variáveis clínicas de maior impacto sobre as DMn e DE nas crianças com ELT. 


\section{Correlação entre Disfunção Executiva e Déficits Mnésticos}

Alguns estudos demonstram a participação de outras regiões cerebrais, além dos lobos temporais, para a preservação das funções mnésticas. O córtex frontal tem sido implicado na memória (Buckner et al., 1999; Fletcher \& Henson, 2001). Além disso, em termos cognitivos, alguns estudos vêm investigando o papel das FE no funcionamento dos processos de aprendizagem e memória (Bryson et al., 2000; Vanderploeg et al., 1994).

A associação das DMn verbal e DE foi relatada em diversas populações clínicas. Fossati et al. (1999) notaram a associação positiva entre a DE e DMn verbal em pacientes com esquizofrenia. Já Vanderploeg et al. (1994) demonstraram a relação entre alguns componentes das FE e a memória verbal em uma amostra mista de pacientes neurológicos. Desta forma, estes autores demonstraram uma correlação positiva entre a memória verbal e a atenção e rastreio mental de informações e ausência de correlação com a abstração, resolução de problemas e planejamento (Vanderploeg et al., 1994). Tremont et al. (2000) corroboraram o achado de relação entre as FE e memória ao demonstrar que pacientes com DE tinham mau desempenho em prova de aprendizagem de lista de palavras.

A investigação da influência da DE sobre a memória não verbal é mais escassa. Cunningham et al. (1997) revelaram que pacientes com tendências a confabulações, ou seja, que preenchiam as lacunas de falta de informações com dados criados, tendiam tanto a uma pior memória visual quanto a uma maior DE.

Além disso, estudos com primatas demonstram que lesões permanentes ou transitórias do córtex frontal prejudicam a capacidade de aprendizagem por associação e a memória de reconhecimento (Bauer \& Fuster, 1976; Voytko, 1986; Bachevalier \& Mishkin, 1986). Pesquisas com humanos também demonstram que as atividades de memória que avaliam a fase de codificação estão associadas com a atividade de regiões frontais (Kapur et al., 1994; Demb et al., 1995; Kelley et al., 1998; Wagner et al., 1998).

Assim, embora lesões nos lobos frontais não produzam a amnésia grave atribuída às lesões no LT mesial, pacientes com lesões frontais apresentam falhas de memória em atividades complexas, como àquelas que requerem o acesso a informações têmporo-espaciais, com altos 
níveis de interferência ou que requerem o acesso de informações contextualizadas (Schacter, 1987; Janowsky et al., 1989; Incisa Della Rochetta \& Millner, 1993). Além disso, as regiões frontais podem estar relacionadas com as funções de controle que contribuem para a codificação da memória e a evocação (Buckner \& Whecler, 2001; Fletcher \& Henson, 2001).

Corroborando as evidências patológicas, estudos anatômicos sugerem que as regiões frontal e temporal devem interagir nos processos de memória. Em primatas, o CPC mantém extensas conexões com o córtex temporal medial (Kuypers et al., 1965; Barbas, 1988; Ungerleider et al., 1989) e tanto os córtices frontal lateral quanto o órbito-frontal recebem conexões monossinápticas das regiões perirrinal, entorrinal, parahipocampal e hipocampal (Rosene \& Van Hoesen, 1977; Van Hoessen, 1982; Barbas, 1993; 2000; Lavenex et al., 2002).

Finalmente, um estudo de RM Funcional (Maccotta et al., 2007) revelou a ativação dos lobos frontais em pacientes com ELT mesial durante a realização de atividades de memória. 
A DMn é uma alteração freqüentemente associada à ELT. Há muitas evidências, em adultos, que sugerem que a DMn verbal está associada à ELT esquerda, enquanto a memória não verbal seria mais vulnerável na ELT direita, embora este efeito não seja consistentemente relatado (Bell \& Davies, 1998). Este padrão material-específico de prejuízos de memória sugere que os LT esquerdo e direito são especializados na capacidade de memória verbal e não verbal, respectivamente.

Embora as crises epilépticas relacionadas à ELT iniciem-se com grande freqüência na infância, poucos estudos investigaram os efeitos lateralizatórios e de localização dos DMn em crianças com ELT (Gonzáles et al., 2007).

Em contraste com a literatura em adultos, muitos estudos na infância relataram que a memória verbal e não verbal estão igualmente prejudicadas nos grupos com ELT esquerda e direita (Adams et al., 1990; Cohen et al., 1992; Szabó et al., 1998; Nolan et al., 2004). Ainda assim, há um pequeno número de estudos que demonstraram DMn verbal em pacientes com ELT esquerda (Fedio \& Mirsky, 1969; Jambaqué et al., 1993). Contudo, estes estudos ou não consideram o impacto de variáveis clínicas da epilepsia no funcionamento cognitivo ou não investigaram crianças com ELT direita (Jambaqué et al., 1993), o que enfraquece a assertiva de que a memória verbal estaria prejudicada em crianças com ELT esquerda e não direita.

Além disso, a demonstração da presença e da natureza de DMn não-verbal nas crianças com ELT também é inconsistente. Enquanto alguns estudos demonstraram este prejuízo (J ambaqué et al., 1993; Nolan et al., 2004), outros não corroboraram os anteriores (Adams et al., 1990; Lendt et al., 1999).

Alguns autores sugeriram que estudos que investigaram efeitos lateralizatórios da memória na infância podem ter empregado um grupo de tarefas de memória não suficientemente sensíveis, uma vez que não consideraram aspectos teóricos da memória na concepção de sua bateria (Gonzáles et al., 2007).

Embora os estudos citados tenham investigado com profundidade a presença e os efeitos lateralizatórios dos prejuízos de memória, ainda é importante investigar a participação de estruturas mesias, particularmente o hipocampo, nestes déficits na infância. 
Ainda é interessante sugerir a possibilidade levantada por Loring et al. (2008) de que os achados de efeitos lateralizatórios dos DMn podem variar, não somente devido à bateria utilizada, como também por uma variabilidade individual de paciente para paciente. Poderia-se postular que há, portanto, uma variação no nível de intensidade desta disfunção de paciente para paciente e que quando considerados como um grupo único, o relativo bom desempenho de um indivíduo balancearia o mau desempenho de outro.

Além dos déficits mnésticos, a presença de DE tem sido relatada em adultos com ELT, sendo caracterizada pela tendência à perseveração e prejuízos nas habilidades de resolver problemas e de abstração (Hermann \& Seidenberg, 1995; Trenerry \& Jack, 1994). Há controvérsias sobre a presença de DE nas crianças com ELT, com estudos com resultados contraditórios.

Os estudos de Hernandez et al. (2002) e de Culhane-Shelburne et al. (2002) utilizando uma bateria de testes neuropsicológicos para avaliar a presença de DE em crianças com epilepsia não demonstraram alterações significativas nas crianças com ELT, quando estas foram comparadas com crianças com Epilepsia de Lobo Frontal. Por outro lado, Igarashi et al. (2002) relataram DE em crianças com ELT, através da avaliação com um único teste - o WCST. Estes autores encontraram, ainda que, crianças com ELT decorrente de AH apresentaram maiores déficits de execução e planejamento do que aquelas com lesões neocorticais temporais ou frontais. No entanto, este estudo incluiu em sua amostra pediátrica, pacientes com idades de até 20 anos (que podem ser considerados adultos), além de ser composto por uma casuística heterogênea com subgrupos de poucos pacientes com AH e lesão neocortical. Por fim, a bateria de testes neuropsicológicos foi pouco abrangente, limitando-se apenas a um teste, creditando uma especificidade teste-função que não é existente.

Em todos os estudos citados, os pacientes com ELT foram comparados com aqueles com epilepsia de lobo frontal, nos quais não foi especificado o tipo de lesão ou a sua localização (córtex motor, área motora suplementar ou córtex pré-frontal). 
Conseqüentemente, ainda é controverso se pacientes com ELT apresentam DE quando comparados a um grupo controle sem epilepsia e se pacientes com lesão hipocampal apresentam maior comprometimento das FE do que os demais pacientes com ELT (Igarashi et al., 2002).

Em relação à epilepsia, as variáveis clínicas que têm relevância sobre a DMn e a DE são controversas em adultos. Os dados escassos em crianças não nos permitem qualquer assertiva. 0 estudo das crianças com ELT é extremamente importante, pois permite estudar pacientes sem duração tão prolongada da doença, como os adultos.

Desta forma, o presente trabalho visa angariar maiores subsídios para a compreensão da relação e do impacto da interferência das estruturas mesiais e neocorticais do LT na DE e DMn de crianças com ELT.

Além disso, do ponto de vista prático, o conhecimento de déficits específicos que interfiram nas habilidades de formação de estratégias, no planejamento e na memória, são extremamente relevantes para o delineamento de uma abordagem educacional apropriada e de um programa de reabilitação neuropsicológica com conseqüente melhora no desempenho global destes pacientes. 
Os objetivos deste estudo foram:

$1^{\circ}$. Analisar a presença de déficit de memória e disfunção executiva/atencional em crianças e adolescentes com ELT.

2ㅇ․ Determinar a influência das etiologias da ELT no desempenho mnéstico e executivo;

3․ Avaliar a influência das variáveis clínicas da epilepsia na presença de déficit de memória e executivo;

4․ Verificar o impacto de fatores do neurodesenvolvimento sobre as funções mnésticas e executivas;

5․ . Classificar a gravidade da disfunção mnéstica e executiva;

$6^{\circ}$. Investigar a influência da disfunção executiva na presença de disfunção mnéstica das crianças e adolescentes com ELT. 


\section{Características dos pacientes e controles estudados:}

\subsection{Critérios de I nclusão}

\section{Pacientes}

Neste estudo caso-controle, experimental, transversal e prospectivo, foram incluídos, pacientes com idades entre 9 e 16 anos, com eficiência intelectual (QI) entre 80 e 120 (QI estimado - sub-testes Cubos e Vocabulários, WISC-III, Wechsler, 1992), consecutivamente avaliados no Ambulatório de Epilepsia Infantil do Laboratório de Neurofisiologia Clínica do Instituto de Psiquiatria do HCFMUSP ou do Departamento de Neurologia da UNICAMP. Todos os pacientes tiveram autorização dos pais ou responsáveis através da assinatura de um termo de Consentimento Livre e Esclarecido (Anexo 1).

Os pacientes com diagnóstico de ELT sintomático apresentavam comprovação de lesão restrita ao LT através de exame de RM 1,5T, além de dados concordantes de EEG e/ou vídeo-EEG. Já aqueles com ELT criptogênica apresentavam necessariamente comprovação de crises provenientes dos lobos temporais através dos exames de vídeo-EEG.

\section{Controles}

Os sujeitos controles foram recrutados na cidade de São Paulo, para fins de controle das variáveis demográficas. Foram incluídas crianças e adolescentes saudáveis, de ambos os sexos, voluntários, sem parentesco com os sujeitos da pesquisa, pareados com os pacientes do estudo por idade, escolaridade e fatores sociodemográficos.

O critério escolaridade foi assumido por anos de educação formal e foi dada preferência a sujeitos controles no mesmo ano escolar dos pacientes da pesquisa.

Foram incluídas apenas crianças que tivessem pontuação inferior a 17 no Questionário de Morbidade Psiquiátrica Infantil (Almeida Filho, 1985). 


\subsection{Critérios de Exclusão:}

\section{Pacientes}

Foram excluídas crianças com QI estimado inferior a 80 ou superior a 120, com sinais de intoxicação medicamentosa ou qualquer outra condição que implicasse em déficit cognitivo que impossibilitasse a testagem destes pacientes (diagnóstico psiquiátrico maior, abuso de drogas ou álcool, neurocirurgia prévia, não estarem matriculadas na escola).

\section{Controles}

Foram excluídas crianças controles com QI estimado inferior a 80 ou superior a 120, com história de diagnóstico prévio ou atual de transtornos psiquiátricos ou neurológicos, cujos responsáveis não aceitaram assinar o termo de consentimento livre e esclarecido e que não estavam matriculados na escola no momento da avaliação.

Foram excluídas deste estudo duas crianças com QI inferior a 80 (todos pacientes com ELT) e 11 crianças por apresentarem QI superior a 120 (3 pacientes com ELT e 8 sujeitos controles).

Seguindo estes critérios, foram avaliados 32 pacientes, sendo $14(43,80 \%)$ do sexo masculino, com idade média de 11,69 anos [SD 2,12], 5,06 anos [SD 1,90] de escolaridade e QI estimado médio de 95,94 [SD 9,46], conforme Tabela 1.

Tabela 1. Caracterização dos Pacientes

\begin{tabular}{|c|c|c|c|c|c|}
\hline & $\begin{array}{c}\text { Pacientes } \\
(n=32) \\
\text { Média(SD) }\end{array}$ & $\begin{array}{l}\text { Controles } \\
(n=21) \\
\text { Média(SD) }\end{array}$ & $\mathbf{T}$ & $\mathbf{p}$ & Cohen's d \\
\hline I dade & $11,69(2,12)$ & $11,95(2,11)$ & $-0,446$ & 0,657 & $-0,13$ \\
\hline Escolaridade & $5,06(1,90)$ & $5,91(2,26)$ & $-1,465$ & 0,149 & $-0,41$ \\
\hline QI estimado & $95,94(9,46)$ & $103,52(10,36)$ & $-2,754$ & 0,009 & $-0,76$ \\
\hline \multicolumn{6}{|l|}{ Sexo } \\
\hline Fem & $18(56,2 \%)$ & $15(71,4 \%)$ & \multirow{2}{*}{$0,153^{*}$} & \multirow{2}{*}{0,274} & \\
\hline Masc & $14(43,8 \%)$ & $6(28,6 \%)$ & & & \\
\hline
\end{tabular}

* qui-quadrado 


\subsection{Caracterização dos Pacientes segundo Etiologia:}

1. Pacientes Sintomáticos - 26 pacientes ( 13 homens), com idade média de 11,54 anos [SD 2,20], com 4,96 anos [SD 1,89] de escolaridade e QI estimado médio de 94,80 [SD 9,34]. Este grupo foi composto por 15 pacientes com atrofia hipocampal (Figura 5), três pacientes com tumores temporais, um paciente com tumor desembrioplásico neuro-epitelial, um paciente com lesão no giro parahipocampal, um paciente com rotação do hipocampo, três pacientes com displasias temporais corticais e dois pacientes com esclerose tuberosa.

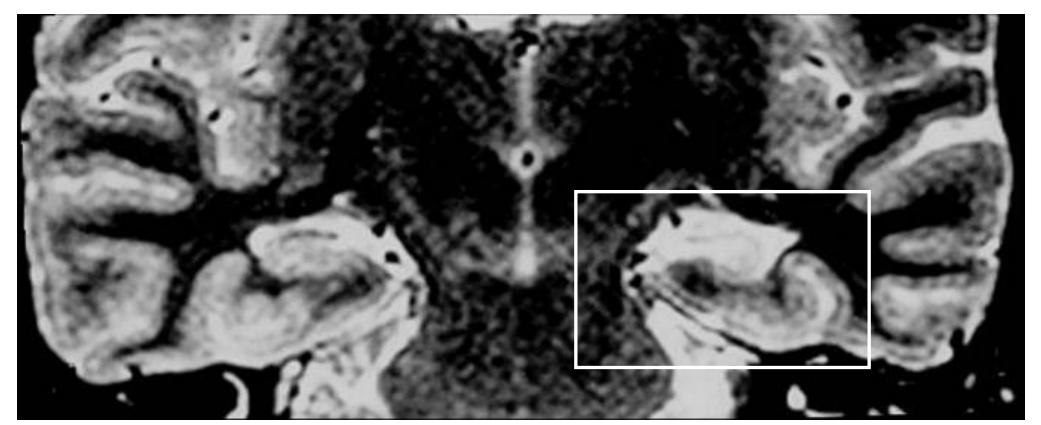

Figura 5- Atrofia Hipocampal no Lobo Temporal Esquerdo evidenciada por hipersinal em imagens pesadas em T2

2. Pacientes com ELT criptogênica - seis pacientes, sendo um $(16,7 \%)$ do sexo masculino, com idade média de 12,33 anos [SD 1,75], com 5,50 anos [SD 2,07] de escolaridade e QI estimado médio de 100,67 [SD 9,18].

Os dados referentes a estes pacientes encontram-se na Tabela $\mathbf{2}$ e os dados referentes às variáveis clínicas da epilepsia encontram-se na Tabela 3.

Tabela 2. Caracterização intragrupo de Pacientes com ELT Sintomática e Criptogênica

\begin{tabular}{|c|c|c|c|c|c|}
\hline & $\begin{array}{c}\text { Sintomático } \\
(n=26) \\
\text { Média(SD) }\end{array}$ & $\begin{array}{c}\text { Criptogênico } \\
(n=6) \\
\text { Média(SD) }\end{array}$ & $\begin{array}{l}\text { Controles } \\
(n=21) \\
\text { Média(SD) }\end{array}$ & $\mathbf{F}$ & $\mathbf{P}$ \\
\hline I dade & $11,54(2,20)$ & $12,33(1,75)$ & $11,95(2,11)$ & 0,442 & 0,646 \\
\hline Escolaridade & $4,96(1,89)$ & $5,50(2,07)$ & $5,91(2,26)$ & 1,226 & 0,302 \\
\hline QI estimado & $94,80(9,34)$ & $100,67(9,18)$ & $103,52(10,36)$ & 4,665 & 0,014 \\
\hline \multicolumn{6}{|l|}{ Sexo } \\
\hline Fem & $13(50 \%)$ & $5(83,3 \%)$ & $15(71,4 \%)$ & \multirow{2}{*}{$0,212 *$} & \multirow{2}{*}{0,127} \\
\hline Masc & $13(50 \%)$ & $1(16,7 \%)$ & $6(28,6 \%)$ & & \\
\hline
\end{tabular}

* qui-quadrado 


\section{Tabela 3: Tabela descritiva das variáveis clínicas da Epilepsia}

\begin{tabular}{|c|c|c|c|}
\hline & $\begin{array}{c}\text { ELT } \\
(n=32)\end{array}$ & $\begin{array}{l}\text { Sintomático } \\
(n=26)\end{array}$ & $\begin{array}{c}\text { Criptogênico } \\
(n=6)\end{array}$ \\
\hline $\begin{array}{l}\text { Idade de I nício, } \mu \\
\text { (SD) }\end{array}$ & $4,17(3,05)$ & $3,89(2,93)$ & $5,33(3,56)$ \\
\hline $\begin{array}{l}\text { Duração da } \\
\text { Epilepsia, } \mu \text { (SD) }\end{array}$ & $6,95(2,97)$ & $6,96(3,05)$ & $6,90(2,89)$ \\
\hline \multicolumn{4}{|l|}{ Lateralidade* } \\
\hline Direita, n (\%) & $14(43,75)$ & $14(53,85)$ & 0 \\
\hline Esquerda, n (\%) & $10(31,25)$ & $10(38,46)$ & 0 \\
\hline Bilateral, n (\%) & $2(6,25)$ & $2(7,69)$ & 0 \\
\hline \multicolumn{4}{|l|}{ Status Epilepticus } \\
\hline Presente, n (\%) & $9(28,13)$ & $9(34,62)$ & 0 \\
\hline Ausente, n (\%) & $23(71,87)$ & $17(47,22)$ & $6(100,0)$ \\
\hline \multicolumn{4}{|l|}{ História Familiar } \\
\hline Presente, $\mathrm{n}(\%)$ & $18(56,25)$ & $13(50,0)$ & $5(83,33)$ \\
\hline Ausente, n (\%) & $14(43,75)$ & $13(50,0)$ & $1(16,66)$ \\
\hline \multicolumn{4}{|l|}{$\begin{array}{l}\text { História de Crises } \\
\text { Febris }\end{array}$} \\
\hline Presente, n (\%) & $10(31,25)$ & $10(38,46)$ & 0 \\
\hline Ausente, n (\%) & $22(68,75)$ & $16(61,54)$ & $6(100,0)$ \\
\hline \multicolumn{4}{|l|}{$\begin{array}{l}\text { Freqüência de } \\
\text { Crises }\end{array}$} \\
\hline Sem Crises, n (\%) & $14(43,75)$ & $10(38,46)$ & $4(66,66)$ \\
\hline Diária, n (\%) & $8(25,0)$ & $8(30,77)$ & 0 \\
\hline Semanal, n (\%) (\%) & $7(21,88)$ & $7(26,92)$ & 0 \\
\hline Mensal, n (\%) & $2(6,25)$ & 0 & $2(33,33)$ \\
\hline Semestral, n (\%) & $1(3,13)$ & $1(3,85)$ & 0 \\
\hline \multicolumn{4}{|l|}{ Número de DAEs } \\
\hline Sem Medicação & $3(9,38)$ & $1(3,85)$ & $2(33,33)$ \\
\hline Monoterapia & $20(62,5)$ & $16(61,54)$ & $4(66,66)$ \\
\hline Politerapia & $9(28,13)$ & $9(34,62)$ & 0 \\
\hline \multicolumn{4}{|l|}{ Tipo de Crises } \\
\hline CPS, n (\%) & $2(6,25)$ & $1(3,85)$ & $1(16,66)$ \\
\hline CPC, n (\%) & $11(34,38)$ & $11(42,31)$ & 0 \\
\hline CPS, CPC, n (\%) & $10(31,25)$ & $6(23,08)$ & $4(66,66)$ \\
\hline CPC, TCG, n (\%) & $3(9,38)$ & $3(11,54)$ & 0 \\
\hline $\begin{array}{r}\text { CPS, CPC, TCG, n } \\
(\%)\end{array}$ & $6(18,75)$ & $5(19,23)$ & $1(16,66)$ \\
\hline
\end{tabular}

* Lateralidade: definida pela imagem e dados neurofisiológicos

$\mu$ : Média; SD: Desvio padrão; n: número; DAEs - drogas antiepilépticas; CPS: Crise Parcial Simples; CPC: Crise Parcial Complexa; TCG: Crise Tônico-Clônica Generalizada

\subsection{Caracterização dos Controles}

Foram incluídos 21 sujeitos controles, sendo seis $(28,6 \%)$ do sexo masculino, com idade média de 11,95 anos [SD 2,11], 5,91 anos [SD 2,07] de escolaridade e QI estimado médio de 100,67 [SD 10,36], conforme Tabela 1. 


\section{Características dos fatores estudados}

Para a avaliação neuropsicológica que será apresentada, adotou-se o intervalo mínimo de 48 horas entre a última crise e a data da avaliação neuropsicológica. Três pacientes que tiveram crises durante a avaliação, tiveram sua testagem interrompida e voltaram para reavaliação após uma semana.

\subsection{Instrumentos Neuropsicológicos:}

A bateria de testes neuropsicológicos compõe-se de testes que se propõem a avaliar as mais variadas funções atencionais, executivas e mnésticas. Os testes foram selecionados a partir de compêndios de testes neuropsicológicos (Lezak, 1995; Spreen \& Strauss, 2006) e dos testes utilizados em estudos prévios em ELT na infância.

\subsubsection{Inteligência}

- Ql estimado (Cubos - WISCIII + Vocabulário - WISCIII, Wechsler, 1991)- Quociente de Inteligência (QI) estimado.

\subsubsection{Memória}

\section{a) Memória Episódica}

- Memória para Cenas (Sheslow \& Adams, 1990 - WRAML) - Neste teste, são apresentados ao sujeito dois cartões contendo cenas desenhadas. O primeiro cartão é apresentado ao sujeito que deve memorizar a cena do cartão. Em seguida um segundo cartão contendo a cena original, contudo com algumas alterações, é exposto ao sujeito que deve dizer tudo o que está diferente. Neste teste são utilizados quatro grupos de cenas. Avalia-se, portanto, memória para estímulos visuais contextualizados.

- Memória para Figuras (Sheslow \& Adams, 1990 - WRAML) - Nesta atividade, o sujeito deve desenhar em uma folha de papel o cartão, contendo figuras geométricas, a que foi exposto anteriormente por um breve período de tempo. São apresentados quatro cartões ao sujeito. Examina-se memória para estímulos visuais não contextualizados, complexos.

- Memória para Histórias (Sheslow \& Adams, 1990 - WRAML) - Nesta atividade o sujeito é instruído a repetir o mais semelhantemente possível a história que acabou de ouvir o examinador contar. Este teste contém uma fase de evocação imediata, tardia (após 30 minutos) e questões de múltipla escolha sobre a segunda história contada. Avalia-se, 
desta forma, a memória para estímulos verbais contextualizados, de curto e longo prazo e memória de reconhecimento destes conteúdos.

\section{b) Memória Semântica}

- Memória para Sentenças (Sheslow \& Adams, 1990 - WRAML) - Neste teste, o indivíduo deve repetir frases lidas pelo examinador. O nível de dificuldade da atividade aumenta conforme o sujeito acerta. Investiga-se com este teste a memória semântica e armazenamento de informações em memória de curto prazo.

\section{c) Aprendizagem}

- Aprendizagem Verbal (Sheslow \& Adams, 1990 - WRAML) - Trata-se de teste de aprendizagem de lista de palavras. Este teste possui fase de evocação imediata e tardia (após 30 minutos). Avalia-se a aprendizagem de conteúdos verbais, evocação imediata e após interferência.

- $\quad$ Aprendizagem Visual (Sheslow \& Adams, 1990 - WRAML) - Nesta atividade o indivíduo é apresentado para um tabuleiro contendo 14 figuras simples cujas localizações ele deve memorizar. As figuras são então escondidas e é apresentado um livreto com as figuras do tabuleiro. A criança é instruída a apontar o local correto onde se encontra aquele desenho no tabuleiro. Esta prova conta com quatro apresentações de todas as figuras e uma fase de evocação tardia após um intervalo de 30 minutos. Avalia-se a aprendizagem de conteúdos visuais, evocação imediata e após interferência.

\subsubsection{Atenção}

- Lanelas Digitais (JD) (Sheslow \& Adams, 1990 - WRAML) - Esta atividade consiste de um cartão contendo nove "janelas" no qual a criança deve repetir manualmente uma seqüência visual realizada pelo examinador. Trata-se de um teste de sustentação da atenção para estímulos visuais.

- Dígitos Direto (DD) e Indireto (DI) (Wechsler, 1991- WISC-III) - Ambos os subtestes consistem de sete pares de seqüências de dígitos que o examinador lê em voz alta para a criança. No subteste Dígitos Diretos a criança deve repetir exatamente o que foi dito pelo examinador. No subteste Dígitos Indiretos, a criança deve repetir as sequências na ordem inversa. Avalia-se a sustentação da atenção e manipulação mental de informações áudioverbais. 
- $\quad$ Número-Letra (NL) (Sheslow \& Adams, 1990 - WRAML) - Este é um teste similar ao Dígitos Diretos, entretanto, a criança deve repetir uma seqüência contendo números e letras. A combinação de números e letras tende a dificultar a estratégia de codificação de dígitos tais como "trezentos e sessenta e oito" para a seqüência 3-6-8. Desta forma, também é avaliada a sustentação da atenção para estímulos áudio-verbais.

\subsubsection{Funções Executivas}

\section{a) Controle I nibitório}

- Matching Familiar Figures Test (MFFT) (Cairns \& Cammock, 1994) - Neste teste a criança deve encontrar o mais rapidamente possível e cometendo o menor número de erros um par de figuras iguais dentre sete desenhos muito similares. Avalia-se, portanto, a capacidade de inibição da emissão de respostas a partir de estímulos visuais.

\section{b) Flexibilidade Mental e Abstração}

- Wisconsin Card Sorting Test (WCST) (Heaton et al., 1993) - Trata-se de teste padrão ouro para avaliar comportamento abstrato, mudança de setting, inibição de respostas e flexibilidade mental. Neste teste, quatro cartões de estímulos (um triângulo vermelho, duas estrelas verdes, três cruzes amarelas e quatro círculos azuis) são colocados na frente da criança e ela é instruída a colocar cada carta embaixo do cartão estímulo que ela achar que combina melhor. Durante a testagem, a criança deve tentar adivinhar qual é a característica do estímulo que deve associar segundo o feedback (correto e incorreto) do examinador que recebe em cada resposta que ela dá. O teste inicia-se com cor como princípio de escolha, passa para forma, depois número, volta à cor, e finaliza com o término das 128 cartas.

\section{c) Rastreio Mental para I nformações Semânticas}

- $\quad$ Fluência Verbal Categorias (FV animais e comidas) (Strauss et al., 2006) - Neste teste a criança precisa dizer o maior número de palavras que conseguir pensar segundo as instruções do examinador (primeiro são solicitados nomes de animais e depois nomes de comidas) em um período de 60 segundos. Este é um teste de nomeação semântica, onde estão envolvidas a iniciação de respostas, busca mental de informações verbais e produção de palavras sob condições delimitadas. O sujeito não pode repetir palavras já emitidas, não deve dizer o nome de machos e fêmeas na categoria animal ou palavras com a mesma raiz semântica (por exemplo feijão e feijoada) na categoria comida. 


\section{d) Atenção Dividida}

- Trail Making Test, versão infantil (TMT) (Strauss et al., 2006) - Este teste consiste em duas partes. Na parte A, o sujeito deve ligar círculos numerados, seguindo, portanto, a ordem numérica crescente. Na parte B, o sujeito deve conectar círculos, mas alternando números e letras, seguindo as ordens numéricas crescentes e alfabéticas. O sujeito é instruído a conectar os círculos o mais rápido possível, sem retirar o lápis do papel. São avaliados o tempo necessário para terminar a prova e a quantidade de erros cometidos pelo indivíduo. Investiga-se o rastreamento visual complexo, atenção visual, flexibilidade mental e controle inibitório.

\subsection{Análises Estatísticas}

Inicialmente foi verificada a homogeneidade dos grupos com relação as variáveis sóciodemográficas através do teste t (para as variáveis quantitativas) e qui-quadrado (para as variáveis nominais).

$\mathbf{1}^{\circ}$. Os testes de funções executivas e de memória foram comparados entre os grupos através de uma Análise de Covariância (ANCOVA) considerando QI como co-variáveis.

$2^{\circ}$. A influência das variáveis clinicas da epilepsia sobre o desempenho dos testes mnésticos e executivos foi verificada através da Correlação de Spearman e do teste de Mann-Whitney. Neste caso um teste não paramétrico foi escolhido por considerar somente os pacientes em sua análise e por se tratar de uma amostra pequena.

$3^{\circ}$ Os aspectos de neurodesenvolvimento das funções executivas foram analisados através da ANCOVA, utilizando o QI como covariável através de duas análises:

1. Desempenho de pacientes foi comparado segundo a sua idade no momento da avaliação neuropsicológica (pacientes com idades inferiores e superiores a 12 anos) e;

2. Desempenho de pacientes foi comparado segundo a idade de início da epilepsia (precoce $[<4$ anos de idade] e tardia [ $\geq 4$ anos de idade]).

$4^{\circ}$. Gravidade da disfunção de memória e executiva: Estabeleceu-se um critério clínico para a avaliação do nível de gravidade da DMn e DE dos pacientes com ELT. Assim, consideramos DMn e DE quando o score bruto em um teste do paciente foi pelo menos um desvio padrão 
inferior à média dos controles naquele teste em pelo menos dois paradigmas em comparação com a média os sujeitos controles.

Desta forma, avaliou-se como sutil quando déficits ocorreram em dois testes; moderada quando ocorreram em três ou quatro testes e grave quando ocorreram em cinco ou mais testes.

Quadro 1. Descrição do critério clínico para avaliação da gravidade da DMn e DE

$\begin{array}{ll}\text { Presença de DMn ou DE } & \text { Score do paciente } 1 \text { SD abaixo no mínimo em } 2 \text { subtestes } \\ \text { DMn ou DE sutil } & \text { Score do paciente 1SD abaixo em } 2 \text { subtestes } \\ \text { DMn ou DE moderada } & \text { Score do paciente 1SD abaixo em } 3 \text { ou } 4 \text { subtestes } \\ \text { DMn ou DE grave } & \text { Score do paciente 1SD abaixo em } 5 \text { ou mais subtestes }\end{array}$

$4^{\circ}$. A influencia dos testes de FE sobre os testes de memória foi verificada de duas formas: por análise teste a teste e por domínios (função executiva e memória) construídos a partir dos escores padronizados dos testes que os compõem. O método utilizado em os ambos casos foi o coeficiente de correlação de Spearman com uma análise para cada grupo de sujeitos (pacientes e controles).

A medida d de Cohen foi obtida para calcular a magnitude do efeito (effect size) entre grupos (Conboy, 2003)

As analises foram realizadas através do software SPSS for Windows, versão 14.0 e foi adotado em todos os testes um nível de significância de 5\%. 


\section{Presença de disfuncão de memória e de disfuncão executiva nos pacientes com}

\section{ELT}

\subsection{Funções Mnésticas}

\subsubsection{Presença de Disfunção Mnéstica em Pacientes com ELT}

a. Os pacientes com ELT tiveram pior desempenho do que os sujeitos controles nos seguintes testes de memória: Memória para Figuras $(\mathbf{p}=\mathbf{0 , 0 6 6})$, Memóra para Histórias imediata $(\mathbf{p}=\mathbf{0 , 0 4 0 )}$ e tardia $(\mathbf{p}=\mathbf{0 , 0 6 8 )}$ e Memória para Sentenças $(p=0,010)$. (Tabela 4)

Tabela 4. Comparação do desempenho de Pacientes e Controles nos testes de Memória

\begin{tabular}{lccccc}
\hline & $\begin{array}{c}\text { Pacientes } \\
(\mathbf{n = 3 2}) \\
\text { Média( SD) }\end{array}$ & $\begin{array}{c}\text { Controles } \\
(\mathbf{n = 2 1 )} \\
\text { Média( SD) }\end{array}$ & F & p & Cohen's d \\
\hline M. Cenas & $22,16(5,85)$ & $21,87(5,73)$ & 0,109 & 0,372 & 0,05 \\
\hline M. Figuras & $32,26(9,20)$ & $38,38(9,21)$ & $\mathbf{2 , 3 4 5}$ & $\mathbf{0 , 0 6 6}$ & $\mathbf{- 0 , 6 6}$ \\
M. Histórias & $22,71(8,28)$ & $28,57(10,52)$ & $\mathbf{3 , 1 9 2}$ & $\mathbf{0 , 0 4 0}$ & $\mathbf{- 0 , 6 2}$ \\
M. Histórias II & $18,20(8,38)$ & $24,14(11,96)$ & $\mathbf{2 , 3 0 3}$ & $\mathbf{0 , 0 6 8}$ & $\mathbf{- 0 , 5 8}$ \\
M. Sentenças & $14,83(5,60)$ & $20,86(6,85)$ & $\mathbf{5 , 7 9 9}$ & $\mathbf{0 , 0 1 0}$ & $\mathbf{- 0 , 9 6}$ \\
\hline A. Verbal & $36,35(8,55)$ & $38,29(8,88)$ & 0,375 & 0,272 & $-0,22$ \\
A. Visual & $23,83(12,31)$ & $27,65(7,75)$ & 0,072 & 0,395 & $-0,37$ \\
E. A. Verbal & $3,25(2,17)$ & $2,80(0,95)$ & 0,277 & 0,301 & 0,27 \\
E. A. Visual & $4,34(1,70)$ & $4,10(1,52)$ & 1,196 & 0,140 & 0,15 \\
Reconhecimento & $9,86(3,59)$ & $11,05(2,11)$ & 0,494 & 0,243 & $-0,40$ \\
\hline
\end{tabular}

Legenda: M. Cenas: Memória para Cenas; M. Figuras: Memória para Figuras; M. Histórias: Memória para Histórias; M. Sentenças: Memória para Sentenças; A. Verbal: Aprendizagem Verbal; A. Visual: Aprendizagem Visual; E. A. Verbal: Evocação Aprendizagem Verbal; E. A. Visual: Evocação Aprendizagem Visual.

\subsubsection{Diferença de desempenho de pacientes com lesão à esquerda e à direita}

a. Pacientes com lesão à $D$ e à $E$ não diferiram em seu desempenho em testes de memória. ( Tabela 5) 
Tabela 5. Comparação do desempenho de Pacientes com lesão à $D$ e à E nos testes de Memória

\begin{tabular}{lccccc}
\hline & $\begin{array}{c}\text { Pacientes } \\
\text { com lesão à } \\
\mathbf{D}(\mathbf{n}=\mathbf{1 9}) \\
\text { Média( SD) }\end{array}$ & $\begin{array}{c}\text { Pacientes com } \\
\text { lesão à E (n=5) } \\
\text { Média( SD) }\end{array}$ & F & P & Cohen's d \\
\hline M. Cenas & $20,68(5,26)$ & $23,40(5,13)$ & 0,823 & 0,188 & $-0,52$ \\
\hline M. Figuras & $32,26(10,08)$ & $27,80(8,26)$ & 0,098 & 0,379 & 0,48 \\
M. Histórias & $20,68(6,76)$ & $20,60(9,48)$ & 0,055 & 0,408 & 0,01 \\
M. Histórias II & $16,83(7,38)$ & $14,60(7,96)$ & 0,063 & 0,403 & 0,29 \\
M. Sentenças & $14,17(5,26)$ & $11,00(5,61)$ & 0,379 & 0,273 & 0,58 \\
\hline A. Verbal & $35,53(8,65)$ & $35,20(5,72)$ & 0,002 & 0,482 & 0,04 \\
A. Visual & $22,33(12,76)$ & $20,20(5,07)$ & 0,046 & 0,416 & 0,22 \\
\hline E. A. Verbal & $3,24(2,22)$ & $4,50(3,11)$ & 0,864 & 0,183 & $-0,47$ \\
\hline E. A. Visual & $4,24(1,89)$ & $4,40(2,07)$ & 0,385 & 0,271 & $-0,08$ \\
\hline Reconhecimento & $9,06(3,90)$ & $9,20(3,09)$ & 0,015 & 0,452 & $-0,04$ \\
\hline
\end{tabular}

Legenda: M. Cenas: Memória para Cenas; M. Figuras: Memória para Figuras; M. Histórias: Memória para Histórias; M. Sentenças: Memória para Sentenças; A. Verbal: Aprendizagem Verbal; A. Visual: Aprendizagem Visual; E. A. Verbal:

Evocação Aprendizagem Verbal; E. A. Visual: Evocação Aprendizagem Visual.

\subsection{Funções Executivas}

\subsubsection{Presença de Disfunção Executiva em pacientes com ELT}

a. Os pacientes com ELT tiveram pior desempenho do que os sujeitos controles nos seguintes testes de FE: número de erros no Matching Familiar Figures Test $(\mathbf{p}=\mathbf{0 , 0 6 4 )}$, Trail Making parte B número de erros $(\mathbf{p}=\mathbf{0 , 0 1 5 )}$, Wisconsin Card Sorting Test número de categorias $(\mathbf{p}=\mathbf{0 , 0 5 0})$ e erros não perseverativos $(\mathbf{p}=\mathbf{0 , 0 4 7})$, Fluência Verbal para comidas $(\mathbf{p}=\mathbf{0 , 0 6 4 )}$ e Memória para Número Letra $(\mathbf{p}=\mathbf{0 , 0 3 2 )}$. (Tabela $\mathbf{6})$ 
Tabela 6. Comparação do desempenho de Pacientes e Controles nos testes de FE

\begin{tabular}{|c|c|c|c|c|c|}
\hline & $\begin{array}{c}\text { Pacientes }(n=32) \\
\text { Média(SD) }\end{array}$ & $\begin{array}{c}\text { Controles }(n=21) \\
\text { Média(SD) }\end{array}$ & $\mathbf{F}$ & $\mathbf{P}$ & $\begin{array}{c}\text { Cohen's } \\
\text { d }\end{array}$ \\
\hline DD & $6,77(1,77)$ & $7,33(1,35)$ & 0,575 & 0,226 & $-0,36$ \\
\hline MFFT erros & $20,72(11,00)$ & $13,67(8,59)$ & 2,396 & 0,064 & $-0,71$ \\
\hline MFFT tempo & $222,80(131,08)$ & $245,48(158,79)$ & 0,004 & 0,474 & $-0,16$ \\
\hline MFFT total & $3067,78(1096,20)$ & $2669,05(1596,54)$ & 0,658 & 0,211 & $-0,29$ \\
\hline TM B tempo & $61,11(25,09)$ & $50,48(26,86)$ & 0,554 & 0,231 & $-0,41$ \\
\hline TM B erros & $0,50(0,84)$ & $0,10(0,31)$ & 5,016 & 0,015 & $-0,63$ \\
\hline WCST (categ.) & $4,13(2,68)$ & $6,30(2,41)$ & 2,819 & 0,050 & $-0,85$ \\
\hline WCST (EP) & $23,71(11,35)$ & $21,05(11,36)$ & 0,006 & 0,471 & $-0,23$ \\
\hline WCST (ENP) & $26,63(16,25)$ & $18,70(8,74)$ & 2,933 & 0,047 & $-0,61$ \\
\hline Janelas Digitais & $13,32(5,03)$ & $14,95(4,47)$ & 0,251 & 0,310 & $-0,52$ \\
\hline Número-Letra & $7,71(3,35)$ & $10,48(5,18)$ & 3,612 & 0,032 & $-0,76$ \\
\hline
\end{tabular}

Legenda: DD: Dígitos Diretos; DI: Dígitos Indiretos; MFFT: Matching Familiar Figures Test; TM: Trail Making Test; WCST: Wisconsin Card Sorting Test; WCST (categ): Wisconsin Card Sorting Test (número de categorias); WCST (EP): Wisconsin Card Sorting Test (erros perseverativos); WCST (ENP): Wisconsin Card Sorting Test (erros não perseverativos); WCST (RP): Wisconsin Card Sorting Test (respostas perseverativas); WCST (QS): Wisconsin Card Sorting Test (quebra de setting); FV: Teste de Fluência Verbal

\section{I mpacto da etiologia nos testes de memória e funcões executivas dos pacientes}

\section{COM ELT}

\subsection{Funções Mnésticas}

\subsubsection{Diferença no desempenho de pacientes com ELT Sintomática, Criptogênica e}

\section{Controles Saudáveis}

a. Pacientes Sintomáticos tiveram pior desempenho que Criptogênicos nos seguintes testes de memória: Memória para Histórias imediata $(\mathbf{p = 0 , 0 2 5 )}$ e Memória para Sentenças ( $\mathbf{p = 0 , 0 0 4 ) . ~ ( T a b e l a ~ 7 ) ~}$ 
Tabela 7. Comparação do desempenho de Pacientes Sintomáticos e Criptogênicos nos testes de Memória

\begin{tabular}{lcccccc}
\hline & $\begin{array}{c}\text { Sintomáticos } \\
(\mathbf{n = 2 6}) \\
\text { Média(SD) }\end{array}$ & $\begin{array}{c}\text { Criptogênicos } \\
(\mathbf{n = 6}) \\
\text { Média(SD) }\end{array}$ & $\begin{array}{c}\text { Controles } \\
(\mathbf{n = 2 1 )} \\
\text { Média(SD) }\end{array}$ & F & P & $\begin{array}{c}\text { Cohen's } \\
\mathbf{d}\end{array}$ \\
\hline M. Cenas & $21,36(5,16)$ & $25,50(7,79)$ & $21,87(5,73)$ & 1,214 & 0,153 & $-0,63$ \\
M. Figuras & $31,52(9,57)$ & $35,33(7,33)$ & $38,38(9,21)$ & 1,318 & 0,139 & $-0,45$ \\
M. Histórias & $21,20(7,51)$ & $29,00(9,06)$ & $28,57(10,52)$ & $\mathbf{3 , 2 1 8}$ & $\mathbf{0 , 0 2 5}$ & $-\mathbf{0 , 9 4}$ \\
M. Histórias II & $17,04(7,98)$ & $22,83(9,09)$ & $24,14(11,96)$ & 1,725 & 0,095 & $-0,68$ \\
M. Sentenças & $13,50(5,26)$ & $10,17(3,49)$ & $20,86(6,85)$ & $\mathbf{5 , 3 2 3}$ & $\mathbf{0 , 0 0 4}$ & $\mathbf{0 , 7 5}$ \\
\hline A. Verbal & $35,52(7,85)$ & $39,83(11,14)$ & $38,29(8,88)$ & 0,731 & 0,244 & $-0,45$ \\
A. Visual & $22,29(11,39)$ & $30,00(15,01)$ & $27,65(7,75)$ & 0,712 & 0,248 & $-0,58$ \\
E. A. Verbal & $3,45(2,32)$ & $2,50(1,38)$ & $2,80(0,95)$ & 0,658 & 0,262 & 0,50 \\
E. A. Visual & $4,22(1,86)$ & $4,83(0,75)$ & $4,10(1,52)$ & 0,718 & 0,247 & $-0,43$ \\
Reconhecimento & $9,30(3,82)$ & $12,00(1,10)$ & $11,05(2,11)$ & 1,713 & 0,096 & $-0,96$ \\
\hline
\end{tabular}

Legenda: M. Cenas: Memória para Cenas; M. Figuras: Memória para Figuras; M. Histórias: Memória para Histórias; M. Sentenças: Memória para Sentenças; A. Verbal: Aprendizagem Verbal; A. Visual: Aprendizagem Visual; E. A. Verbal: Evocação Aprendizagem Verbal; E. A. Visual: Evocação Aprendizagem Visual.

\subsubsection{Diferença no desempenho de pacientes com e sem Atrofia Hipocampal}

a. Piores desempenhos do grupo com ELT por AH foram observados nos seguintes testes mnésticos: Memória para Histórias imediata $(\mathbf{p = 0 , 0 3 1 )}$, Memória para Sentenças ( $\mathbf{p}=\mathbf{0 , 0 3 3 )}$ e Aprendizagem Verbal $(\mathbf{p = 0 , 0 6 9 )}$. (Tabela 8)

Tabela 8. Comparação do desempenho de Pacientes com AH e demais Pacientes com ELT nos testes de Memória

\begin{tabular}{|c|c|c|c|c|c|c|}
\hline & $\begin{array}{c}\text { Pacientes } \\
\text { com AH } \\
(n=15) \\
\text { Média(SD) }\end{array}$ & $\begin{array}{c}\text { Pacientes sem } \\
\text { AH ( } n=15) \\
\text { Média(SD) }\end{array}$ & $\begin{array}{l}\text { Controles } \\
(n=21) \\
\text { Média(SD) }\end{array}$ & $\mathbf{F}$ & $\mathbf{p}$ & $\begin{array}{c}\text { Cohen's } \\
\text { d }\end{array}$ \\
\hline M. Cenas & $20,33(5,12)$ & $23,88(6,12)$ & $21,87(5,73)$ & 1,476 & 0,120 & $-0,63$ \\
\hline M. Figuras & $30,00(10,82)$ & $34,38(7,09)$ & $38,38(9,21)$ & 1,909 & 0,080 & $-0,48$ \\
\hline M. Histórias & $19,87(6,31)$ & $25,38(9,18)$ & $28,57(10,52)$ & 2,953 & 0,031 & $-0,70$ \\
\hline M. Histórias I I & $15,79(7,33)$ & $20,31(8,89)$ & $24,14(11,96)$ & 1,787 & 0,090 & $-0,55$ \\
\hline M. Sentenças & $14,14(5,30)$ & $15,44(5,96)$ & $20,86(6,85)$ & 2,895 & 0,033 & $-0,23$ \\
\hline A. Verbal & $33,27(6,28)$ & $39,25(9,53)$ & $38,29(8,88)$ & 2,064 & 0,069 & $-0,74$ \\
\hline A. Visual & $19,79(11,98)$ & $27,38(11,83)$ & $27,65(7,75)$ & 1,655 & 0,101 & $-0,64$ \\
\hline E. A. Verbal & $3,61(2,96)$ & $2,93(1,16)$ & $2,80(0,95)$ & 0,561 & 0,288 & 0,30 \\
\hline E. A. Visual & $3,77(1,83)$ & $4,81(1,47)$ & $4,10(1,52)$ & 1,896 & 0,081 & $-0,63$ \\
\hline Reconhecimento & $9,69(4,30)$ & $10,00(3,03)$ & $11,05(2,11)$ & 0,247 & 0,391 & $-0,08$ \\
\hline
\end{tabular}

Legenda: M. Cenas: Memória para Cenas; M. Figuras: Memória para Figuras; M. Histórias: Memória para Histórias; M. Sentenças: Memória para Sentenças; A. Verbal: Aprendizagem Verbal; A. Visual: Aprendizagem Visual; E. A. Verbal: Evocação Aprendizagem Verbal; E. A. Visual: Evocação Aprendizagem Visual. 


\subsection{Funções Executivas}

\subsubsection{Diferença no desempenho de pacientes com ELT Sintomática, Criptogênica e}

\section{Controles Saudáveis}

a. Pacientes Sintomáticos tiveram pior performance do que os Criptogênicos nos seguintes testes de FE: Números de erros no Trail Making Parte $B(\mathbf{p}=\mathbf{0 , 0 4 8 )}$, número de categorias no Wisconsin Card Sorting Test $(\mathbf{p = 0 , 0 1 7 ) , ~ n u ́ m e r o ~ d e ~}$ erros não perseverativos $(\mathbf{p}=\mathbf{0 , 0 4 4 )}$, Fluência Verbal para comidas $(\mathbf{p}=\mathbf{0}, \mathbf{0 6 0})$ e

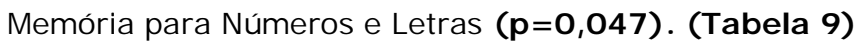

Tabela 9. Comparação do desempenho de Pacientes Sintomáticos e Controles nos testes de FE

\begin{tabular}{|c|c|c|c|c|c|c|}
\hline & $\begin{array}{c}\text { Sintomáticos } \\
(n=26) \\
\text { Média(SD) }\end{array}$ & $\begin{array}{c}\text { Criptogênicos } \\
(n=6) \\
\text { Média(SD) }\end{array}$ & $\begin{array}{c}\text { Controles }(\mathrm{n}=\mathbf{2 1} \text { ) } \\
\text { Média(SD) }\end{array}$ & $\mathbf{F}$ & $\mathbf{P}$ & $\begin{array}{l}\text { Cohen } \\
\text { s d }\end{array}$ \\
\hline DD & $6,88(1,69)$ & $6,20(2,28)$ & $7,33(1,35)$ & 0,858 & 0,215 & 0,34 \\
\hline DI & $4,08(1,61)$ & $5,80(2,28)$ & $4,62(1,20)$ & 2,019 & 0,072 & $-0,87$ \\
\hline MFFT erros & $20,46(10,99)$ & $22,00(12,21)$ & $13,67(8,59)$ & 1,462 & 0,121 & $-1,38$ \\
\hline MFFT tempo & $233,04(139,04)$ & $171,60(68,04)$ & $245,48(158,79)$ & 0,633 & 0,268 & 0,56 \\
\hline MFFT total & $3186,41(1100,93)$ & $2545,80(1014,61)$ & $2669,05(1596,54)$ & 0,734 & 0,243 & 0,61 \\
\hline TM A tempo & $29,62(12,54)$ & $27,50(13,22)$ & $25,05(10,02)$ & 0,193 & 0,413 & 0,16 \\
\hline TM A erros & $0,22(0,52)$ & $0,17(0,41)$ & $0,05(0,22)$ & 0,647 & 0,265 & 0,11 \\
\hline TM B tempo & $63,95(25,21)$ & $50,67(23,71)$ & $50,48(26,86)$ & 0,617 & 0,272 & 0,54 \\
\hline TM B erros & $0,50(0,91)$ & $0,50(0,55)$ & $0,10(0,31)$ & 2,473 & 0,048 & 0,75 \\
\hline $\begin{array}{l}\text { WCST } \\
\text { (categ.) }\end{array}$ & $3,64(2,45)$ & $6,60(2,61)$ & $6,30(2,41)$ & 3,685 & 0,017 & $-1,17$ \\
\hline WCST (EP) & $25,00(11,21)$ & $17,80(10,55)$ & $21,05(11,36)$ & 0,481 & 0,311 & 0,66 \\
\hline WCST (ENP) & $28,32(16,74)$ & $18,20(11,21)$ & $18,70(8,74)$ & 2,565 & 0,044 & 0,71 \\
\hline WCST (RP) & $28,61(15,49)$ & $20,80(13,95)$ & $25,15(14,32)$ & 0,348 & 0,354 & 0,53 \\
\hline WCST (QS) & $1,24(1,27)$ & $0,80(1,10)$ & $0,75(0,85)$ & 0,418 & 0,331 & 0,37 \\
\hline FV animais & $12,24(4,18)$ & $15,50(5,96)$ & $14,90(5,42)$ & 0,871 & 0,213 & $-0,63$ \\
\hline FV comidas & $10,28(4,01)$ & $13,33(5,28)$ & $13,43(3,68)$ & 2,230 & 0,060 & $-0,65$ \\
\hline $\begin{array}{l}\text { Janelas } \\
\text { Digitais }\end{array}$ & $12,60(4,86)$ & $16,33(5,01)$ & $14,95(4,47)$ & 1,185 & 0,157 & $-0,76$ \\
\hline Número-Letra & $7,24(3,17)$ & $9,67(3,67)$ & $10,48(5,18)$ & 2,484 & 0,047 & $-0,71$ \\
\hline
\end{tabular}

Legenda: DD: Dígitos Diretos; DI: Dígitos Indiretos; MFFT: Matching Familiar Figures Test; TM: Trail Making Test; WCST: Wisconsin Card Sorting Test; WCST (categ): Wisconsin Card Sorting Test (número de categorias); WCST (EP): Wisconsin Card Sorting Test (erros perseverativos); WCST (ENP): Wisconsin Card Sorting Test (erros não perseverativos); WCST (RP): Wisconsin Card Sorting Test (respostas perseverativas); WCST (QS): Wisconsin Card Sorting Test (quebra de setting); FV: Teste de Fluência Verbal

\subsubsection{Diferença no desempenho de pacientes com e sem Atrofia Hipocampal}

a. Observou-se piores desempenhos do grupo com ELT por AH nos seguintes testes executivos: Trail Making parte B número de erros $(\mathbf{p}=\mathbf{0 , 0 4 4 )}$, Wisconsin Card Sorting Test número de categorias $(\mathbf{p = 0 , 0 3 2 )}$, número de erros não perseverativos $(\mathbf{p}=\mathbf{0 , 0 3 8 )}$, Fluência Verbal comidas $(\mathbf{p}=\mathbf{0 , 0 6 0})$. (Tabela 10) 
Tabela 10. Comparação do desempenho de Pacientes com AH e demais Pacientes com ELT nos testes de FE

\begin{tabular}{|c|c|c|c|c|c|c|}
\hline & $\begin{array}{l}\text { Pacientes com } \\
\text { AH }(n=15) \\
\text { Média(SD) }\end{array}$ & $\begin{array}{l}\text { Pacientes sem } \\
\text { AH }(n=15) \\
\text { Média(SD) }\end{array}$ & $\begin{array}{l}\text { Controles }(n=21) \\
\text { Média(SD) }\end{array}$ & $\mathbf{F}$ & $\mathbf{P}$ & $\begin{array}{l}\text { Cohen' } \\
\text { s d }\end{array}$ \\
\hline$\overline{D D}$ & $7,07(1,68)$ & $6,47(1,88)$ & $7,33(1,35)$ & 0,897 & 0,208 & 0,34 \\
\hline DI & $4,53(1,41)$ & $4,20(2,18)$ & $4,62(1,20)$ & 0,490 & 0,308 & 0,18 \\
\hline MFFT erros & $19,73(10,44)$ & $21,79(11,86)$ & $13,67(8,59)$ & 1,475 & 0,120 & $-0,18$ \\
\hline MFFT tempo & $233,27(160,80)$ & $212,33(97,46)$ & $245,48(158,79)$ & 0,124 & 0,442 & 0,16 \\
\hline MFFT total & $3333,80(1197,89)$ & $2735,25(892,65)$ & $2669,05(1596,54)$ & 0,947 & 0,198 & 0,57 \\
\hline TM A tempo & $27,75(12,39)$ & $30,27(12,84)$ & $25,05(10,02)$ & 0,523 & 0,298 & $-0,20$ \\
\hline TM A erros & $0,08(0,28)$ & $0,31(0,60)$ & $0,05(0,22)$ & 2,026 & 0,072 & $-0,50$ \\
\hline TM B tempo & $61,85(23,53)$ & $60,47(27,17)$ & $50,48(26,86)$ & 0,282 & 0,378 & 0,05 \\
\hline TM B erros & $0,54(0,88)$ & $0,47(0,83)$ & $0,10(0,31)$ & 2,568 & 0,044 & 0,08 \\
\hline $\begin{array}{l}\text { WCST } \\
\text { (categ.) }\end{array}$ & $3,33(2,50)$ & $4,93(2,69)$ & $6,30(2,41)$ & 2,916 & 0,032 & $-0,62$ \\
\hline WCST (EP) & $22,85(9,49)$ & $24,47(12,87)$ & $21,05(11,36)$ & 0,082 & 0,461 & $-0,14$ \\
\hline WCST (ENP) & $30,60(19,80)$ & $22,67(11,00)$ & $18,70(8,74)$ & 2,733 & 0,038 & 0,49 \\
\hline WCST (RP) & $25,15(13,21)$ & $29,00(17,14)$ & $25,15(14,32)$ & 0,345 & 0,355 & $-0,25$ \\
\hline WCST (QS) & $1,07(1,16)$ & $1,27(1,34)$ & $0,75(0,85)$ & 0,442 & 0,323 & $-0,16$ \\
\hline FV animais & $12,53(3,70)$ & $13,19(5,49)$ & $14,90(5,42)$ & 0,241 & 0,394 & 0,14 \\
\hline FV comidas & $9,73(3,67)$ & $11,94(4,78)$ & $13,43(3,68)$ & 2,213 & 0,060 & $-0,52$ \\
\hline $\begin{array}{l}\text { Janelas } \\
\text { Digitais }\end{array}$ & $12,87(4,64)$ & $13,75(5,48)$ & $14,95(4,47)$ & 0,192 & 0,413 & $-0,17$ \\
\hline Número-Letra & $7,33(3,09)$ & $8,06(3,64)$ & $10,48(5,18)$ & 1,863 & 0,083 & $-0,22$ \\
\hline
\end{tabular}

Legenda:DD: Dígitos Diretos; DI: Dígitos Indiretos; MFFT: Matching Familiar Figures Test; TM: Trail Making Test; WCST: Wisconsin Card Sorting Test; WCST (categ): Wisconsin Card Sorting Test (número de categorias); WCST (EP): Wisconsin Card Sorting Test (erros perseverativos); WCST (ENP): Wisconsin Card Sorting Test (erros não perseverativos); WCST (RP): Wisconsin Card Sorting Test (respostas perseverativas); WCST (QS): Wisconsin Card Sorting Test (quebra de setting); FV: Teste de Fluência Verbal

\section{I nfluência das variáveis clínicas da epilepsia sobre o desempenho nos testes de}

\section{funcões de memória e executiva}

\subsection{Funções Mnésticas}

\subsubsection{Análise da influência das variáveis clínicas nos testes cognitivos}

a. Uso de politerapia esteve relacionado com pior desempenho nos seguintes testes de memória: Memória para Cenas $(\mathbf{p = 0 , 0 0 1 )}$, Memória para Histórias imediata $(\mathbf{p}=\mathbf{0 , 0 0 3 )}$ e tardia $(\mathbf{p = 0 , 0 1 0 )}$, Memória para Sentenças $(\mathbf{p = 0 , 0 6 2 )}$, Aprendizagem Verbal ( $\mathbf{p = 0 , 0 1 5 ) , ~ A p r e n d i z a g e m ~ V i s u a l ~}(\mathbf{p}=\mathbf{0 , 0 0 1})$, Aprendizagem Visual tardia $(\mathbf{p}=\mathbf{0 , 0 5 0}$ e Reconhecimento para Memória para Histórias $(\mathbf{p = 0 , 0 2 9 )}$. (Tabela 11)

b. Idade de Início: teve um impacto significativo nos seguintes testes de funções mnésticas: Memória para Figuras $(\mathbf{p = 0 , 0 3 9 )}$, Memória para Histórias imediata $(\mathbf{p}=\mathbf{0 , 0 5 6 )}$ e tardia $(\mathbf{p}=\mathbf{0 , 0 1 9})$, Memória para Sentenças $(\mathbf{p}=\mathbf{0 , 0 0 5})$, Aprendizagem Verbal $(\mathbf{p}=\mathbf{0 , 0 3 5 )}$. (Tabela 11)

b. Duração da Epilepsia, Presença de Crises Freqüentes ou Infreqüentes e Controle de Crises também influenciaram negativamente o desempenho em testes de memória. 
Duração da Epilepsia influenciou o teste de Memória para Figuras $(\mathbf{p}=\mathbf{0 , 0 4 9 )}$, Crises Freqüentes estava relacionado com o desempenho em Memória para Cenas $(\mathbf{p}=\mathbf{0 , 0 1 8})$, Controle de Crises foi significativa em Aprendizagem Visual $(\mathbf{p = 0 , 0 3 2 )}$ e Reconhecimento de Memória para Histórias $(\mathbf{p = 0 , 0 2 9 )}$. (Tabela 11)

c. Presença de Status Epilepticus, Antecedentes Familiares de epilepsia, Freqüência de Crises, Crises Febris, Tipos de Crises e Generalização Secundária não tiveram impacto sobre o desempenho nos testes de memória. (Tabela 11) 
Resultados

Tabela 11. Influência das Variáveis Clínicas da Epilepsia no desempenho de Pacientes testes de Memória

\begin{tabular}{|c|c|c|c|c|c|c|c|c|c|c|c|}
\hline & $\begin{array}{l}\text { I dade } \\
\text { de } \\
\text { I nício } \\
\text { r(p) }\end{array}$ & $\begin{array}{c}\text { Duração } \\
\mathbf{r ( p )}\end{array}$ & SE Z $(p)$ & HF Z $(p)$ & CF Z (p) & $\begin{array}{l}\text { Freq } \\
r(p)\end{array}$ & $\begin{array}{l}\text { Ranks } \\
Z(p)\end{array}$ & $\begin{array}{l}\text { Tipo } \\
\text { Crise } \\
\text { r(p) }\end{array}$ & $\begin{array}{l}\text { Controle } \\
Z(p)\end{array}$ & $\begin{array}{l}\text { DAES } \\
\text { r(p) }\end{array}$ & $\begin{array}{l}\text { General } \\
2 \mathrm{a} Z(p)\end{array}$ \\
\hline M. Cenas & $\begin{array}{c}0,135 \\
(0,470)\end{array}$ & $\begin{array}{l}-0,219 \\
(0,235)\end{array}$ & $\begin{array}{l}-1,290 \\
(0,197)\end{array}$ & $\begin{array}{l}-0,816 \\
(0,414)\end{array}$ & $\begin{array}{l}-0,393 \\
(0,694)\end{array}$ & $\begin{array}{c}-0,144 \\
(0,439)\end{array}$ & $\begin{array}{c}0,421 \\
(0,018)\end{array}$ & $\begin{array}{c}0,056 \\
(0,766)\end{array}$ & $\begin{array}{l}-2,209 \\
(0,027)\end{array}$ & $\begin{array}{c}-0,556 \\
(0,001)\end{array}$ & $\begin{array}{l}-0,634 \\
(0,526)\end{array}$ \\
\hline M. Figuras & $\begin{array}{c}0,372 \\
(0,039)\end{array}$ & $\begin{array}{c}-0,356 \\
(0,049)\end{array}$ & $\begin{array}{l}-0,791 \\
(0,429)\end{array}$ & $\begin{array}{l}-0,517 \\
(0,605)\end{array}$ & $\begin{array}{l}-0,153 \\
(0,879)\end{array}$ & $\begin{array}{c}0,131 \\
(0,481)\end{array}$ & $\begin{array}{c}0,107 \\
(0,567)\end{array}$ & $\begin{array}{c}0,215 \\
(0,246)\end{array}$ & $\begin{array}{c}-0,020 \\
(0,984)\end{array}$ & $\begin{array}{c}-0,231 \\
(0,210)\end{array}$ & $\begin{array}{l}-0,520 \\
(0,603)\end{array}$ \\
\hline M. Histórias & $\begin{array}{c}0,347 \\
(0,056)\end{array}$ & $\begin{array}{c}-0,198 \\
(0,287)\end{array}$ & $\begin{array}{c}-0,045 \\
(0,964)\end{array}$ & $\begin{array}{l}-1,451 \\
(0,147)\end{array}$ & $\begin{array}{c}-0,545 \\
(0,586)\end{array}$ & $\begin{array}{c}0,103 \\
(0,583)\end{array}$ & $\begin{array}{c}0,218 \\
(0,238)\end{array}$ & $\begin{array}{c}-0,065 \\
(0,729)\end{array}$ & $\begin{array}{c}-0,755 \\
(0,450)\end{array}$ & $\begin{array}{c}-0,509 \\
(0,003)\end{array}$ & $\begin{array}{c}-0,972 \\
(0,331)\end{array}$ \\
\hline M. Histórias II & $\begin{array}{c}0,258 \\
(0,169)\end{array}$ & $\begin{array}{l}-0,039 \\
(0,840)\end{array}$ & $\begin{array}{l}-0,588 \\
(0,557)\end{array}$ & $\begin{array}{l}-1,469 \\
(0,142)\end{array}$ & $\begin{array}{c}0,000 \\
(1,000)\end{array}$ & $\begin{array}{c}0,090 \\
(0,636)\end{array}$ & $\begin{array}{c}0,213 \\
(0,257)\end{array}$ & $\begin{array}{c}-0,180 \\
(0,340)\end{array}$ & $\begin{array}{l}-0,625 \\
(0,532)\end{array}$ & $\begin{array}{c}-0,463 \\
(0,010)\end{array}$ & $\begin{array}{l}-0,590 \\
(0,555)\end{array}$ \\
\hline M. Sentenças & $\begin{array}{c}0,497 \\
(0,005)\end{array}$ & $\begin{array}{c}-0,252 \\
(0,179)\end{array}$ & $\begin{array}{l}-0,400 \\
(0,689)\end{array}$ & $\begin{array}{l}-0,462 \\
(0,644)\end{array}$ & $\begin{array}{c}-0,114 \\
(0,910)\end{array}$ & $\begin{array}{c}0,141 \\
(0,458)\end{array}$ & $\begin{array}{c}0,171 \\
(0,367)\end{array}$ & $\begin{array}{c}0,107 \\
(0,575)\end{array}$ & $\begin{array}{c}-0,230 \\
(0,818)\end{array}$ & $\begin{array}{c}-0,344 \\
(0,062)\end{array}$ & $\begin{array}{c}0,000 \\
(1,000)\end{array}$ \\
\hline A. Verbal & $\begin{array}{c}0,379 \\
(0,035)\end{array}$ & $\begin{array}{l}-0,119 \\
(0,525)\end{array}$ & $\begin{array}{l}-0,747 \\
(0,455)\end{array}$ & $\begin{array}{l}-0,776 \\
(0,438)\end{array}$ & $\begin{array}{c}-1,592 \\
(0,111)\end{array}$ & $\begin{array}{c}0,190 \\
(0,306)\end{array}$ & $\begin{array}{c}-0,040 \\
(0,830)\end{array}$ & $\begin{array}{c}-0,152 \\
(0,414)\end{array}$ & $\begin{array}{l}-0,139 \\
(0,889)\end{array}$ & $\begin{array}{c}-0,432 \\
(0,015)\end{array}$ & $\begin{array}{l}-1,335 \\
(0,182)\end{array}$ \\
\hline A. Visual & $\begin{array}{c}0,078 \\
(0,680)\end{array}$ & $\begin{array}{c}0,179 \\
(0,343)\end{array}$ & $\begin{array}{l}-0,563 \\
(0,573)\end{array}$ & $\begin{array}{l}-0,586 \\
(0,558)\end{array}$ & $\begin{array}{c}-0,861 \\
(0,389)\end{array}$ & $\begin{array}{l}-0,263 \\
(0,160)\end{array}$ & $\begin{array}{c}0,317 \\
(0,088)\end{array}$ & $\begin{array}{c}0,128 \\
(0,499)\end{array}$ & $\begin{array}{c}-2,143 \\
(0,032)\end{array}$ & $\begin{array}{c}-0,616 \\
(0,001)\end{array}$ & $\begin{array}{l}-0,025 \\
(0,980)\end{array}$ \\
\hline E. A. Verbal & $\begin{array}{c}-0,306 \\
(0,121)\end{array}$ & $\begin{array}{l}-0,931 \\
(0,879)\end{array}$ & $\begin{array}{l}-0,486 \\
(0,627)\end{array}$ & $\begin{array}{l}-0,891 \\
(0,413)\end{array}$ & $\begin{array}{l}-0,459 \\
(0,646)\end{array}$ & $\begin{array}{c}0,078 \\
(0,700)\end{array}$ & $\begin{array}{c}0,114 \\
(0,572)\end{array}$ & $\begin{array}{l}-0,155 \\
(0,439)\end{array}$ & $\begin{array}{l}-0,346 \\
(0,730)\end{array}$ & $\begin{array}{c}0,0528 \\
(0,794)\end{array}$ & $\begin{array}{l}-0,844 \\
(0,399)\end{array}$ \\
\hline E. A. Visual & $\begin{array}{c}0,125 \\
(0,517)\end{array}$ & $\begin{array}{c}0,056 \\
(0,775)\end{array}$ & $\begin{array}{l}-1,546 \\
(0,122)\end{array}$ & $\begin{array}{l}-0,317 \\
(0,751)\end{array}$ & $\begin{array}{l}-0,449 \\
(0,654)\end{array}$ & $\begin{array}{c}0,111 \\
(0,566)\end{array}$ & $\begin{array}{c}-0,011 \\
(0,953)\end{array}$ & $\begin{array}{c}-0,343 \\
(0,069)\end{array}$ & $\begin{array}{c}-0,401 \\
(0,688)\end{array}$ & $\begin{array}{c}-0,367 \\
(0,050)\end{array}$ & $\begin{array}{l}-1,239 \\
(0,216)\end{array}$ \\
\hline Reconhecimento & $\begin{array}{c}-0,172 \\
(0,372)\end{array}$ & $\begin{array}{c}0,187 \\
(0,331)\end{array}$ & $\begin{array}{c}-0,074 \\
(0,941)\end{array}$ & $\begin{array}{l}-0,737 \\
(0,461)\end{array}$ & $\begin{array}{c}-0,984 \\
(0,325)\end{array}$ & $\begin{array}{l}-0,297 \\
(0,117)\end{array}$ & $\begin{array}{c}0,241 \\
(0,207)\end{array}$ & $\begin{array}{c}-0,203 \\
(0,290)\end{array}$ & $\begin{array}{c}-2,179 \\
(0,029)\end{array}$ & $\begin{array}{c}-0,406 \\
(0,029)\end{array}$ & $\begin{array}{l}-0,217 \\
(0,828)\end{array}$ \\
\hline
\end{tabular}

Legenda: SE: Status Epilepticus; HF: História Familiar; CF: Crises Febris; Freq: Freqüência de crises; DAES: Drogas Antiepilépticas; General 2ª̣: Generalização Secundária; M. Cenas: Memória para Cenas; M. Figuras: Memória para Figuras; M. Histórias: Memória para Histórias; M. Sentenças: Memória para Sentenças; A. Verbal: Aprendizagem Verbal; A. Visual: Aprendizagem Visual; E. A. Verbal: Evocação Aprendizagem Verbal; E. A. Visual: Evocação Aprendizagem Visual. 


\subsection{Funções Executivas}

\subsubsection{Análise da influência das variáveis clínicas nos testes cognitivos}

a. Idade de Início teve um impacto significativo nos seguintes testes de FE: Dígitos Diretos $(\mathbf{p = 0 , 0 0 1 )}$, Dígitos Indiretos $(\mathbf{p = 0 , 0 0 1 )}$, número de erros no Matching Familiar Figures Test $(\mathbf{p = 0 , 0 4 2 )}$, tempo no Trail Making parte $A(\mathbf{p}=\mathbf{0 , 0 0 1 )}$ e parte $B$ $(\mathbf{p}=\mathbf{0 , 0 0 4 )}$, Fluência Verbal para animais $(\mathbf{p}=\mathbf{0 , 0 0 3 )}$ e comidas $(\mathbf{p}=\mathbf{0 , 0 1 7})$, Janelas Digitais $(\mathbf{p = 0 , 0 0 2 )}$ e Memória para Número Letra $(\mathbf{p = 0 , 0 1 3 )}$. (Tabela 12)

b. Duração da epilepsia esteve relacionado com pior desempenho nos seguintes testes de FE: Dígitos Diretos $(\mathbf{p}=\mathbf{0 , 0 0 1})$, tempo no Trail Making parte $A(\mathbf{p}=\mathbf{0 , 0 1 8})$ e Teste Memória para Números e Letras $(\mathbf{p = 0 , 0 2 0 )}$. ( Tabela 12)

b. Uso de Politerapia também influenciou negativamente o desempenho executivo nos testes Índice total do Matching Familiar Figure Test $(\mathbf{p = 0 , 0 0 2 )}$ e número de categorias no Wisconsin Card Sorting Test $(\mathbf{p}=\mathbf{0 , 0 4 9})$. (Tabela 12)

c. História de Status Epilepticus, Antecedentes Familiares de Epilepsia, Tipo de Crises, Controle de Crises e Crises Generalizadas Secundárias tiveram pouco impacto sobre o funcionamento executivo, influenciando os seguintes testes respectivamente: número de quebras de set no Wisconsin Card Sorting Test $(\mathbf{p}=\mathbf{0 , 0 1 9})$, tempo no Trail Making parte A $(\mathbf{p}=\mathbf{0}, \mathbf{0 3 3})$, Janelas Digitais $(\mathbf{p}=\mathbf{0 , 0 2 2})$, tempo no Trail Making parte $A$ e Índice total do Matching Familiar Figure Test $(\mathbf{p}=\mathbf{0 , 0 2 8})$. (Tabela 12) 
Tabela 12. Influência das Variáveis Clínicas da Epilepsia no desempenho de Pacientes testes de Funções Executivas

\begin{tabular}{|c|c|c|c|c|c|c|c|c|c|c|c|}
\hline & $\begin{array}{l}\text { I dade de } \\
\text { I nício } r(p)\end{array}$ & $\begin{array}{c}\text { Duração } \\
\mathbf{r ( p )}\end{array}$ & SE $Z(p)$ & HF Z(p) & CF Z(p) & $\begin{array}{l}\text { Freq } \\
r(p)\end{array}$ & $\begin{array}{l}\text { Ranks } \\
Z(p)\end{array}$ & $\begin{array}{l}\text { Tipo Crise } \\
\mathbf{r ( p )}\end{array}$ & $\begin{array}{l}\text { Controle } \\
Z(p)\end{array}$ & $\begin{array}{l}\text { DAES } \\
\mathbf{r}(p)\end{array}$ & $\begin{array}{l}\text { General } \\
\text { 2a } Z(p)\end{array}$ \\
\hline$\overline{D D}$ & $\begin{array}{c}0,596 \\
(0,001)\end{array}$ & $\begin{array}{c}-0,572 \\
(0,001)\end{array}$ & $\begin{array}{c}-0,243 \\
(0,808)\end{array}$ & $\begin{array}{c}-0,347 \\
(0,728)\end{array}$ & $\begin{array}{c}-1,291 \\
(0,197)\end{array}$ & $\begin{array}{c}0,084 \\
(0,660)\end{array}$ & $\begin{array}{c}-0,066 \\
(0,728)\end{array}$ & $\begin{array}{c}0,289 \\
(0,122)\end{array}$ & $\begin{array}{c}-0,846 \\
(0,397)\end{array}$ & $\begin{array}{c}0,044 \\
(0,819)\end{array}$ & $\begin{array}{c}-0,712 \\
(0,476)\end{array}$ \\
\hline DI & $\begin{array}{c}0,587 \\
(0,001)\end{array}$ & $\begin{array}{c}-0,331 \\
(0,074)\end{array}$ & $\begin{array}{c}-0,574 \\
(0,566)\end{array}$ & $\begin{array}{l}-0,961 \\
(0,336)\end{array}$ & $\begin{array}{r}-0,600 \\
(0,548)\end{array}$ & $\begin{array}{l}-0,006 \\
(0,973)\end{array}$ & $\begin{array}{c}0,082 \\
(0,666)\end{array}$ & $\begin{array}{c}0,087 \\
(0,649)\end{array}$ & $\begin{array}{c}-0,150 \\
(0,881)\end{array}$ & $\begin{array}{c}-0,240 \\
(0,202)\end{array}$ & $\begin{array}{c}-0,175 \\
(0,861)\end{array}$ \\
\hline MFFT erros & $\begin{array}{c}-0,380 \\
(0,042)\end{array}$ & $\begin{array}{c}0,293 \\
(0,123)\end{array}$ & $\begin{array}{c}-0,195 \\
(0,845)\end{array}$ & $\begin{array}{c}-1,087 \\
(0,277)\end{array}$ & $\begin{array}{c}-1,464 \\
(0,143)\end{array}$ & $\begin{array}{l}-0,258 \\
(0,177)\end{array}$ & $\begin{array}{c}0,148 \\
(0,443)\end{array}$ & $\begin{array}{r}-0,148 \\
(0,444)\end{array}$ & $\begin{array}{c}-0,922 \\
(0,356)\end{array}$ & $\begin{array}{c}0,092 \\
(0,636)\end{array}$ & $\begin{array}{c}-1,021 \\
(0,307)\end{array}$ \\
\hline MFFT tempo & $\begin{array}{c}0,211 \\
(0,263)\end{array}$ & $\begin{array}{c}-0,121 \\
(0,526)\end{array}$ & $\begin{array}{c}-0,023 \\
(0,981)\end{array}$ & $\begin{array}{c}-1,716 \\
(0,086)\end{array}$ & $\begin{array}{r}-1,358 \\
(0,174)\end{array}$ & $\begin{array}{c}0,102 \\
(0,591)\end{array}$ & $\begin{array}{c}0,038 \\
(0,842)\end{array}$ & $\begin{array}{c}0,108 \\
(0,569)\end{array}$ & $\begin{array}{l}-1,005 \\
(0,315)\end{array}$ & $\begin{array}{c}0,154 \\
(0,415)\end{array}$ & $\begin{array}{c}-1,324 \\
(0,185)\end{array}$ \\
\hline MFFT total & $\begin{array}{c}0,007 \\
(0,973)\end{array}$ & $\begin{array}{c}-0,071 \\
(0,721)\end{array}$ & $\begin{array}{c}-0,102 \\
(0,919)\end{array}$ & $\begin{array}{c}-2,135 \\
(0,033)\end{array}$ & $\begin{array}{c}-0,615 \\
(0,539)\end{array}$ & $\begin{array}{c}0,152 \\
(0,441)\end{array}$ & $\begin{array}{l}-0,216 \\
(0,269)\end{array}$ & $\begin{array}{c}0,153 \\
(0,438)\end{array}$ & $\begin{array}{l}-1,207 \\
(0,227)\end{array}$ & $\begin{array}{c}0,559 \\
(0,002)\end{array}$ & $\begin{array}{c}-2,202 \\
(0,028)\end{array}$ \\
\hline TM A tempo & $\begin{array}{c}-0,600 \\
(0,001)\end{array}$ & $\begin{array}{c}0,462 \\
(0,018)\end{array}$ & $\begin{array}{c}-0,463 \\
(0,643)\end{array}$ & $\begin{array}{l}-0,078 \\
(0,938)\end{array}$ & $\begin{array}{c}-0,390 \\
(0,697)\end{array}$ & $\begin{array}{l}-0,234 \\
(0,251)\end{array}$ & $\begin{array}{c}0,346 \\
(0,083)\end{array}$ & $\begin{array}{l}-0,257 \\
(0,205)\end{array}$ & $\begin{array}{c}-1,881 \\
(0,060)\end{array}$ & $\begin{array}{l}-0,197 \\
(0,335)\end{array}$ & $\begin{array}{l}-0,116 \\
(0,908)\end{array}$ \\
\hline TM A erros & $\begin{array}{l}-0,289 \\
(0,136)\end{array}$ & $\begin{array}{c}0,217 \\
(0,268)\end{array}$ & $\begin{array}{c}-0,496 \\
(0,620)\end{array}$ & $\begin{array}{c}-1,150 \\
(0,250)\end{array}$ & $\begin{array}{c}-0,665 \\
(0,506)\end{array}$ & $\begin{array}{c}0,094 \\
(0,633)\end{array}$ & $\begin{array}{c}0,084 \\
(0,670)\end{array}$ & $\begin{array}{r}-0,264 \\
(0,175)\end{array}$ & $\begin{array}{c}-0,208 \\
(0,836)\end{array}$ & $\begin{array}{c}0,144 \\
(0,466)\end{array}$ & $\begin{array}{c}-1,394 \\
(0,163)\end{array}$ \\
\hline TM B tempo & $\begin{array}{c}-0,532 \\
(0,004)\end{array}$ & $\begin{array}{c}0,271 \\
(0,172)\end{array}$ & $\begin{array}{c}-0,876 \\
(0,381)\end{array}$ & $\begin{array}{c}-0,659 \\
(0,510)\end{array}$ & $\begin{array}{c}-0,797 \\
(0,425)\end{array}$ & $\begin{array}{l}-0,174 \\
(0,386)\end{array}$ & $\begin{array}{c}0,200 \\
(0,316)\end{array}$ & $\begin{array}{l}-0,255 \\
(0,198)\end{array}$ & $\begin{array}{l}-1,001 \\
(0,317)\end{array}$ & $\begin{array}{l}-0,086 \\
(0,670)\end{array}$ & $\begin{array}{c}-1,079 \\
(0,280)\end{array}$ \\
\hline TM B erros & $\begin{array}{l}-0,171 \\
(0,393)\end{array}$ & $\begin{array}{c}0,192 \\
(0,337)\end{array}$ & $\begin{array}{c}-1,474 \\
(0,141)\end{array}$ & $\begin{array}{r}-1,178 \\
(0,239)\end{array}$ & $\begin{array}{r}-0,869 \\
(0,385)\end{array}$ & $\begin{array}{l}-0,204 \\
(0,307)\end{array}$ & $\begin{array}{l}-0,109 \\
(0,587)\end{array}$ & $\begin{array}{l}-0,201 \\
(0,314)\end{array}$ & $\begin{array}{c}-0,029 \\
(0,977)\end{array}$ & $\begin{array}{c}-0,113 \\
(0,574)\end{array}$ & $\begin{array}{l}-1,268 \\
(0,205)\end{array}$ \\
\hline WCST ( categ.) & $\begin{array}{c}0,235 \\
(0,211)\end{array}$ & $\begin{array}{c}-0,167 \\
(0,376)\end{array}$ & $\begin{array}{c}-1,561 \\
(0,118)\end{array}$ & $\begin{array}{c}-0,401 \\
(0,688)\end{array}$ & $\begin{array}{c}-0,776 \\
(0,438)\end{array}$ & $\begin{array}{c}0,158 \\
(0,404)\end{array}$ & $\begin{array}{c}0,059 \\
(0,758)\end{array}$ & $\begin{array}{c}0,176 \\
(0,353)\end{array}$ & $\begin{array}{c}-0,359 \\
(0,720)\end{array}$ & $\begin{array}{c}-0,362 \\
(0,049)\end{array}$ & $\begin{array}{l}-0,495 \\
(0,621)\end{array}$ \\
\hline WCST (EP) & $\begin{array}{l}-0,322 \\
(0,095)\end{array}$ & $\begin{array}{c}0,285 \\
(0,142)\end{array}$ & $\begin{array}{c}-0,983 \\
(0,325)\end{array}$ & $\begin{array}{c}-0,208 \\
(0,835)\end{array}$ & $\begin{array}{c}-0,408 \\
(0,684)\end{array}$ & $\begin{array}{l}-0,079 \\
(0,690)\end{array}$ & $\begin{array}{c}0,054 \\
(0,786)\end{array}$ & $\begin{array}{c}-0,244 \\
(0,211)\end{array}$ & $\begin{array}{c}-0,369 \\
(0,712)\end{array}$ & $\begin{array}{c}0,263 \\
(0,177)\end{array}$ & $\begin{array}{c}-0,611 \\
(0,541)\end{array}$ \\
\hline WCST (ENP) & $\begin{array}{l}-0,122 \\
(0,521)\end{array}$ & $\begin{array}{c}0,029 \\
(0,881)\end{array}$ & $\begin{array}{c}-1,127 \\
(0,260)\end{array}$ & $\begin{array}{c}-0,754 \\
(0,451)\end{array}$ & $\begin{array}{c}-0,227 \\
(0,821)\end{array}$ & $\begin{array}{l}-0,126 \\
(0,506)\end{array}$ & $\begin{array}{c}0,033 \\
(0,863)\end{array}$ & $\begin{array}{c}0,053 \\
(0,780)\end{array}$ & $\begin{array}{c}-0,524 \\
(0,600)\end{array}$ & $\begin{array}{c}0,103 \\
(0,587)\end{array}$ & $\begin{array}{l}-0,687 \\
(0,492)\end{array}$ \\
\hline WCST (RP) & $\begin{array}{l}-0,297 \\
(0,125)\end{array}$ & $\begin{array}{c}0,287 \\
(0,139)\end{array}$ & $\begin{array}{c}-1,221 \\
(0,222)\end{array}$ & $\begin{array}{c}-0,277 \\
(0,782)\end{array}$ & $\begin{array}{c}-0,051 \\
(0,959)\end{array}$ & $\begin{array}{l}-0,074 \\
(0,708)\end{array}$ & $\begin{array}{c}0,054 \\
(0,785)\end{array}$ & $\begin{array}{l}-0,230 \\
(0,240)\end{array}$ & $\begin{array}{r}-0,369 \\
(0,712)\end{array}$ & $\begin{array}{c}0,186 \\
(0,344)\end{array}$ & $\begin{array}{c}-0,664 \\
(0,507)\end{array}$ \\
\hline WCST (QS) & $\begin{array}{l}-0,077 \\
(0,686)\end{array}$ & $\begin{array}{c}-0,283 \\
(0,130)\end{array}$ & $\begin{array}{c}-2,341 \\
(0,019)\end{array}$ & $\begin{array}{l}-0,022 \\
(0,982)\end{array}$ & $\begin{array}{c}-0,595 \\
(0,552)\end{array}$ & $\begin{array}{l}-0,242 \\
(0,198)\end{array}$ & $\begin{array}{c}0,231 \\
(0,219)\end{array}$ & $\begin{array}{c}0,014 \\
(0,940)\end{array}$ & $\begin{array}{c}-1,649 \\
(0,099)\end{array}$ & $\begin{array}{c}0,068 \\
(0,720)\end{array}$ & $\begin{array}{l}-0,155 \\
(0,877)\end{array}$ \\
\hline FV animais & $\begin{array}{c}0,522 \\
(0,003)\end{array}$ & $\begin{array}{c}-0,287 \\
(0,117)\end{array}$ & $\begin{array}{c}-0,249 \\
(0,803)\end{array}$ & $\begin{array}{c}-1,115 \\
(0,265)\end{array}$ & $\begin{array}{c}-0,153 \\
(0,879)\end{array}$ & $\begin{array}{c}0,095 \\
(0,612)\end{array}$ & $\begin{array}{c}-0,029 \\
(0,876)\end{array}$ & $\begin{array}{c}0,268 \\
(0,145)\end{array}$ & $\begin{array}{c}-0,538 \\
(0,591)\end{array}$ & $\begin{array}{c}-0,131 \\
(0,481)\end{array}$ & $\begin{array}{c}-1,155 \\
(0,248)\end{array}$ \\
\hline FV comidas & $\begin{array}{c}0,425 \\
(0,017)\end{array}$ & $\begin{array}{c}-0,074 \\
(0,692)\end{array}$ & $\begin{array}{c}-0,091 \\
(0,928)\end{array}$ & $\begin{array}{r}-0,279 \\
(0,780)\end{array}$ & $\begin{array}{c}-0,721 \\
(0,471)\end{array}$ & $\begin{array}{c}0,160 \\
(0,389)\end{array}$ & $\begin{array}{c}-0,255 \\
(0,166)\end{array}$ & $\begin{array}{c}0,154 \\
(0,407)\end{array}$ & $\begin{array}{c}-1,635 \\
(0,098)\end{array}$ & $\begin{array}{c}-0,063 \\
(0,737)\end{array}$ & $\begin{array}{l}-0,340 \\
(0,734)\end{array}$ \\
\hline J anelas Digitais & $\begin{array}{c}0,525 \\
(0,002)\end{array}$ & $\begin{array}{c}-0,289 \\
(0,115)\end{array}$ & $\begin{array}{c}-1,088 \\
(0,277)\end{array}$ & $\begin{array}{r}-1,156 \\
(0,248)\end{array}$ & $\begin{array}{c}-0,612 \\
(0,541)\end{array}$ & $\begin{array}{c}0,103 \\
(0,583)\end{array}$ & $\begin{array}{c}-0,186 \\
(0,316)\end{array}$ & $\begin{array}{c}0,410 \\
(0,022)\end{array}$ & $\begin{array}{l}-1,195 \\
(0,232)\end{array}$ & $\begin{array}{c}0,006 \\
(0,974)\end{array}$ & $\begin{array}{c}-1,337 \\
(0,181)\end{array}$ \\
\hline Número-Letra & $\begin{array}{c}0,443 \\
(0,013)\end{array}$ & $\begin{array}{c}-0,417 \\
(0,020)\end{array}$ & $\begin{array}{c}-0,319 \\
(0,750)\end{array}$ & $\begin{array}{c}-0,360 \\
(0,719)\end{array}$ & $\begin{array}{c}-0,022 \\
(0,982)\end{array}$ & $\begin{array}{c}0,096 \\
(0,606)\end{array}$ & $\begin{array}{c}0,166 \\
(0,373)\end{array}$ & $\begin{array}{c}0,232 \\
(0,208)\end{array}$ & $\begin{array}{l}-0,360 \\
(0,719)\end{array}$ & $\begin{array}{c}-0,218 \\
(0,239)\end{array}$ & $\begin{array}{c}-0,114 \\
(0,909)\end{array}$ \\
\hline
\end{tabular}

Legenda: SE: Status Epilepticus; HF: História Familiar; CF: Crises Febris; Freq: Freqüência de crises; DAES: Drogas Antiepilépticas; General 2åa: Generalização Secundária; DD: Dígitos Diretos; DI: Dígitos Indiretos; MFFT: Matching Familiar Figures Test; TM: Trail Making Test; WCST: Wisconsin Card Sorting Test; WCST (categ): Wisconsin Card Sorting Test (número de
categorias); WCST (EP): Wisconsin Card Sorting Test (erros perseverativos); WCST (ENP): Wisconsin Card Sorting Test (erros não perseverativos); WCST (RP): Wisconsin Card Sorting Test (respostas perseverativas); WCST (QS): Wisconsin Card Sorting Test (quebra de setting); FV: Teste de Fluência Verbal. 


\section{Avaliação dos aspectos de neurodesenvolvimento}

\subsection{Funções Mnésticas}

4.1.1. Análise da influência da idade no momento da avaliação sobre os testes cognitivos

a. Pacientes com menos de 12 anos apresentaram maiores dificuldades nos seguintes testes de memória: Memória para Figuras $(\mathbf{p = 0 , 0 0 3 ) , ~ M e m o ́ r i a ~ p a r a ~}$ Sentenças ( $\mathbf{p = 0 , 0 1 7 )}$ e Aprendizagem Verbal $(\mathbf{p}=\mathbf{0 , 0 1 3})$. (Tabela 13)

Tabela 13. Comparação do Desempenho de Pacientes segundo a idade no momento da testagem nos Testes de Memória

\begin{tabular}{|c|c|c|c|c|c|}
\hline & $\begin{array}{l}\text { Pacientes } \\
\text { com menos } \\
\text { de } 12 \text { anos } \\
(n=14) \\
\text { Média(SD) }\end{array}$ & $\begin{array}{c}\text { Pacientes com } \\
\text { mais de } 12 \\
\text { anos ( } n=18) \\
\text { Média(SD) }\end{array}$ & $\mathbf{F}$ & $\mathbf{P}$ & Cohen's d \\
\hline M. Cenas & $21,57(6,68)$ & $22,65(5,23)$ & 0,288 & 0,596 & $-0,18$ \\
\hline M. Figuras & $27,71(6,53)$ & $36,00(9,55)$ & 10,496 & 0,003 & $-1,01$ \\
\hline M. Histórias & $20,07(8,72)$ & $24,88(7,46)$ & 2,986 & 0,095 & $-0,91$ \\
\hline M. Histórias II & $16,00(8,19)$ & $19,88(8,37)$ & 1,805 & 0,190 & $-0,47$ \\
\hline M. Sentenças & $12,38(5,91)$ & $16,71(4,70)$ & 6,494 & 0,017 & $-0,81$ \\
\hline A. Verbal & $32,29(6,72)$ & $39,71(8,59)$ & 7,032 & 0,013 & $-0,96$ \\
\hline A. Visual & $20,69(9,56)$ & $26,24(13,86)$ & 2,063 & 0,162 & $-0,57$ \\
\hline E. A. Verbal & $3,77(2,20)$ & $2,80(2,11)$ & 1,265 & 0,271 & 0,65 \\
\hline E. A. Visual & $4,17(1,90)$ & $4,47(1,59)$ & 0,292 & 0,592 & $-0,27$ \\
\hline Reconhecimento & $11,00(3,86)$ & $9,06(3,27)$ & 2,019 & 0,167 & 0,84 \\
\hline
\end{tabular}

Legenda: M. Cenas: Memória para Cenas; M. Figuras: Memória para Figuras; M. Histórias: Memória para Histórias; M. Sentenças: Memória para Sentenças; A. Verbal: Aprendizagem Verbal; A. Visual: Aprendizagem Visual; E. A. Verbal: Evocação Aprendizagem Verbal; E. A. Visual: Evocação Aprendizagem Visual.

\subsubsection{Análise da influência de idade de início precoce e tardia sobre os testes}

\section{cognitivos}

a. Pacientes com início precoce tiveram pior desempenho nos seguintes testes de memória: Memória para Figuras $(\mathbf{p}=\mathbf{0 , 0 4 8 )}$, Memória para Sentenças $(\mathbf{p}=\mathbf{0 , 0 4 4 )}$ e Aprendizagem Visual tardia $(\mathbf{p = 0 , 0 1 0 )}$. (Tabela 14) 
Tabela 14. Comparação do Desempenho de Pacientes segundo a idade de início da epilepsia nos Testes de Memória

\begin{tabular}{|lccccc}
\hline & $\begin{array}{c}\text { Antes dos 4 } \\
\text { anos (n=18) } \\
\text { Média(SD) }\end{array}$ & $\begin{array}{c}\text { Depois dos 4 } \\
\text { anos (n=14) } \\
\text { Média(SD) }\end{array}$ & F & P & Cohen's d \\
\hline M. Cenas & $21,63(6,44)$ & $22,85(5,73)$ & 0,100 & 0,905 & $-0,30$ \\
\hline M. Figuras & $28,31(7,58)$ & $36,85(9,36)$ & $\mathbf{3 , 4 2 8}$ & $\mathbf{0 , 0 4 8}$ & $\mathbf{- 1 , 2 9}$ \\
\hline M. Histórias & $19,88(8,76)$ & $25,31(7,18)$ & 1,516 & 0,238 & $-1,07$ \\
\hline M. Histórias II & $16,33(8,63)$ & $19,85(8,38)$ & 0,380 & 0,687 & $-0,59$ \\
\hline M. Sentenças & $12,20(5,17)$ & $17,92(5,06)$ & $\mathbf{3 , 5 3 8}$ & $\mathbf{0 , 0 4 4}$ & $\mathbf{- 1 , 6 0}$ \\
\hline A. Verbal & $33,44(6,91)$ & $39,85(9,61)$ & 2,227 & 0,128 & $-0,94$ \\
\hline A. Visual & $22,40(10,26)$ & $24,69(15,22)$ & 0,015 & 0,985 & $-0,21$ \\
\hline E. A. Verbal & $3,54(2,26)$ & $3,00(2,27)$ & 0,197 & 0,822 & 0,34 \\
\hline E. A. Visual & $4,43(1,34)$ & $4,69(1,70)$ & $\mathbf{5 , 6 5 2}$ & $\mathbf{0 , 0 1 0}$ & $\mathbf{- 0 , 2 2}$ \\
\hline Reconhecimento & $10,57(3,72)$ & $8,93(3,60)$ & 1,182 & 0,324 & 0,64 \\
\hline
\end{tabular}

Legenda: M. Cenas: Memória para Cenas; M. Figuras: Memória para Figuras; M. Histórias: Memória para Histórias; M. Sentenças: Memória para Sentenças; A. Verbal: Aprendizagem Verbal; A. Visual: Aprendizagem Visual; E. A. Verbal: Evocação Aprendizagem Verbal; E. A. Visual: Evocação Aprendizagem Visual.

\subsection{Funções Executivas}

\subsubsection{Análise da influência da idade no momento da avaliação sobre os testes}

\section{cognitivos}

a. Pacientes com menos de 12 anos no momento da avaliação apresentaram piores desempenhos nos seguintes testes executivos: Dígitos Diretos $(\mathbf{p = 0 , 0 0 5 )}$, Dígitos Indiretos $(\mathbf{p}=\mathbf{0 , 0 0 1})$, número de erros Matching Familiar Figures Test $(\mathbf{p}=\mathbf{0 , 0 3 8 )}$, tempo $(\mathbf{p}=\mathbf{0 , 0 0 1 )}$ e erros $(\mathbf{p = 0 , 0 5 4 )}$ no Trail Making parte A e tempo no Trail Making parte $\mathbf{B}(\mathbf{p}=\mathbf{0 , 0 1 4 )}$, Fluência Verbais para animais $(\mathbf{p}=\mathbf{0 , 0 0 6})$ e comidas $(\mathbf{p = 0 , 0 0 2 )}$ e Janelas Digitais $(\mathbf{p = 0 , 0 0 2 )}$. (Tabela $\mathbf{1 5})$ 
Tabela 15. Comparação do Desempenho de Pacientes segundo a idade no momento da testagem nos Testes de Funções Executivas

\begin{tabular}{|c|c|c|c|c|c|}
\hline & $\begin{array}{c}\text { Pacientes com } \\
\text { menos de } 12 \text { anos } \\
(n=14) \\
\text { Média(SD) }\end{array}$ & $\begin{array}{l}\text { Pacientes com } \\
\text { mais de } 12 \text { anos } \\
(n=18) \\
\text { Média(SD) }\end{array}$ & $\mathbf{F}$ & $\mathbf{P}$ & Cohen's d \\
\hline $\begin{array}{l}\text { DD } \\
\text { DI }\end{array}$ & $\begin{array}{l}5,77(1,59) \\
3,23(1,36)\end{array}$ & $\begin{array}{l}7,53(1,55) \\
5,24(1,64)\end{array}$ & $\begin{array}{c}9,150 \\
19,748\end{array}$ & $\begin{array}{l}0,005 \\
0,001\end{array}$ & $\begin{array}{l}-1,61 \\
-1,73\end{array}$ \\
\hline MFFT erros & $25,08(12,02)$ & $17,19(8,97)$ & 4,783 & 0,038 & 1,24 \\
\hline MFFT tempo & $182,85(118,28)$ & $253,35(135,49)$ & 2,541 & 0,123 & $-0,74$ \\
\hline MFFT total & $3109,17(947,20)$ & $3034,67(1234,53)$ & 0,028 & 0,869 & 0,07 \\
\hline TM A tempo & $38,82(11,10)$ & $22,50(8,45)$ & 19,147 & 0,001 & 1,65 \\
\hline TM A erros & $0,42(0,67)$ & $0,06(0,24)$ & 4,072 & 0,054 & 0,72 \\
\hline TM B tempo & $74,55(26,70)$ & $52,41(20,30)$ & 7,008 & 0,014 & 0,93 \\
\hline TM B erros & $0,45(0,93)$ & $0,53(0,80)$ & 0,097 & 0,758 & $-0,09$ \\
\hline WCST (categ.) & $3,69(2,25)$ & $4,47(2,98)$ & 1,503 & 0,231 & $-0,30$ \\
\hline WCST (EP) & $27,31(10,66)$ & $20,60(11,16)$ & 2,897 & 0,101 & 0,61 \\
\hline WCST (ENP) & $31,31(14,50)$ & $23,06(17,01)$ & 1,892 & 0,180 & 0,52 \\
\hline WCST (RP) & $30,92(14,18)$ & $24,00(15,96)$ & 1,484 & 0,235 & 0,46 \\
\hline WCST (QS) & $1,23(1,09)$ & $1,12(1,36)$ & 0,081 & 0,778 & 0,09 \\
\hline FV animais & $10,86(3,92)$ & $14,53(4,64)$ & 8,738 & 0,006 & $-0,85$ \\
\hline FV comidas & $8,57(3,69)$ & $12,76(4,01)$ & 11,556 & 0,002 & $-1,09$ \\
\hline Janelas Digitais & $10,50(4,09)$ & $15,65(4,60)$ & 11,791 & 0,002 & $-1,18$ \\
\hline Número-Letra & $6,64(3,15)$ & $8,59(3,34)$ & 2,796 & 0,106 & $-0,60$ \\
\hline
\end{tabular}

\subsubsection{Análise da influência de idade de início precoce e tardia sobre os testes}

\section{cognitivos}

a. Pacientes com início precoce tiveram pior desempenho nos seguintes testes executivos: Dígitos Diretos $(\mathbf{p}=\mathbf{0 , 0 0 2})$, Dígitos Indiretos $(\mathbf{p = 0 , 0 1 2 )}$, número de erros Matching Familiar Figures Test $(\mathbf{p}=\mathbf{0 , 0 2 6 )}$, tempo no Trail Making parte $A$ $(\mathbf{p}=\mathbf{0 , 0 0 1 )}$ e tempo no Trail Making parte B $(\mathbf{p = 0 , 0 0 5 )}$, número de erros não perseverativos no Wisconsin Card Sorting Test $\mathbf{(} \mathbf{p}=\mathbf{0 , 0 2 9 )}$ Fluência Verbal para animais $(\mathbf{p = 0 , 0 4 5 )}$, Janelas Digitais $(\mathbf{p}=\mathbf{0 , 0 0 6})$ e Memória para Número e Letras $(p=0,063)$. (Tabela 16) 
Tabela 16. Comparação do Desempenho de Pacientes segundo a idade de início da epilepsia nos Testes de Funções Executivas

\begin{tabular}{|c|c|c|c|c|c|}
\hline & $\begin{array}{c}\text { Antes dos } 4 \\
\text { anos ( } n=18) \\
\text { Média(SD) }\end{array}$ & $\begin{array}{c}\text { Depois dos } 4 \\
\text { anos }(n=14) \\
\text { Média(SD) }\end{array}$ & $\mathbf{F}$ & $\mathbf{P}$ & Cohen's d \\
\hline DD & $5,73(1,22)$ & $8,00(1,68)$ & 8,437 & 0,002 & $-1,55$ \\
\hline $\begin{array}{l}\text { DI } \\
\text { MFFT erros }\end{array}$ & $\begin{array}{c}3,40(1,45) \\
24,07(11,11)\end{array}$ & $\begin{array}{c}5,46(1,71) \\
15,00(8,32)\end{array}$ & $\begin{array}{l}5,332 \\
4,271\end{array}$ & $\begin{array}{l}0,012 \\
0,026\end{array}$ & $\begin{array}{r}-1,30 \\
0,92\end{array}$ \\
\hline MFFT tempo & $185,60(129,19)$ & $264,62(121,10)$ & 1,796 & 0,187 & $-0,63$ \\
\hline MFFT total & $3061,14(951,43)$ & $3071,17(1330,46)$ & 0,001 & 0,999 & $-0,01$ \\
\hline TM A tempo & $37,50(10,74)$ & $20,50(6,68)$ & 21,870 & 0,001 & 1,90 \\
\hline TM A erros & $0,33(0,62)$ & $0,08(0,28)$ & 1,662 & 0,209 & 0,52 \\
\hline TM B tempo & $74,79(23,76)$ & $47,38(19,19)$ & 9,588 & 0,005 & 1,27 \\
\hline TM B erros & $0,64(1,08)$ & $0,31(0,28)$ & 1,417 & 0,246 & 0,42 \\
\hline WCST (categ.) & $3,60(2,17)$ & $4,77(3,22)$ & 1,115 & 0,344 & $-0,43$ \\
\hline WCST (EP) & $28,50(10,06)$ & $19,33(10,32)$ & 1,829 & 0,183 & 0,90 \\
\hline WCST (ENP) & $26,33(10,95)$ & $25,00(17,95)$ & 4,084 & 0,029 & 0,09 \\
\hline WCST (RP) & $33,36(15,93)$ & $21,75(13,71)$ & 1,545 & 0,235 & 0,78 \\
\hline WCST (QS) & $1,13(1,13)$ & $0,92(0,95)$ & 0,040 & 0,961 & 0,20 \\
\hline FV animais & $10,63(3,78)$ & $15,00(4,49)$ & 3,509 & 0,045 & $-1,05$ \\
\hline FV comidas & $9,13(4,03)$ & $12,77(4,21)$ & 2,363 & 0,114 & $-0,88$ \\
\hline J anelas Digitais & $10,94(3,91)$ & $16,15(4,43)$ & 6,273 & 0,006 & $-1,66$ \\
\hline Número-Letra & $6,50(2,53)$ & $9,46(3,78)$ & 3,088 & 0,063 & $-1,11$ \\
\hline
\end{tabular}

Legenda: DD: Dígitos Diretos; DI: Dígitos Indiretos; MFFT: Matching Familiar Figures Test; TM: Trail Making Test; WCST: Wisconsin Card Sorting Test; WCST (categ): Wisconsin Card Sorting Test (número de categorias); WCST (EP): Wisconsin Card Sorting Test (erros perseverativos); WCST (ENP): Wisconsin Card Sorting Test (erros não perseverativos); WCST (RP): Wisconsin Card Sorting Test (respostas perseverativas); WCST (QS): Wisconsin Card Sorting Test (quebra de setting); FV: Teste de Fluência Verbal

\section{Avaliação da gravidade da Disfunção Executiva e de Memória dos Pacientes com}

\section{$\underline{\text { ELT }}$}

\subsection{Funções Mnésticas}

a. Ausência da DMn: Cinco pacientes não preencheram o critério clínico de DMn, destes três eram sintomáticos e dois criptogênicos. (Tabela 17)

b. DMn Leve: Três pacientes apresentaram DMn leve, sendo todos sintomáticos. (Tabela 17)

c. DMn Moderada: Seis pacientes apresentaram DMn moderada; sendo que três eram sintomáticos e três não tinham lesões. (Tabela 17)

d. DMn Grave: Dezoito pacientes revelaram DMn avaliadas como graves, dezessete deles eram sintomáticos e um era criptogênico. (Tabela 17) 


\subsection{Funções Executivas}

a. Ausência da DE: Três pacientes não preencheram o critério clínico de $D E$, destes dois eram sintomáticos e um era criptogênico. (Tabela 17)

b. DE Leve: Dois pacientes apresentaram DE leve, sendo todos com ELT criptogênica. (Tabela 17)

c. DE Moderada: Quatro pacientes apresentaram DE moderada; sendo que todos eram sintomáticos. (Tabela 17)

d. DE Grave: Vinte e três pacientes possuíam DE avaliadas como graves. Destes, vinte eram sintomáticos e três não tinham lesões. (Tabela 17)

Neste grupo de pacientes com ELT, 29 pacientes $(90,62 \%)$ apresentaram DE, sendo que $28(84,38 \%)$ dos 32 pacientes avaliados apresentaram DE classificada como moderada ou grave. (Figura 6) Em relação aos testes de memória 27 (84,37\%) pacientes apresentavam dificuldades de memória, sendo que 24 destes (75\%) apresentaram dificuldades moderadas ou graves. (Figura 7)

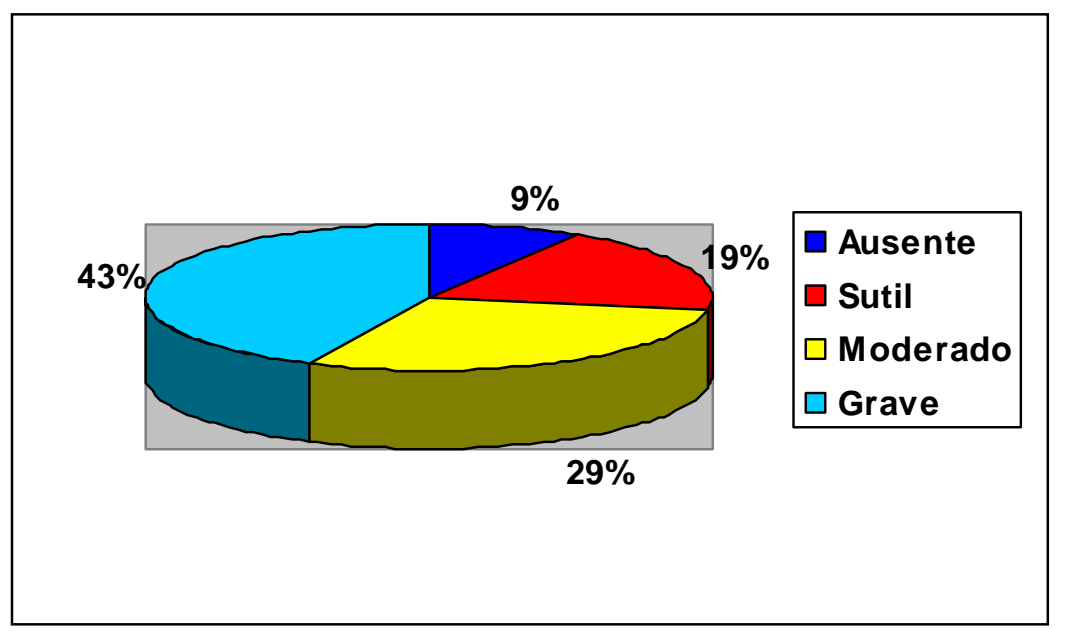

Figura 6 - Gravidade da Disfunção Executiva em Pacientes com ELT 


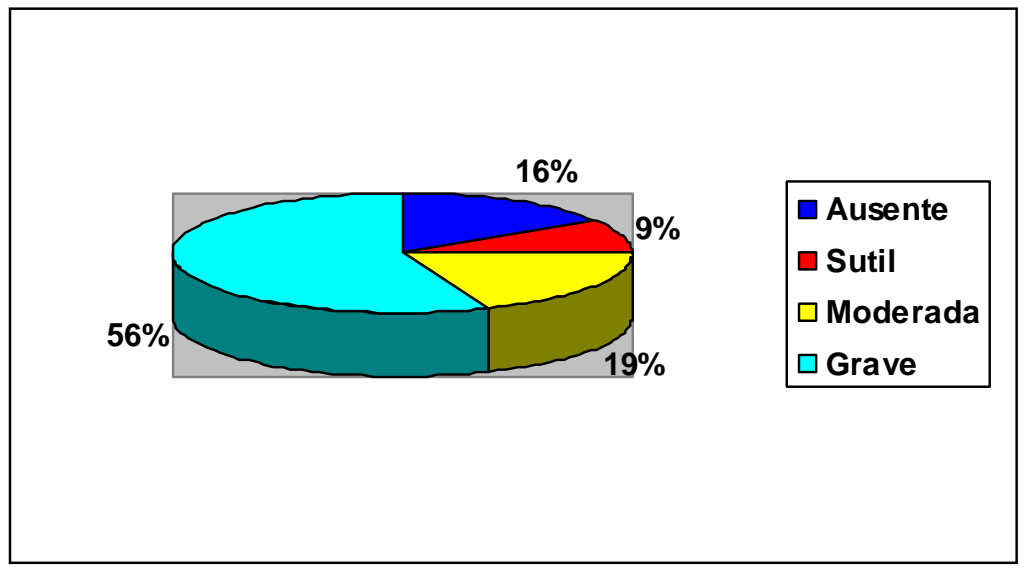

Figura 7 - Gravidade da Disfunção Mnéstica de Pacientes com ELT

\begin{tabular}{|c|c|c|c|c|c|c|}
\hline & \multicolumn{2}{|c|}{ Pacientes $(n=32)$} & \multicolumn{2}{|c|}{ Sintomáticos $(n=26)$} & \multicolumn{2}{|c|}{ Criptogênicos $(n=6)$} \\
\hline & $\mathbf{D E}$ & DMn & DE & DMn & DE & DMn \\
\hline \multirow{2}{*}{$\begin{array}{l}\text { Ausente } \\
\text { n(\%) } \\
\text { Leve n(\%) }\end{array}$} & $\begin{array}{c}3 \\
(9,38 \%)\end{array}$ & $\begin{array}{c}5 \\
(15,63 \%)\end{array}$ & $\begin{array}{c}2 \\
(7,69 \%)\end{array}$ & $\begin{array}{c}3 \\
(11,54 \%)\end{array}$ & $\begin{array}{c}1 \\
(16,67 \%)\end{array}$ & $\begin{array}{c}2 \\
(33,33 \%)\end{array}$ \\
\hline & $\begin{array}{c}2 \\
(6,25 \%)\end{array}$ & $\begin{array}{c}3 \\
(9,38 \%)\end{array}$ & 0 & $\begin{array}{c}3 \\
(11,54 \%)\end{array}$ & $\begin{array}{c}2 \\
(33,33 \%)\end{array}$ & 0 \\
\hline $\begin{array}{l}\text { Moderado } \\
\text { n(\%) }\end{array}$ & $\begin{array}{c}4 \\
(12,50 \%)\end{array}$ & $\begin{array}{c}6 \\
(18,75 \%)\end{array}$ & $\begin{array}{c}4 \\
(15,38 \%)\end{array}$ & $\begin{array}{c}3 \\
(11,54 \%)\end{array}$ & 0 & $\begin{array}{c}3 \\
(50 \%)\end{array}$ \\
\hline Grave n(\%) & $\begin{array}{c}23 \\
(71,88 \%)\end{array}$ & $\begin{array}{c}18 \\
(56,25 \%)\end{array}$ & $\begin{array}{c}20 \\
(76,92 \%)\end{array}$ & $\begin{array}{c}17 \\
(65,38 \%)\end{array}$ & $\begin{array}{c}3 \\
(50 \%)\end{array}$ & $\begin{array}{c}1 \\
(16,67 \%)\end{array}$ \\
\hline
\end{tabular}

Legenda: n: número de sujeitos; DE: disfunção executiva; DM: disfunção de memória.

\section{Avaliacão da correlacão entre os testes de Funcões Executivas e de Memória}

\subsection{Pacientes com ELT}

a. Testes de Atenção: Os testes de atenção correlacionaram-se positivamente com testes de memória episódica, semântica e de aprendizagem. (Tabela 18)

\section{b. Testes de Funções Executivas}

Controle Inibitório: A habilidade de controle inibitório correlacionou-se com a memória episódica e aprendizagem. (Tabela 18)

Atenção Dividida: A atenção dividida correlacionou-se com memória episódica e semântica. (Tabela 18). 
Resultados 53

Flexibilidade Mental e Abstração: As capacidades de flexibilidade mental e abstração correlacionaram-se com memória episódica e aprendizagem. (Tabela 18)

Rastreio Mental de Informações semânticas: Esta subfunção correlacionou-se com a memória episódica, memória semântica e aprendizagem. ( Tabela 18) 
Resultados

Tabela 18. Correlação entre os testes de Funções Executivas e Memória dos pacientes com ELT

\begin{tabular}{|c|c|c|c|c|c|c|c|c|c|c|c|c|}
\hline & & \multicolumn{5}{|c|}{ Memória Episódica } & \multicolumn{2}{|l|}{ M.Sem. } & \multicolumn{3}{|c|}{ Aprendizagem } & \multirow[t]{2}{*}{ TOTAL } \\
\hline & & M.Cenas & M.Figuras & M.Hist I & M.Hist II & Reconh & M.Sent. & A.Verb & E.A.Verb & A.Visual & $\overline{\text { E.A.Vis }}$ & \\
\hline Atenção & $\begin{array}{l}\text { DD } \\
R(p) \\
D I \\
R(p) \\
\text { Janelas Digitais } \\
R(p) \\
\text { Número-Letra } \\
\text { R(p) }\end{array}$ & $\begin{array}{l}\mathbf{0 , 3 5 7} \\
\mathbf{( 0 , 0 4 9 )} \\
\mathbf{0 , 4 0 2} \\
(\mathbf{0 , 0 2 5 )} \\
0,225 \\
(0,215) \\
\mathbf{0 , 4 7 1} \\
(\mathbf{0 , 0 0 7 )}\end{array}$ & $\begin{array}{l}0,457 \\
(0,010) \\
0,567 \\
(0,001) \\
0,417 \\
(0,018) \\
0,470 \\
(0,007)\end{array}$ & $\begin{array}{l}0,326 \\
(0,073) \\
\mathbf{0 , 5 0 1} \\
(\mathbf{0 , 0 0 4 )} \\
0,130 \\
(0,479) \\
0,286 \\
(0,112)\end{array}$ & $\begin{array}{l}0,292 \\
(0,117) \\
\mathbf{0 , 4 5 1} \\
(\mathbf{0 , 0 1 2 )} \\
0,051 \\
(0,784) \\
0,052 \\
(0,780)\end{array}$ & $\begin{array}{l}-0,166 \\
(0,391) \\
0,028 \\
(0,945) \\
-0,159 \\
(0,401) \\
-0,073 \\
(0,701)\end{array}$ & $\begin{array}{l}0,512 \\
(0,004) \\
0,603 \\
(0,001) \\
0,460 \\
(0,009) \\
0,585 \\
(0,001)\end{array}$ & $\begin{array}{l}0,184 \\
(0,323) \\
\mathbf{0 , 3 3 9} \\
(\mathbf{0 , 0 6 2 )} \\
\mathbf{0 , 3 6 5} \\
(\mathbf{0 , 0 4 0 )} \\
0,249 \\
(0,169)\end{array}$ & $\begin{array}{l}0,091 \\
(0,650) \\
-0,035 \\
(0,863) \\
0,044 \\
(0,823) \\
0,162 \\
(0,411)\end{array}$ & $\begin{array}{l}0,208 \\
(0,270) \\
\mathbf{0 , 4 7 7} \\
(\mathbf{0 , 0 0 8 )} \\
0,310 \\
(0,089) \\
\mathbf{0 , 3 3 3} \\
(\mathbf{0 , 0 6 8 )}\end{array}$ & $\begin{array}{l}0,087 \\
(0,655) \\
0,214 \\
(0,264) \\
0,113 \\
(0,553) \\
0,210 \\
(0,268)\end{array}$ & 3 \\
\hline \multirow[t]{14}{*}{ Funções Executiı } & $\begin{array}{l}\text { MFFT erros } \\
R(p)\end{array}$ & $\begin{array}{l}-0,435 \\
(0,016)\end{array}$ & $\begin{array}{l}-0,623 \\
(0,001)\end{array}$ & $\begin{array}{l}-0,283 \\
(0,130)\end{array}$ & $\begin{array}{l}-0,263 \\
(0,168)\end{array}$ & $\begin{array}{l}0,028 \\
(0,888)\end{array}$ & $\begin{array}{l}-0,243 \\
(0,203)\end{array}$ & $\begin{array}{l}-0,436 \\
(0,016)\end{array}$ & $\begin{array}{l}-0,132 \\
(0,520)\end{array}$ & $\begin{array}{l}-0,432 \\
(0,019)\end{array}$ & $\begin{array}{l}-0,258 \\
(0,186)\end{array}$ & 4 \\
\hline & $\begin{array}{l}\text { MFFT tempo } \\
\mathbf{R}(p)\end{array}$ & $\begin{array}{l}0,171 \\
(0,357)\end{array}$ & $\begin{array}{l}0,532 \\
(0,002)\end{array}$ & $\begin{array}{l}0,151 \\
(0,417)\end{array}$ & $\begin{array}{l}0,184 \\
(0,331)\end{array}$ & $\begin{array}{l}-0,343 \\
(0,069)\end{array}$ & $\begin{array}{l}0,058 \\
(0,761)\end{array}$ & $\begin{array}{l}-0,203 \\
(0,272)\end{array}$ & $\begin{array}{l}-0,038 \\
(0,851)\end{array}$ & $\begin{array}{l}0,278 \\
(0,137)\end{array}$ & $\begin{array}{l}0,040 \\
(0,836)\end{array}$ & 2 \\
\hline & $\begin{array}{l}\text { MFFT total } \\
\mathbf{R}(p)\end{array}$ & $\begin{array}{l}-0,322 \\
(0,095)\end{array}$ & $\begin{array}{l}-0,087 \\
(0,660)\end{array}$ & $\begin{array}{l}-0,259 \\
(0,183)\end{array}$ & $\begin{array}{l}-0,048 \\
(0,812)\end{array}$ & $\begin{array}{l}-0,334 \\
(0,095)\end{array}$ & $\begin{array}{l}-0,307 \\
(0,120)\end{array}$ & $\begin{array}{l}-0,423 \\
(0,025)\end{array}$ & $\begin{array}{l}-0,413 \\
(0,045)\end{array}$ & $\begin{array}{l}-0,335 \\
(0,088)\end{array}$ & $\begin{array}{l}-0,238 \\
(0,241)\end{array}$ & 2 \\
\hline & $\begin{array}{l}\text { TM A tempo } \\
R(p)\end{array}$ & $\begin{array}{l}-0,215 \\
(0,281)\end{array}$ & $\begin{array}{l}-0,454 \\
(0,017)\end{array}$ & $\begin{array}{l}-0,175 \\
(0,383)\end{array}$ & $\begin{array}{l}-0,118 \\
(0,557)\end{array}$ & $\begin{array}{l}0,306 \\
(0,129)\end{array}$ & $\begin{array}{l}-0,425 \\
(0,027)\end{array}$ & $\begin{array}{l}-0,205 \\
(0,306)\end{array}$ & $\begin{array}{l}-0,060 \\
(0,775)\end{array}$ & $\begin{array}{l}-0,085 \\
(0,674)\end{array}$ & $\begin{array}{l}-0,015 \\
(0,942)\end{array}$ & 2 \\
\hline & $\begin{array}{l}\text { TM A erros } \\
R(p)\end{array}$ & $\begin{array}{l}-0,452 \\
(0,014)\end{array}$ & $\begin{array}{l}-0,283 \\
(0,137)\end{array}$ & $\begin{array}{l}-0,337 \\
(0,074)\end{array}$ & $\begin{array}{l}-0,214 \\
(0,265)\end{array}$ & $\begin{array}{l}-0,344 \\
(0,073)\end{array}$ & $\begin{array}{l}-0,425 \\
(0,021)\end{array}$ & $\begin{array}{l}-0,034 \\
(0,861)\end{array}$ & $\begin{array}{l}-0,014 \\
(0,946)\end{array}$ & $\begin{array}{l}-0,303 \\
(0,110)\end{array}$ & $\begin{array}{l}0,025 \\
(0,900)\end{array}$ & 2 \\
\hline & $\begin{array}{l}\text { TM B tempo } \\
R(p)\end{array}$ & $\begin{array}{l}-0,020 \\
(0,918)\end{array}$ & $\begin{array}{l}-0,479 \\
(0,010)\end{array}$ & $\begin{array}{l}-0,206 \\
(0,294)\end{array}$ & $\begin{array}{l}-0,232 \\
(0,235)\end{array}$ & $\begin{array}{l}0,047 \\
(0,817)\end{array}$ & $\begin{array}{l}-0,386 \\
(0,042)\end{array}$ & $\begin{array}{l}-0,217 \\
(0,268)\end{array}$ & $\begin{array}{l}-0,052 \\
(0,801)\end{array}$ & $\begin{array}{l}-0,227 \\
(0,245)\end{array}$ & $\begin{array}{l}0,071 \\
(0,726)\end{array}$ & 2 \\
\hline & $\begin{array}{l}\text { TM B erros } \\
R(p)\end{array}$ & $\begin{array}{l}-0,039 \\
(0,844)\end{array}$ & $\begin{array}{l}-0,127 \\
(0,519)\end{array}$ & $\begin{array}{l}0,031 \\
(0,875)\end{array}$ & $\begin{array}{l}0,129 \\
(0,514)\end{array}$ & $\begin{array}{l}0,267 \\
(0,178)\end{array}$ & $\begin{array}{l}0,281 \\
(0,148)\end{array}$ & $\begin{array}{l}-0,155 \\
(0,430)\end{array}$ & $\begin{array}{l}-0,152 \\
(0,459)\end{array}$ & $\begin{array}{l}0,127 \\
(0,519)\end{array}$ & $\begin{array}{l}0,033 \\
(0,870)\end{array}$ & 0 \\
\hline & $\begin{array}{l}\text { WCST (categ.) } \\
\text { R(p) }\end{array}$ & $\begin{array}{l}0,457 \\
(0,010)\end{array}$ & $\begin{array}{l}0,598 \\
(0,001)\end{array}$ & $\begin{array}{l}0,275 \\
(0,135)\end{array}$ & $\begin{array}{l}0,194 \\
(0,305)\end{array}$ & $\begin{array}{l}-0,058 \\
(0,766)\end{array}$ & $\begin{array}{l}0,258 \\
(0,168)\end{array}$ & $\begin{array}{l}\mathbf{0 , 4 0 6} \\
(0,024)\end{array}$ & $\begin{array}{l}0,182 \\
(0,362)\end{array}$ & $\begin{array}{l}0,362 \\
(0,050)\end{array}$ & $\begin{array}{l}0,242 \\
(0,206)\end{array}$ & 4 \\
\hline & $\begin{array}{l}\text { WCST (EP) } \\
R(p)\end{array}$ & $\begin{array}{l}-0,409 \\
(0,028)\end{array}$ & $\begin{array}{l}-0,583 \\
(0,001)\end{array}$ & $\begin{array}{l}-0,351 \\
(0,062)\end{array}$ & $\begin{array}{l}-0,298 \\
(0,124)\end{array}$ & $\begin{array}{l}-0,091 \\
(0,652)\end{array}$ & $\begin{array}{l}-0,338 \\
(0,078)\end{array}$ & $\begin{array}{l}-0,396 \\
(0,033)\end{array}$ & $\begin{array}{l}-0,082 \\
(0,690)\end{array}$ & $\begin{array}{l}-0,421 \\
(0,026)\end{array}$ & $\begin{array}{l}-0,123 \\
(0,541)\end{array}$ & 5 \\
\hline & $\begin{array}{l}\text { WCST (ENP) } \\
\text { R(p) }\end{array}$ & $\begin{array}{l}-0,326 \\
(0,074)\end{array}$ & $\begin{array}{l}-0,170 \\
(0,061)\end{array}$ & $\begin{array}{l}-0,021 \\
(0,911)\end{array}$ & $\begin{array}{l}0,051 \\
(0,787)\end{array}$ & $\begin{array}{l}0,115 \\
(0,552)\end{array}$ & $\begin{array}{l}-0,197 \\
(0,297)\end{array}$ & $\begin{array}{l}-0,419 \\
(0,019)\end{array}$ & $\begin{array}{l}-0,043 \\
(0,829)\end{array}$ & $\begin{array}{l}-0,164 \\
(0,388)\end{array}$ & $\begin{array}{l}-0,097 \\
(0,617)\end{array}$ & 1 \\
\hline & $\begin{array}{l}\text { WCST (RP) } \\
\text { R(p) }\end{array}$ & $\begin{array}{l}-0,408 \\
(0,028)\end{array}$ & $\begin{array}{l}-0,557 \\
(0,002)\end{array}$ & $\begin{array}{l}-0,284 \\
(0,136)\end{array}$ & $\begin{array}{l}-0,256 \\
(0,188)\end{array}$ & $\begin{array}{l}-0,099 \\
(0,624)\end{array}$ & $\begin{array}{l}-0,278 \\
(0,152)\end{array}$ & $\begin{array}{l}-0,345 \\
(0,067)\end{array}$ & $\begin{array}{l}-0,116 \\
(0,572)\end{array}$ & $\begin{array}{l}-0,369 \\
(0,054)\end{array}$ & $\begin{array}{l}-0,362 \\
(0,054)\end{array}$ & 5 \\
\hline & $\begin{array}{l}\text { WCST (QS) } \\
\text { R(p) }\end{array}$ & $\begin{array}{l}0,269 \\
(0,144)\end{array}$ & $\begin{array}{l}0,199 \\
(0,283)\end{array}$ & $\begin{array}{l}0,056 \\
(0,764)\end{array}$ & $\begin{array}{l}-0,058 \\
(0,759)\end{array}$ & $\begin{array}{l}0,062 \\
(0,749)\end{array}$ & $\begin{array}{l}-0,159 \\
(0,402)\end{array}$ & $\begin{array}{l}0,073 \\
(0,698)\end{array}$ & $\begin{array}{l}0,043 \\
(0,832)\end{array}$ & $\begin{array}{l}0,122 \\
(0,522)\end{array}$ & $\begin{array}{l}-0,362 \\
(0,054)\end{array}$ & 1 \\
\hline & $\begin{array}{l}F V \text { animais } \\
R(p)\end{array}$ & $\begin{array}{l}0,263 \\
(0,146)\end{array}$ & $\begin{array}{l}0,467 \\
(0,007)\end{array}$ & $\begin{array}{l}0,173 \\
(0,343)\end{array}$ & $\begin{array}{l}0,141 \\
(0,450)\end{array}$ & $\begin{array}{l}0,037 \\
(0,845)\end{array}$ & $\begin{array}{l}0,486 \\
(0,006)\end{array}$ & $\begin{array}{l}0,386 \\
(0,029)\end{array}$ & $\begin{array}{l}-0,018 \\
(0,926)\end{array}$ & $\begin{array}{l}0,422 \\
(0,018)\end{array}$ & $\begin{array}{l}0,109 \\
(0,569)\end{array}$ & 4 \\
\hline & $\begin{array}{l}\text { FV comidas } \\
R(p)\end{array}$ & $\begin{array}{l}0,197 \\
(0,280)\end{array}$ & $\begin{array}{l}0,350 \\
(0,049)\end{array}$ & $\begin{array}{l}0,215 \\
(0,237)\end{array}$ & $\begin{array}{l}0,272 \\
(0,138)\end{array}$ & $\begin{array}{l}0,172 \\
(0,364)\end{array}$ & $\begin{array}{l}0,432 \\
(0,015)\end{array}$ & $\begin{array}{l}0,357 \\
(0,045)\end{array}$ & $\begin{array}{l}0,011 \\
(0,956)\end{array}$ & $\begin{array}{l}0,303 \\
(0,098)\end{array}$ & $\begin{array}{l}0,283 \\
(0,130)\end{array}$ & 3 \\
\hline
\end{tabular}

Legenda: DD: Dígitos Diretos; DI: Dígitos Indiretos; MFFT: Matching Familiar Figures Test; TM: Trail Making Test; WCST: Wisconsin Card Sorting Test; WCST (categ): Wisconsin Card Sorting Test (número de categorias); WCST (EP): Wisconsin Card Sorting Test (erros perseverativos); WCST (ENP): Wisconsin Card Sorting Test (erros não perseverativos); WCST (RP): Wisconsin Card Sorting Test (respostas perseverativas); WCST (QS): Wisconsin Card Sorting Test (quebra de setting); FV: Teste de Fluência Verbal; M. Cenas: Memória para Cenas; M. Figuras: Memória para Figuras; M. Hist: Memória para Histórias; M. Sent: Memória para Sentenças; A. Verb: Aprendizagem Verbal; A. Visual: Aprendizagem Visual; E. A. Verb: Evocação Aprendizagem Verbal; E. A. Vis: Evocação

Aprendizagem Visual; Reconh: Reconhecimento. 


\subsection{Controles}

a. Testes de Atenção: Os testes de atenção correlacionaram-se positivamente com testes de memória episódica, semântica e de aprendizagem. (Tabela 19)

\section{b. Testes de Funções Executivas}

Controle Inibitório: A habilidade de controle inibitório correlacionou-se com a memória episódica, semântica e aprendizagem. (Tabela 19)

Atenção Dividida: A atenção dividida correlacionou-se com memória episódica e semântica. (Tabela 19).

Flexibilidade Mental e Abstração: As capacidades de flexibilidade mental e abstração não se correlacionaram com a memória. (Tabela 19)

Rastreio Mental de Informações semânticas: Esta subfunção correlacionou-se com a memória episódica e aprendizagem. (Tabela 19)

No grupo de pacientes com ELT observou-se que houve uma maior correlação entre os testes de função executiva e memória e, relação ao número de subtestes e em relação ao valor da correlação. 
Resultados 56

Tabela 19. Correlação entre os testes de Funções Executivas e Memória dos controles

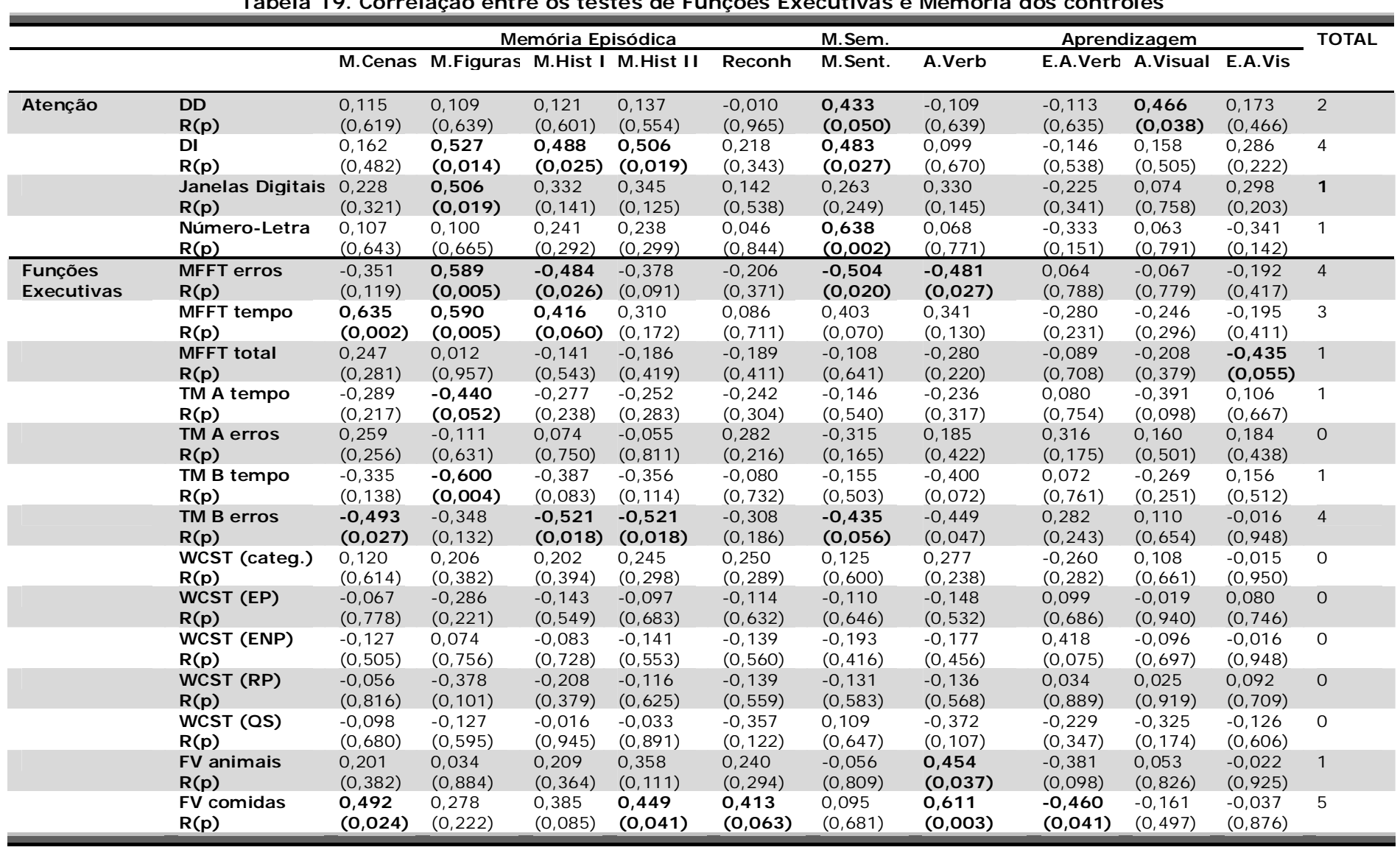

Legenda: DD: Dígitos Diretos; DI: Dígitos Indiretos; MFFT: Matching Familiar Figures Test; TM: Trail Making Test; WCST: Wisconsin Card Sorting Test; WCST (categ): Wisconsin Card Sorting Test (número de categorias); WCST (EP): Wisconsin Card Sorting Test (erros perseverativos); WCST (ENP): Wisconsin Card Sorting Test (erros não perseverativos); WCST (RP): Wisconsin Card Sorting Test (respostas perseverativas); WCST (QS): Wisconsin Card Sorting Test (quebra de setting); FV: Teste de Fluência Verbal; M. Cenas: Memória para Cenas; M. Figuras: Memória para Figuras; M.
Hist: Memória para Histórias; M. Sent: Memória para Sentenças; A. Verb: Aprendizagem Verbal; A. Visual: Aprendizagem Visual; E. A. Verb: Evocação Aprendizagem Verbal; E. A. Vis: Evocação Aprendizagem Visual; Reconh: Reconhecimento. 
c. Os domínios DE e DMn correlacionaram-se positivamente e de forma substancial (r:0,57; p:0,001). (Tabela 20).

Tabela 20. Correlação entre o Desempenho em Testes Executivos e de Memória

\begin{tabular}{cccc}
\hline & \multicolumn{3}{c}{$\mathrm{DE}$} \\
\cline { 2 - 3 } & $\mathrm{R}$ & $\mathrm{P}$ \\
\hline $\mathrm{DMn}$ & 0,565 & 0,001 \\
\hline
\end{tabular}

Legenda: DE: disfunção executiva; DMn: Disfunção Mnéstica 
Este estudo, desenvolvido com uma série de 32 crianças com ELT, demonstrou que: 1․ crianças com ELT apresentam DE e DMn mesmo quando o QI é considerado como covariável; 2o. crianças com ELT sintomática, em especial com $\mathrm{AH}$, têm pior performance do que as criptogênicas e as controles; 3o. variáveis clínicas da epilepsia distintas têm impacto sobre a DMn (idade de início e politerapia) e DE (idade de início e duração da doença); 4o. níveis de gravidade de DE e DMn diferentes podem ser encontrados em crianças com ELT, com impacto relevante sobre o funcionamento cognitivo destas crianças e, finalmente, que 5ㅇ. a presença de DE tem implicação sobre a performance mnéstica das crianças com ELT.

O estudo de crianças e adolescentes com ELT é essencial para a melhor compreensão da relação entre esta síndrome e as funções cognitivas, visto que apesar de crianças e adultos com ELT apresentarem a mesma patologia de base, as crianças e adolescentes ainda não estão sob o efeito duradouro da epilepsia e têm menor tempo de atividade elétrica anormal (Martin et al., 2000).

\section{Métodos}

Este estudo contou com critérios restritivos na seleção de suas amostras de pacientes e controles. Desta forma, além da exclusão de todos os sujeitos com QI inferior a 80 - devido ao reconhecido impacto da deficiência intelectual na performance em testes neuropsicológicos (Lezak, 1995) - também excluímos pacientes e controles com potencial intelectual superior a 120, considerando estudos que demonstraram que o potencial intelectual superior pode revelar uma reserva cognitiva (Helmstaedter et al., 2003). Além disso, restringiu-se a faixa etária do estudo (admitiu-se pacientes entre 9 e 16 anos) diminuindo as possíveis diferenças relacionadas com o desenvolvimento das habilidades cognitivas.

Cabe ressaltar que este é o primeiro estudo, entre as séries sobre funções cognitivas e ELT na infância, a considerar a influência das co-morbidades psiquiátricas no desempenho cognitivo, excluindo aquelas crianças e adolescentes com transtornos psiquiátricos maiores. Esta exclusão deveu-se a reconhecida influência dos quadros psiquiátricos sobre o funcionamento atencional, mnéstico e executivo conforme já fora demonstrado em pacientes com depressão unipolar (Gohier et al., 2009), com transtorno bipolar (Thompson et al., 2009) e esquizofrênicos (Raffard et al., 2009). Este também é o primeiro estudo a utilizar um critério clínico para o estabelecimento do nível de gravidade da DE e DMn nestes pacientes. A 
necessidade de investigar a intensidade da disfunção cognitiva em pacientes com ELT já foi demonstrada por Hermann et al. (2007) que utilizaram análises estatísticas (análise de cluster) para a divisão de seus pacientes - adultos com ELT - em grupos com diferentes níveis de comprometimento cognitivo.

O uso de sujeitos controles e não da norma para efeito de comparação do desempenho mnéstico e executivo foi necessário dada a ausência de dados normativos para a população brasileira para a maior parte dos testes utilizados. A escolha de uma bateria que contivesse apenas testes normatizados para a nossa população limitaria a sensibilidade da avaliação, uma vez que ainda não contamos com medidas de FE e mnésticas normatizadas suficientes para avaliação de todos os componentes destas funções investigadas neste estudo.

Apesar dos critérios restritivos e da bateria ampla, neste estudo avaliamos 32 crianças com ELT, o que pode ser considerado como uma amostra grande, se comparada aos estudos realizados anteriormente em crianças com ELT (Hernandez et al., 2002, CulhaneShelburne et al., 2002, Igarashi et al., 2002, Lendt et al., 1999).

Outras duas variáveis importantes que não puderam ser controladas neste estudo são: (i) presença de crises no mês da testagem e (ii) uso de DAE. A exclusão de crianças com epilepsia com crises mais freqüentes do que mensais e que utilizassem medicação antiepiléptica faria com que o grupo de pacientes não fosse representativo da população com ELT, que é a síndrome epiléptica com maior porcentagem de refratariedade (Cendes \& Kobayashi, 2000).

A escolha da bateria neuropsicológica levou em consideração a necessidade de uma bateria extensa para avaliar tanto a memória quanto as FE. Neste cenário, este é um dos únicos estudos que utiliza nove paradigmas (18 subtestes) para avaliar as funções atencionais e executivas de crianças com ELT e dez para avaliar as funções mnésticas. A presença de performance similar aos controles em alguns subtestes, mas não em outros, evidencia a natureza complementar destes testes e reforça a concepção das funções executivas e mnésticas como fenômenos multidimensionais, que contemplam uma gama de habilidades que não podem ser avaliadas com um único paradigma.

Escolhemos a bateria do Wide Range Assessment of Memory and Learning (WRAML) dentre os testes existentes para avaliar a memória. Esta escolha deu-se, primeiro, por ser um grupo de testes desenvolvidos especialmente para a infância. Isto significa que suas provas 
consideram as diferenças no nível de desempenho de crianças e adultos em testes de memória. Além disso, trata-se de uma bateria que não somente apresenta as contrapartes verbais e não verbais, como investiga diferentes componentes da memória, tais como: a memória episódica, semântica e aprendizagem, tanto a curto como a longo prazo (Sheslow \& Adams, 1990).

A memória episódica é difícil de ser avaliada adequadamente e identificada antes dos seis anos, como demonstrado em pacientes com amnésia do desenvolvimento (VarghaKhadem et al., 1997; 2001). Desta forma, acreditamos que os pacientes incluídos, com idades superiores a nove anos, tenham as habilidades de memória episódica suficientemente consolidadas para serem avaliados.

Alguns estudos que investigam as funções mnésticas em crianças com ELT optaram por utilizar os mesmos testes empregados em adultos (Gonzalez et al., 2007) ou estes mesmos testes com versões adaptadas para a infância (Jambaqué et al., 2007). Acreditamos que ao usar esta metodologia, estes estudos perdem parte de sua sensibilidade devido ao alto nível de dificuldade das atividades propostas, tanto para os pacientes quanto para os controles.

Além disso, observamos que muitos dos estudos, principalmente em adultos, ficam restritos à avaliação das comparações entre as memórias verbal e não verbal (Blume, 2003; Grammaldo et al., 2006; Nolan et al., 2004; Helmstaedter, 2001; Elger et al., 2004) não levando em conta outros processos mnésticos que também são relevantes e encontram-se prejudicados em pacientes com ELT.

Em relação às funções atencionais e executivas levou-se em consideração a complexidade das funções cognitivas mediadas pelos lobos frontais. A DE inclui dificuldades de antecipação, planejamento e organização, iniciação de planos de ação, inibição de distratores e interferências, auto-monitoramento do processo, capacidade de mudar para novas formas de realizar ações quando necessário e memória operacional (Doval et al., 2001; Gioia et al., 2002; Lezak, 1995).

Os estudos sobre as FE de pacientes com epilepsia (Hermann et al., 2002; Igarashi et al., 2002; Martin et al., 2000; Oyegbile et al., 2004), utilizam o WCST como o teste goldstandard e, por vezes, como o único teste. Para pacientes com lesões frontais e prejuízos executivos graves existe um consenso de que este teste é extremamente sensível à sua 
disfunção (Goldstein et al., 2004; Igarashi et al., 2002; Meyer et al., 2004; Romine et al., 2004). No entanto, existem controvérsias quanto à presença de DE em pacientes com ELT em estudos que utilizam o WCST isoladamente. Podemos postular, frente ao que foi observado em nosso estudo, que o WCST pode não ser suficientemente sensível à DE sutil presente em pacientes com ELT (Doval et al., 2001; Hermann et al., 1997; Horner et al., 1989). Nossos achados em crianças reforçam esta hipótese, visto que os sete pacientes que tiveram performance adequada no WCST, tiveram um mau desempenho em outro teste de FE. Isto caracteriza a presença de DE, o que demonstra que o WCST é um teste adequado, mas não suficiente e que seu uso isolado pode levar a uma menor sensibilidade e a não diferenciação de diferentes subtipos de DE (Rzezak et al., 2009).

Uma dificuldade adicional, no estudo das FE e atencionais em crianças, diz respeito aos aspectos maturacionais que envolvem o lobo frontal. O estudo com crianças vem demonstrando que as regiões pré-frontais só ficam plenamente desenvolvidas no final da infância e início da adolescência (Goldman, 1974; Golden, 1981; Grattan \& Eslinger, 1991). Alterações de desenvolvimento foram descritas no estudo realizado por Igarashi \& Kato (2000), utilizando o WCST em crianças saudáveis. Estes autores demonstraram que o padrão de desempenho do adulto é atingido após os 12 anos de idade. Embora esta limitação não seja totalmente contornável, com o intuito de utilizar a mesma bateria de testes em todos os pacientes, estudamos uma série com idade restrita.

Tendo em vista esta limitação, realizamos análises separadas quanto às funções executivas das crianças e adolescentes com idades inferiores e superiores a 12 anos. Estes achados serão discutidos a seguir, na sessão da Discussão referente às FE.

\section{Funções Mnésticas}

Presença de Disfunção Mnéstica

Apesar da ELT freqüentemente ter início na infância, em comparação aos adultos, poucos estudos avaliaram a lateralização e a localização dos DMn em crianças com ELT (Gonzalez et al., 2007). Além disso, os trabalhos existentes são contraditórios em relação à presença de dificuldades de memória (específicas ou não) na faixa etária pediátrica, sua localização e lateralização (Adams et al., 1990; Lendt et al., 1999; Jambaqué et al., 1993; 1997; Szabó et al., 1998). 
No presente estudo, crianças com ELT apresentaram dificuldades de memória episódica verbal imediata e memória semântica. Os déficits de memória episódica verbal tardia e memória episódica não verbal apresentaram uma tendência com impacto clínico demonstrado pela análise de Cohen's. Assim, corroboramos estudos prévios que demonstram déficits de evocação imediata nos pacientes tanto para material verbal quanto visual (CronelOhayon et al., 2006; Gonzales et al., 2007; Jambaqué et al., 2007) e também os que encontraram déficits em fase de evocação tardia, sugerindo uma dificuldade de armazenamento a longo-prazo (Fedio \& Mirsky, 1969; Lavadas et al., 1979, Delaney et al. 1980).

Além disso, atribuímos às diferenças metodológicas os achados incompatíveis de nosso estudo com aqueles que não encontraram pior performance das crianças com ELT em atividades de memória imediata (Fedio \& Mirsky, 1969; Lavadas et al., 1979, Delaney et al. 1980; Lendt et al., 1999), ou que só encontraram déficits em etapa de evocação tardia (Fedio \& Mirsky, 1969; Lavadas et al., 1979, Delaney et al. 1980). Estes estudos usaram faixasetárias muito amplas (crianças de 6 a 18 anos), grupos de pacientes com patologias distintas, grupos de comparação diferentes (controles, norma, outros tipos de epilepsias) e bateria de testes neuropsicológicas standards que não consideravam as subfunções de memória investigadas e se eram adequadas para esta população.

Além disso, nossos achados quanto aos déficits de memória episódica (verbal) e memória semântica corroboram o estudo de Helmstaedter (2002), em uma das maiores séries sobre ELT, com 100 pacientes adultos.

A pior performance em memória episódica verbal observada em nosso estudo é um resultado esperado, visto que há um grande número de pacientes com lesões em estruturas mesiais. O hipocampo além de ter um papel essencial na consolidação de novas memórias e armazenamento das mesmas à longo-prazo, parece estar envolvido com a associação ou a conexão entre informações não relacionadas, uma vez que o nível de prejuízo mnéstico está relacionado com a gravidade da $\mathrm{AH}$ (Cohen \& Eichenbaum, 1993).

O prejuízo de memória semântica pode refletir a lesão de estruturas laterais e mesiais do LT que prejudicam as funções neocorticais em sua capacidade de armazenamento e evocação de informação ou funções hipocampais em processar estímulos com significado (Giovagnoli et al., 2005). Desta forma, uma possível explicação para o seu prejuízo, em 
nosso grupo, poderia ser a presença de uma zona epileptogênica que se estende além da lesão, envolvendo as estruturas neocorticais.

Déficits memória-específico (déficit de memória verbal para pacientes com ELT no hemisfério dominante), enfatizados na literatura em estudos com adultos, não puderam ser corroborados neste estudo e em outros estudos prévios com crianças (Adams et al., 1990; Szabó et al., 1998; Nolan et al., 2004; Guimarães et al., 2008 submetido).

Cabe ressaltar que os poucos estudos que demonstraram déficits de memória verbal em pacientes com ELT esquerda, ou não controlaram variáveis da epilepsia (Fedio \& Mirsky, 1969) ou enfatizaram as diferenças entre pacientes com ELT esquerda e controles (Jambaqué et al., 1993). Desta forma, ainda não está determinado se a memória verbal não é comprometida em pacientes com ELT direita.

A base deste déficit de memória não lateralizado é incerta, mas pode revelar uma não especialização hemisférica para a memória. É possível que a memória, em idade precoce, seja sustentada por uma rede bitemporal e que a presença das descargas epileptogênicas dificulte o processo de lateralização da memória (Gonzalez et al., 2007).

Grammaldo et al. (2006) postularam que o efeito lateralizatório nos testes de memória somente pode ser observado nos pacientes com $\mathrm{AH}$. Na infância, este pode representar uma limitação para o estudo da lateralização da memória em pacientes com ELT, visto que a $\mathrm{AH}$ não é a causa mais comum de ELT. As causas mais comuns são as malformações corticais e tumores, seguidos pela AH (Duchowny et al., 1998; Maton et al., 2008; Wyllie, 2000). Esta, portanto, é mais uma explicação para a não existência do déficit memória específico, ao considerarmos o nosso grupo como um todo.

\section{Etiologia e Disfunção de Memória}

Neste estudo observamos que pacientes com lesão demonstrável à RM têm pior desempenho do que pacientes com ELT criptogênica; sendo que pacientes com $A H$ apresentaram maiores dificuldades em testes de memória do que os demais pacientes sintomáticos.

Sabe-se que o hipocampo tem um papel fundamental na consolidação de novas memórias, estando relacionado com o processamento da memória declarativa de longo prazo no período de desenvolvimento de crianças, o que explica os nossos achados quanto ao 
comprometimento da memória semântica e episódica, que são componentes da memória declarativa (Riva et al., 2001).

Estes achados foram parcialmente demonstrados por Gonzáles et al. (2007) que verificaram que crianças com ELT com lesões em estruturas mesiais apresentam maiores dificuldades com as atividades mnésticas (verbais e não-verbais) do que aqueles com ELT lateral. Uma dificuldade de comparação deste estudo (Gonzáles et al., 2007) com o nosso é a presença de etiologias distintas.

Há evidências pungentes de que a ELT, determinada pela $A H$, é uma entidade distinta em seus aspectos clínicos, neurofisiológicos, prognósticos, quanto à prevalência de comorbidades psiquiátricas e impacto sobre a qualidade de vida (Volcy Gómez, 2004; Shamim et al., 2008; Mohamed et al., 2001). Embora não tenhamos corroborado os efeitos lateralizatórios da memória em adultos com ELT por AH (Grammaldo et al., 2006), demonstramos que estas crianças não só apresentam piores desempenhos mnésticos que as demais com ELT, quanto apresentam tendências de dificuldades de aprendizagem com importante impacto clínico (Cohen's $d=0,69$ ), não demonstradas pelas demais crianças. Este achado fala a favor da ELT com a AH como uma entidade distinta das demais ELT, também no que diz respeito à gravidade do prejuízo cognitivo.

Impacto das Variáveis Clínicas da Epilepsia nos Déficits de Memória

Quando observamos a influência das variáveis clínicas da epilepsia (etiologia, idade de início da epilepsia e duração, freqüência de crises, tipo de crise, presença de generalização secundária, uso de mono ou politerapia, história de crises febris, história de antecedentes familiares de epilepsia e status epilepticus) sobre o desempenho mnéstico, revelamos a interferência da idade de início precoce da epilepsia sobre funções de memória verbal, visual, semântica e de aprendizagem.

A lesão precoce de estruturas temporais mesiais não pode ser compensada por regiões alternativas e possivelmente o prejuízo mnéstico é relacionado a idade em que se adquiriu a lesão visto que a idade de início, mas não a duração da doença, foi um fator determinante na presença de DMn nestes pacientes, corroborando o que foi previamente postulado (Riva et al., 2001; Hermann et al., 2002; Lespinet et al., 2002; Strauss et al., 1995). 
Além disso, demonstramos que crianças com idade de início da epilepsia anterior aos quatro anos apresentaram maiores dificuldades de memória episódica visual, evocação tardia de material visual e memória semântica, mais uma vez demonstrando o impacto da idade de início da epilepsia na aquisição e consolidação de processos cognitivos na infância.

Cabe ressaltar que a duração da epilepsia é relevante na determinação e na gravidade dos DMn, como observado em adultos com ELT de longa duração (Cheung et al., 2006; Riva et al., 2001). Entretanto, baseado nos nossos achados, a presença da lesão em fases precoces da vida parece ser um fator predominante. Postulamos que a duração da epilepsia é de fato relevante não só pelos efeitos diretos da atividade epileptogênica, como pelos efeitos indiretos da doença (incapacitação com privação e isolamento social) em especial nos pacientes refratários. Esta variável, que se torna um fator confusional nos estudos em adultos, pôde ser excluída, ou pelo menos atenuada neste grupo devido à amostra estudada e ao caráter transversal do estudo.

Em relação à politerapia, o efeito das DAEs sobre a cognição é conhecido, em especial quando estas drogas são usadas em associação (Uijl et al., 2006; Lagae, 2006). Além disso, a politerapia é um marcador indireto da maior refratariedade e, portanto, também um indicador de maior gravidade.

As DAEs reduzem as crises ao diminuir a irritabilidade neuronal, contudo, esta mesma ação pode afetar a excitabilidade neuronal e prejudicar a cognição (Meador, 2006). Desta forma, praticamente todas as DAE têm efeitos negativos sobre a cognição quando indivíduos saudáveis com e sem DAE são comparados (Meador, 2006). Seu impacto é prejudicial sobre as funções de memória, especialmente quando está requer um componente atencional. Assim, em atividade de repetição de sentenças, pacientes sob medicação anti-epiléptica tinham redução de $15 \%$ de sua habilidade mnéstica em comparação a indivíduos sem medicação (Meador, 2006).

\section{Funções Executivas}

Presença de Disfunção Executiva 
Nossos achados (Guimarães et al. 2006; Rzezak et al. 2007) corroboram o estudo previamente realizado por Igarashi et al. (2002) em crianças com ELT sobre a presença de DE nestes pacientes.

O estudo de Igarashi et al. (2002) utilizando o WCST demonstrou menor flexibilidade mental. Em nossa série, além de menor flexibilidade mental, pelo método empregado e previamente discutido, pudemos observar que crianças e adolescentes com ELT apresentam déficits em outras habilidades, tais como: controle inibitório, fluência verbal e manutenção da atenção.

Os achados de Hernandez et al. (2002) e Culhane-Shelburne et al. (2002) demonstrando pior desempenho em testes executivos nas crianças com epilepsia do lobo frontal se comparado às crianças com ELT, já seriam esperados. Entretanto, estes resultados não excluem a presença de DE sutil nas crianças com ELT que podem interferir em seu desempenho global. Além disso, estes resultados devem ser analisados com cautela, tendo em vista a amostra com ELT avaliada composta por oito (Hernandez et al., 2002) e 15 pacientes (Culhane-Shelburne et al., 2002) com ELT.

A disfunção de áreas pré-frontais decorrentes de uma lesão ou uma disfunção no LT pode em parte ser compreendida através das conexões anatômicas do LT com o lobo frontal. O LT, em especial o Complexo Subicular e o Corno de Ammon, projetam-se para o Córtex Entorrinal que possui conexões cortico-corticais eferentes para o CPF, córtex órbito-frontal, giro parahipocampal, giro do cíngulo e córtex insular. Através das conexões que emergem do córtex entorrinal para áreas corticais de associação, a Formação Hipocampal pode influenciar, virtualmente, todas as áreas de associação dos lobos temporal, parietal e frontal, bem como outras áreas sensoriais terciárias (Duvernoy, 1998; Martin, 2003).

Nossos resultados sugerem que o envolvimento do LT per se é importante, uma vez que este padrão de prejuízo cognitivo extenso, relatado em adultos (Corcoran \& Upton, 1993; Hermann \& Seidenberg, 1995; Hermann et al., 1997; Martin et al., 2000), também pode ser encontrado em estágios precoces de vida.

Etiologia e Disfunção Executiva 
Quanto à etiologia, pacientes com ELT sintomática tiveram pior desempenho nos testes de FE comparado aos pacientes com ELT criptogênica e controles. No grupo de pacientes sintomáticos, não houve diferença entre pacientes mesiais e laterais. Cabe ressaltar, no entanto, que o número de sujeitos no grupo de ELT lateral era pequeno (com seis pacientes) o que pode representar um fator limitante da análise.

Baseado em nossos achados concordamos com a hipótese de Corcoran \& Upton (1993) de que o hipocampo atua como um comparador de ações, cuja lesão determina a presença de disfunção executiva. Contudo, é importante enfatizar que pacientes com ELT lateral também demonstraram déficits executivos e por esta razão acreditamos que uma rede anatômica e funcional conectando os lobos temporal e frontal permitindo que a região epileptogênica temporal afete ambas as regiões frontais e pré-frontais (Hermann et al., 2002; Igarashi et al., 2002; Martin et al., 2000).

Portanto, acreditamos que as hipóteses de Corcoran \& Upton (1993) do hipocampo como um modulador do funcionamento executivo e a de Hermann \& Seidenberg (1995), da atividade epileptogênica (epileptigenic noise) sendo espraiado por um circuito de conexão entre os lobos temporal e frontal, sejam complementares e não excludentes para explicar a pior performance destes pacientes.

Em concordância com esta assertiva, estudos recentes de neuroimagem demonstraram presença de hipometabolismo nas regiões pré-frontais de pacientes com ELT (Nelissen et al., 2006; Takaya et al., 2006). O estudo de Nelissen et al. (2006) usando SPECT e PET, demonstraram hipometabolismo interictal no córtex pré-frontal de adultos com ELT. Estes autores sugerem um processo dinâmico de inibição dos lobos frontais, que poderia representar um processo de proteção contra a propagação da atividade epileptiforme, mas que em contrapartida poderia ser responsável pelos déficits funcionais apresentados por estes pacientes. Num estudo de imagem estrutural, usando MBV, Cormack et al. (2005) encontraram redução da densidade da substância cinzenta ipsilateral ao foco epileptogênico no hipocampo, lobo temporal e estruturas extrahipocampais, tais como o tálamo, córtex cingulado anterior, cerebelo, córtex opercular frontal e parietal. Segundo os autores, estes achados poderiam refletir uma alteração estrutural determinada pela interrupção do desenvolvimento cortical determinada por crises recorrentes e precoces bem como pela perda de inputs funcionais do hipocampo esclerosado. Estes achados sugerem mais uma alteração 
funcional ou estrutural permanente do que um processo intermitente (Nelissen et al., 2006) que poderia explicar nossos achados de pior desempenho em pacientes com ELT.

Variáveis Clínicas da Epilepsia e a Disfunção Executiva

Pacientes com idade de início de epilepsia precoce apresentaram um pior desempenho nos testes de FE corroborando os achados de Cormack et al. (2007) que demonstraram que a idade de início precoce era o melhor indicador de disfunção intelectual, sugerindo que o primeiro ano de vida representa um período crítico para o desenvolvimento das habilidades intelectuais. No entanto, deve ser enfatizado que a maior duração da epilepsia foi relevante na determinação da presença de $\mathrm{DE}$, corroborando a idéia da necessidade de intervenções cirúrgicas precoces.

Além disso, no estudo de Cormack et al. (2007), crianças mais novas, pacientes e controles tiveram pior desempenho em atividades executivas, como era esperado. Apesar desse achado, consideramos que a avaliação de crianças pequenas faz-se necessária com o objetivo de desenvolver um programa de reabilitação neuropsicológica.

As alterações de neurodesenvolvimento podem ser consideradas como limitações para o estudo de crianças, uma vez que os instrumentos disponíveis para a avaliação neuropsicológica podem não ser completamente adequados para esta população. Ainda assim, acreditamos que este efeito foi minimizado, no nosso estudo, através do pareamento por idade com um grupo de voluntários saudáveis.

Também demonstramos que presença de idade de início precoce (inferior aos quatro anos de idade), mas não o controle de crises, teve um impacto relevante em um grande número de testes utilizados na avaliação das FE nas crianças com ELT. Estes resultados corroboram os achados de Hessen et al. (2006) que demonstraram que idade de início e duração da epilepsia são mais importantes do que a gravidade da epilepsia em relação ao funcionamento executivo. Estes dados também estão em concordância com o estudo de Hermann et al. (2002), contradizendo a teoria de que a plasticidade neuronal pode ser um fator de proteção. De fato, as evidências apontam para o fato de que a atividade epileptiforme anormal, em idade precoce, pode influenciar negativamente as funções cognitivas, mais do que era esperado.

O estudo de Hermann et al. (2002) sugere existir conseqüências negativas do neurodesenvolvimento, associadas ao início precoce de crises epilépticas focais em estruturas 
cerebrais distantes do foco epileptogênico (Marsh et al., 1997) promovendo uma implicação funcional (cognitivo). Este impacto estrutural e funcional precoce do desenvolvimento pode estar relacionado com conseqüências cognitivas adversas em uma ELT com longa duração e refratária ao tratamento medicamentoso (Hermann et al., 2002).

Portanto, nossos achados sugerem que o envolvimento do LT per se é uma importante variável que poderia determinar a presença de DE e que intervenções precoces são necessárias, uma vez que o padrão de prejuízos cognitivos extenso, observados por Hermann \& Seidenberg (1995) em adultos já pode ser observado nos primeiros estágios da vida e poderia ser agravado por uma maior duração da epilepsia.

Algumas variáveis relacionadas à maior gravidade da epilepsia, como a presença de status epilepticus, uso de politerapia, controle de crises e generalização secundária também tiveram relação com a pior desempenho em alguns subtestes, ainda que o impacto seja menos relevante do que as variáveis idade de início e duração da doença levando-se em conta o número de testes com significância estatística.

\section{Gravidade da Disfunção Executiva e Mnéstica}

Em estudo atual, Hermann et al. (2007) delineou fenótipos cognitivos para pacientes com ELT através da análise de 96 adultos. Três perfis foram delineados segundo a gravidade da performance cognitiva: (1) prejuízo mínimo (47\% dos pacientes); (2) prejuízo de memória (24\%); e (3) prejuízo de memória e funções executivas (29\%).

O estudo de Hermann et al. (2007) ilustra a necessidade de delinear perfis mais específicos não baseados no agrupamento indistinto dos pacientes. Durante a execução deste trabalho, pudemos observar que embora a DE e a DMn estivessem presentes na maior parte dos pacientes, havia diferentes níveis de acometimento.

A gravidade da DE e DMn nos pacientes com ELT não foi avaliada previamente em pacientes com epilepsia. Desta forma, elaboramos um critério clínico com o qual determinamos que $84,38 \%$ das crianças e adolescentes com ELT tinham uma DE moderada ou grave e que $75 \%$ das crianças e adolescentes com ELT tinham uma DMn moderada ou grave, com um inegável efeito sobre sua qualidade de vida, uma vez que todos os pacientes estavam em idade escolar, embora, estes efeitos não tenham sido mensurados, por não ser o objetivo deste estudo. 
Desta forma, é importante ressaltar que além das diferenças qualitativas, há diferenças quantitativas no comprometimento cognitivo destes pacientes. Embora a maioria destes pacientes tenha DE e DMn, estas se apresentam de uma forma diferente em cada um dos pacientes e com intensidades diferentes, conseqüentemente o impacto destas disfunções será desigual.

Nossos achados indicam que além de ser necessária a utilização de baterias amplas de testes neuropsicológicos para avaliar as funções mnésticas e executivas, há também a necessidade de um critério clínico para classificar os níveis de DMn e DE em crianças e adolescentes, porque algumas das medidas mais amplamente usadas não são suficientemente sensíveis para detectar prejuízos muito sutis.

\section{I mpacto das Disfunções Executivas sobre os Processos Mnésticos}

O estudo de funções cognitivas isoladas é uma prática antiga e bastante comum da neuropsicologia desde a sua criação. Contudo, o aprofundamento de seu estudo e o avanço no conhecimento do papel da conectividade entre diferentes regiões cerebrais revelou que esta é uma prática coerente apenas didaticamente. Assim sendo, sabemos que as funções cognitivas se sobrepõem em grande escala e o funcionamento de uma delas depende grandemente de outras (Lezak, 1995; Baron, 2004).

Os estudos sobre o funcionamento cognitivo de pacientes com ELT iniciaram-se com a memória, uma vez que este é o comprometimento mais visível e esperado nesta população. Contudo, como já foi mencionado anteriormente, vários estudos (Corcoran \& Upton, 1993; Hermann \& Seidenberg, 1995; Igarashi et al., 2002; Rzezak et al., 2007) vêm revelando prejuízos em outras esferas cognitivas além da memória, tais como os déficits atencionais e executivos.

Nossos achados revelaram que os prejuízos atencional e executivo tiveram um impacto significativo sobre o desempenho em testes de memória de crianças e adolescentes com ELT. Isto significa que as habilidades de controle inibitório, atenção dividida, flexibilidade mental e abstração e o rastreio mental de informações (componentes das funções executivas) são necessários para o processo de armazenamento de informações.

Além disso, os processos atencionais são essenciais para boa capacidade de armazenamento, uma vez que os processos de recepção dos estímulos precisam estar 
aguçados, caso contrário nenhuma informação é armazenada (Lezak, 1995). Os testes atencionais utilizados neste estudo estiveram correlacionados positivamente com até sete dos dez testes de memória utilizados, corroborando esta assertiva.

Este é o primeiro estudo a procurar uma associação entre as DE e os prejuízos de memória em pacientes com ELT, adultos ou crianças, considerando o desempenho na avaliação neuropsicológica. No entanto, esta associação já foi demonstrada em outras populações, inclusive em indivíduos saudáveis. Dessa forma, corroboramos os estudos realizados em pacientes com esquizofrenia (Fossati et al., 1999), populações neurológicas mistas (Vanderploeg et al., 1994) pacientes com acidente vascular cerebral (Simard et al., 2000) e em pacientes com traumatismos crânio-encefálicos (Mangels et al., 2004).

Neste estudo, demonstramos que em crianças e adolescentes com ELT, o comprometimento de diferentes subfunções executivas estão associadas ao pior desempenho em diferentes modalidades de memória. Desta foram, corroboramos os achados de Vanderploeg et al. (1994) com pacientes neurológicos e contradizemos a assertiva de que as FE influenciam diretamente as memórias episódica, semântica e a aprendizagem, como um todo.

Além disso, observamos um padrão de associação entre as FE e mnésticas diferente entre pacientes com ELT e controles. Desta forma, a DE esteve associada de forma mais significativa com às DMn em pacientes com ELT do que em sujeitos saudáveis. Esse achado revela que populações com patologias diversas poderão apresentar um perfil de associação entre as FE e mnésticas diferente e que mais estudos são necessários para delinear este perfil na população com ELT.

Estudos com primatas (Bauer \& Fuster, 1976; Voytko, 1986; Bachevalier \& Mishkin, 1986) e humanos (Kapur et al., 1994; Demb et al., 1995; Kelley et al., 1998; Wagner et al., 1998) também demonstraram a participação do córtex frontal para as atividades de codificação e armazenamento de informações.

A conexão de vias temporais mesiais e pré-frontais foi demonstrada por diversos autores (Kim et al., 2003; Bernasconi et al., 2004; Muller et al., 2006). Entretanto, esta inter-relação em pacientes com lesão no LT não foi devidamente investigada. Nosso estudo demonstra que crianças e adolescentes com lesões temporais apresentam déficits cognitivos extratemporais, apesar da menor duração da epilepsia. Corroboramos a noção da atividade 
epileptogênica anormal do LT afetando estruturas extratemporais do lobo frontal, responsáveis pelas FE, enfatizando, assim, a existência de uma rede neural conectando os lobos frontal e temporal. A existência de DE em pacientes com ELT pode estar relacionada com a existência de microdisgenesias não visíveis em exames de neuroimagem de rotina nas regiões extratemporais. A hipótese da rede neural e da existência de anormalidades estruturais não visíveis no córtex frontal não são excludentes, mas podem ser coexistentes e correlacionadas.

A inter-relação entre as FE e memória não é uma via de mão dupla. O orquestramento frontal é essencial para uma boa memorização através da sustentação da atenção e manipulação mental de informações, ou seja, os lobos frontais atuam como um sistema central que gerencia a memória hipocampal. (Baddeley, 1986; Moscovitch's 1992)

Nossos resultados sugerem que sem a investigação adequada das FE e atencionais, a investigação da memória em pacientes com ELT está fundamentado em um conceito ultrapassado do estudo compartimentalizado das funções cognitivas, que pode levar ao delineamento de um perfil cognitivo errôneo para estes pacientes.

\section{Perspectivas Futuras}

Uma forma de avaliar objetivamente os efeitos da atividade epileptiforme sobre o cérebro em maturação é a realização de estudos longitudinais, com acompanhamento e reavaliações neuropsicológicas com uma certa periodicidade. Com esta metodologia poderíamos responder perguntas ainda pouco compreendidas, tais como: em que momento do desenvolvimento a memória passa a apresentar uma lateralização hemisférica em pacientes com ELT? A influência da DE sobre a DMn fica mais evidente com o passar do tempo? O perfil de desempenho executivo se mantém ao longo da vida?

Uma outra abordagem igualmente relevante no estudo e tratamento destes pacientes é programar um plano de intervenção, ou de reabilitação neuropsicológica, para os déficits mnésticos e executivos. Até o momento, ressaltou-se o importante trabalho de diagnóstico destas dificuldades, no entanto, após a identificação e mapeamento destes déficits faz-se necessário testar programas de reabilitação que possam diminuir o impacto destas dificuldades no dia-a-dia destes pacientes. 
1. Nossos achados demonstraram que crianças e adolescentes com ELT apresentam pior desempenho das funções mnésticas e executivas quando comparadas a crianças saudáveis. Em nossos pacientes, observamos déficits das seguintes habilidades: memória episódica verbal, visual e semântica, concentração, atenção dividida, controle inibitório, formação de conceito e busca mental de informações semânticas demonstrando que as funções cognitivas, em especial as executivas, constituem-se em um complexo de habilidades distintas, mas em interdependência,

2. A etiologia da ELT foi um fator determinante para o nível de comprometimento mnéstico e executivo destas crianças. Assim, embora tenhamos demonstrado prejuízos nos dois grupos de pacientes com ELT (sintomático e criptogênico), as crianças com lesões no LT (grupo sintomático), particularmente àquelas com AH, apresentaram pior performance.

3. A idade de início precoce esteve associada ao pior desempenho global; mnéstico e executivo. O uso de politerapia esteve associado ao pior desempenho mnéstico, assim como a duração da epilepsia esteve associada com as funções executivas. Portanto, a investigação da DMn e da DE em crianças e adolescentes com ELT deve levar em consideração o impacto relevante de algumas variáveis clínicas da epilepsia.

4. Este estudo evidenciou a existência de diferentes níveis de gravidade da disfunção mnéstica e executiva em crianças e adolescentes com ELT. Assim, 84,38\% dos pacientes apresentaram DE moderada ou grave e 75\% tinham comprometimento mnéstico moderado ou grave.

5. A DE esteve associada a presença de déficits de memória em crianças e adolescentes com ELT. Desta forma, deve-se considerar o funcionamento executivo ao avaliar as funções mnésticas nos pacientes com ELT. 
HOSPITAL DAS CLÍNICAS

DA

FACULDADE DE MEDICINA DA UNIVERSIDADE DE SÃO PAULO

TERMO DE CONSENTIMENTO LIVRE E ESCLARECIDO

\section{I - DADOS DE IDENTIFICAÇÃO DO SUJEITO DA PESQUISA OU RESPONSÁVEL LEGAL}

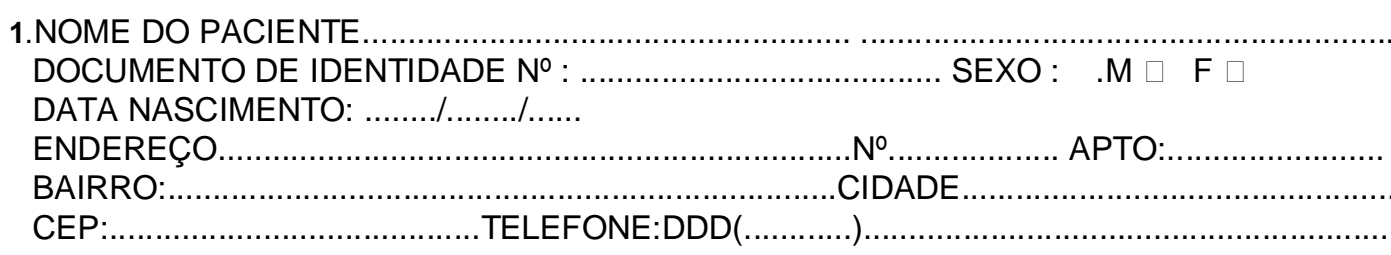

2. RESPONSÁVEL LEGAL

NATUREZA (grau de parentesco, tutor, curador etc.). DOCUMENTO DE IDENTIDADE :..... SEXO: $M \square \mathrm{F}$ DATA NASCIMENTO.: .....................

ENDEREÇO

BAIRRO:.

CEP: TELEFONE:DDD(

№ CIDADE

APTO: .).

\section{II - DADOS SOBRE A PESQUISA CIENTÍFICA}

1. TÍTULO DO PROTOCOLO DE PESQUISA: Avaliação das Funções Executivas e Mnésticas em crianças e adolescentes com epilepsia de lobo temporal

2. PESQUISADOR: Dr.a Kette DR Valente

CARGO/FUNÇÃO: Médica INSCRIÇÃO CONSELHO REGIONAL

UNIDADE DO HCFMUSP: Instituto de Psiquiatria.

3. AVALIAÇÃO DO RISCO DA PESQUISA:

$\begin{array}{lll}\text { SEM RISCO } & \text { RISCO MÍNIMO } \square & \text { RISCO MÉDIO } \\ \text { RISCO BAIXO } \square & \text { RISCO MAIOR } \square\end{array}$

(probabilidade de que o indivíduo sofra algum dano como conseqüência imediata ou tardia do estudo) 4.DURAÇÃO DA PESQUISA : esta pesquisa está prevista para ter duração de dois anos 


\section{II - REGISTRO DAS EXPLICAÇÕES DO PESQUISADOR AO PACIENTE OU SEU REPRESENTANTE LEGAL SOBRE A PESQUISA, CONSIGNANDO:}

1. justificativa e os objetivos da pesquisa: O Sr.(a) concordaria que seu filho(a) participe de um estudo que tem como objetivo analisar o funcionamento do cérebro através de testes psicológicos? Nestas atividades (testes) será avaliada a memória e funções que estão relacionadas com a execução e planejamento de tarefas diárias, como por exemplo, conseguir fazer a lição de casa.

2. procedimentos que serão utilizados e propósitos, incluindo a identificação dos procedimentos que são experimentais; Os testes são extremamente simples e são todos freqüentemente utilizados, não havendo nada experimental, ou seja, nenhum em experiência que será utilizado com o seu (sua) filho(a). Uma psicóloga irá dar as instruções de como fazer e a seguir serão feitas as atividades.

3. desconfortos e riscos esperados; O único desconforto que o teste pode causar é o cansaço, que é o mesmo do de fazer a lição de casa. Caso isto ocorra, o teste será interrompido e será continuado em outro dia.

4. benefícios que poderão ser obtidos; Para nós, é importante sabermos quais as funções que seu(sua) filho(a) possa ter prejudicadas, para que possamos orientar melhor nossos pacientes no futuro. Nós acreditamos que seja importante para vocês, da família, saberem o por quê de seu filho(a) apresentar algumas dificuldades, se ele apresentar. Desta forma, vocês poderão aprender a como lidar melhor com as dificuldades dele(a).

5. procedimentos alternativos que possam ser vantajosos para o indivíduo: Não há nenhum outro procedimento alternativo para saber o que pretendemos de forma mais simples do que este.

\section{IV - ESCLARECIMENTOS DADOS PELO PESQUISADOR SOBRE GARANTIAS DO SUJEITO DA PESQUISA:}

1. acesso, a qualquer tempo, às informações sobre procedimentos, riscos e benefícios relacionados à pesquisa, inclusive para dirimir eventuais dúvidas: $O$ Sr.(a) poderá ter acesso, em qualquer momento, às informações, procedimento, riscos e benefícios relacionados à essa pesquisa, podendo se sentir à vontade para retirar eventuais dúvidas. 
2. liberdade de retirar seu consentimento a qualquer momento e de deixar de participar do estudo, sem que isto traga prejuízo à continuidade da assistência: O Sr.(a) tem a liberdade de retirar o seu consentimento sobre a participação de seu filho(a) neste serviço ou em qualquer outro deste Hospital.

3. salvaguarda da confidencialidade, sigilo e privacidade: Caso o Sr.(a) resolva que seu filho(a) participe desta pesquisa, o nome ou qualquer referência que sirva para identificar o seu filho(a) não será divulgado em momento algum, sendo respeitado desta forma o seu direito de confidencialidade, sigilo e privacidade.

4. disponibilidade de assistência no HCFMUSP, por eventuais danos à saúde, decorrentes da pesquisa: Não há qualquer possibilidade de eventuais danos à saúde decorrentes desta pesquisa.

5. viabilidade de indenização por eventuais danos à saúde decorrentes da pesquisa: Não há qualquer possibilidade de eventuais danos à saúde decorrentes desta pesquisa.

\section{INFORMACCÕES DE NOMES, ENDEREÇOS E TELEFONES DOS RESPONSÁVEIS PELO ACOMPANHAMENTTO DA PESQUISA, PARA CONTATO EM CASO DE INTERCORRÊNCIAS CLÍNICAS E REAÇÕES ADVERSAS.}

Patrícia Rzezak - (0xx11) 3069-6969

Daniel Fuentes - (0xx11) 3069-6969

Serviço de Psicologia e Neuropsicologia do Instituto de Psiquiatria HCMFUSP que se localiza na Rua Dr. Ovídio Pires de Campos no Instituto de Psiquiatria do Hospital das Clínicas, $4^{\circ}$ andar.

Kette Dualibi Ramos Valente - (0xx11) 3069-6518

Laboratório de Neurofisiologia Clínica do Instituto de Psiquiatria HCMFUSP que se localiza na Rua Dr. Ovídio Pires de Campos no Instituto de Psiquiatria do Hospital das Clínicas, andar Térreo. 


\section{VII - CONSENTIMENTO PÓS-ESCLARECIDO}

Declaro que, após convenientemente esclarecido pelo pesquisador e ter entendido o que me foi explicado, consinto em participar do presente Protocolo de Pesquisa

São Paulo,

de

de

assinatura do sujeito da pesquisa ou responsável legal

Kette Valente

Médica 
Epilepsy \& Behavior sxx (2009) xxx-xxx

Brief Communication

\section{Executive dysfunction in children and adolescents with temporal lobe epilepsy:} Is the Wisconsin Card Sorting Test enough?

Patricia Rzezak ${ }^{\mathrm{a}, \mathrm{b}}$, Daniel Fuentes ${ }^{\mathrm{a}}$, Catarina A. Guimarães ${ }^{\mathrm{c}}$, Sigride Thome-Souza ${ }^{\mathrm{b}}$, Evelyn Kuczynski ${ }^{\mathrm{b}}$, Marilisa Guerreiro ${ }^{c}$, Kette D.R. Valente ${ }^{b, *}$

a Psychalagy \& Neuropsychalagy Unit, institute of Psychiatry, Unive sity of Säo Paulo Medical school (IFq-HC-FMUSP), Sđo Paula, Brazil bPraject for the Study of Psychiatric Disarders in Children and Adolescents with Epilepsy, Psychiatry institute, HCrMUSP, Sđo Paulo, Brazil ${ }^{\mathrm{C}}$ Neurology Department, University of Compinas (UNICAMP), Sđo Paula, Brazil

\section{ARTICLE I N F O}

\section{Anide history:}

Received 10 November 2008

Revised 6 April 2009

Accepted 11 April 2009

Available online $\mathrm{xxxx}$

\section{Keywords:}

Children

Adolescents

Temporal bbe epilepsy

Attention function

Executive functions

Neuropsychological battery

Wisconsin Card Sorting Test

\begin{abstract}
A B S T R A C T
The Wisconsin Card Sorting Test (WCST) is the gold standard in the evaluation of executive dysfunction (ED) in patients with temporal lobe epilepsy (TLE). We evaluated 35 children with TLE and 25 healthy controls with the WCST and with a more comprehensive battery. Among the children with TLE. 77.14\% showed impairment on the WCST. On other tests (Wechsler Intelligence Scale for Children-Digit Forward, Matching Familiar Figures Test, Trail Making Test, Word Fluency, Finger Windows, and NumberLetter Memory), impairment was demonstrated in $94.29 \%$. The authors concluded that the WCST is a good paradigm to measure executive impairment in children with TLE; however, it may be not enough. Evaluation performed only with the WCST not only underestimated the number of patients with ED, but also missed relevant information regarding the type of ED.
\end{abstract}

Q 2009 Elsevier Inc. All rights reserved.

\section{Introduction}

Despite several and distinct definitions of executive function, there is a consensus that it encompasses the ability to maintain an appropriate set to achieve a future goal [1]. Executive function represents a set of mechanisms by which performance is optimized in situations requiring the simultaneous operation of a number of different cognitive processes [2]. It involves strategic planning. impulse control, and organized search, as well as mental and action flexibility [3]. Moreover, it requires the ability to plan and sequence complex behaviors, to simultaneously attend to multiple sources of information, to resist distraction and interference, to inhibit inappropriate responses, and to sustain behavior for prolonged periods of time [4].

Several studies have used the Wisconsin Card Sorting Test (WCST) to measure executive dysfunction (ED), as this paradigm evaluates a wide range of abilities related to executive function, requiring strategic planning. organized searching. the ability to use environmental feedback to shift cognitive sets, goal-oriented behavior, and the ability to modulate impulsive response $[5,6]$.

\footnotetext{
- Corresponding author. Rua jesuíno Arruda, 901/51 Săo Paulo, SP Brasil ZIP 04532-082, Brazil. Fax: +551130795493.
}

E-mail address: kettevalenteđmsnoom (K.D.R. Valente).
For this reason, the WCST has been considered the gold standard test, being used by some authors as the only test to evaluate ED in patients with epilepsy [7-10]. Although the use of only one paradigm is tempting, especially in children who have a shorter attention span, it may lead to the underdiagnosis of ED. Other authors have used a comprehensive battery to assess the neuropsychological functioning of these patients [11-15], reinforcing the classic concept that executive functioning is a multidimensional construct and that there is no single measure to assess all processes contained under this rubric. Individuals may be impaired in some but not all functions in the executive and attentional domains.

There is robust evidence that adults with temporal lobe epilepsy (TLE) have ED $[7-9,11,12,16-19]$ characterized by perseverative responding and impairment in abstraction and problemsolving abilities $[8,9,11,18]$. In children with TLE, this issue remains controversial. Although some authors [9] have reported impairment of executive function in children with TLE, others have shown that children with TLE perform better than children with frontal lobe epilepsy $[13,14]$ and generalized epilepsy [14].

The few studies addressing executive function in childhood differ with respect to many methodological aspects such as number of paradigms, age range, sample size, and control groups. Igarashi et al. [9] used only the WCST to evaluate 19 children with TLE aged 7 to 20 years compared with healthy controls and patients with

1525-5050/\$ - see front matter $\$ 2009$ Elsevier Inc All rights reserved. doi:10.1016/jyebeh.2009.04.014

Please cite this article in press as: Rzezak $\mathbf{P}$ et al Executive dysfunction in children and adolescents with temporal lobe epilepsy: Is the Wisconsin Card Sorting Test enough?. Epilepsy Behav (2009), doi:10.1016/j.yebeh.2009.04.014 


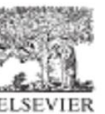

\section{Frontal Lobe Dysfunction in Children With Temporal Lobe Epilepsy}

Patrícia Rzezak, BSc*, Daniel Fuentes, $\mathrm{PhD}^{*}$, Catarina A. Guimarães, $\mathrm{PhD}^{\hat{p}}$, Sigride Thome-Souza, MD ${ }^{8 s}$, Evelyn Kuczynski, MD, PhD ${ }^{\S}$, Li M. Li, MD, PhD ${ }^{\uparrow}$, Renata C. Franzon, MD, $\mathrm{PhD}^{\dagger}$, Claudia C. Leite, $\mathrm{MD}, \mathrm{PhD}^{\mathrm{I}}$, Marilisa Guerreiro, $\mathrm{MD}, \mathrm{PhD}^{\uparrow}$, and Kette D. Valente, MD, $\mathrm{PhD}^{28}$

There is evidence that adults with temporal lobe epilepsy present executive impairments. However, there is limited information in children, especially when using a comprehensive neuropsychologic battery. We aimed to: 1) investigate the presence and severity of executive dysfunctions in children with temporal lobe epilepsy, and 2) determine the implications of elinical variables (including etiology) in the occurrence and severity of executive dysfunction, using eight paradigms. Thirty-one children with temporal lobe epilepsy were evaluated and compared with 21 age-matched controls. Patients with temporal lobe epilepsy had significantly worse performance than controls. Intragroup analysis indicated that patients with symptomatic epilepsy were more impaired than those with cryptogenic epilepsy. In the former group, patients with mesial lesions performed worse than those with lateral lesions. Regarding the severity of executive dysfunction, $83.87 \%$ manifested severe to moderate executive impairment. Early age of onset, longer duration of epilepsy, and use of polytherapy were correlated with worse executive dysfunction. These findings indicated the presence of frontal lobe dysfunction in children with temporal lobe epilepsy, with worse performance in those with mesial temporal lobe epilepsy, early onset, longer duration of disease, and use of polytherapy. Our study corroborates the hypothesis that temporal lobe epileptogenic activity affects the extratemporal regions that mediate attentional and executive functions. (1) 2007 by Elsevier Inc. All rights reserved.
Rzezak P, Fuentes D, Guimarães CA, Thome-Souza S, Kuczynski E, Li LM, Franzon RC, Leite CC, Guerreiro M, Valente KD. Frontal lobe dysfunction in children with temporal lobe epilepsy. Pediatr Neurol 2007;37:176-185.

\section{Introduction}

In temporal lobe epilepsy, the presence of specific cognitive deficits, such as learning and memory impairments (functions known to be associated with the temporal lobes), are fully recognized as part of the typical clinical picture [1-3].

In addition, some studies demonstrated the occurrence of frontal lobe dysfunction, characterized by executive malfunctioning, in adults with temporal lobe epilepsy. These patients show perseverative responding and impairments in abstraction and problem-solving abilities [4-7].

Two hypotheses were postulated to explain this executive dysfunction in patients with temporal lobe epilepsy. According to Corcoran and Upton [8], perseverative responding could be explained by an impairment of working memory, determined by the involvement of the hippocampus per se. In their study, patients with hippocampal sclerosis performed poorly in a modified version of the Wisconsin Card Sorting Test compared with patients with either temporal neocortical lesions or frontal lobe lesions. On the other hand, Hermann and Seidenberg [5] proposed that temporal lobe epileptogenic activity might disrupt the extratemporal lobe connections responsible for executive

Communications should be addressed to: Dr. Valente; Rua Jesuíno Arruda 901/51; São Paulo, $04532-082$ São Paulo, Brazil. E-mail: kettevalente@msn.com Received July 31, 2006; accepted May 25, 2007

Psychiatry. Clinical Hospital, Medical School, University of Så Paulo, Sấo Paulo, Brazil; ; 'Department of Neurology, University of Campinas, Campinas, Brazil; and "Laboratory of Clinical Neurophysiology, Institute of Psychiatry and Department of Psychiatry, "Project for the Study of Psychiatric Disorders in Children and Adolescents with Epilepsy, Institute of Psychiatry, and ${ }^{\boldsymbol{T}}$ Institute and Department of Radiology Clinical Hospital, Medical School,
University of São Paulo, São Paulo, Brazil. 
Anexo IV 80

\title{
Review Article
}

\begin{tabular}{|l|}
$\qquad \begin{array}{l}\text { Journal of } \\
\text { Epilepsy and } \\
\text { Clinical } \\
\text { Neurophysiology }\end{array}$ \\
J Epilepsy Clin Neurophysiol 2005; 11(3):131-136
\end{tabular}

\section{A Disfunção do Lobo Frontal em Crianças e Adolescentes com Epilepsia de Lobo Temporal e sua Possível Correlação com a Ocorrência de Transtornos Psiquiátricos}

\author{
Patricia Rzezak*, Daniel Fuentes*, Catarina A. Guimarāes**, Marilisa Guerreiro**, \\ Kette D. R. Valente $* * * *$
}

Laboratótio de Neurofisiologia, Instituto e Departamento de Poiquiatria - Hotpital das Clínicas/USP

RESUMO

Introdução: Hấ evidencias de que pessoas com alguns tipos de epilepsia podem apresentar prejufzos cognitivos, sendo que para alguns pacientes, tais deficits cognitivos podem ser mais debilitantes do que suas crises epilepticas. A disfunçáo do lobo frontal $e$ relatada em adultos com epilepsia do lobo temporal, caracterizada pela disfunção executiva. Objetivo: Rever a literatura sobre a ocorrencia de disfunção de lobo frontal em crianças e adolescentes com epilepsia do lobo temporal. Métodos: Revisão sistemática da literatura compulsada no PUBMED. Resultados: A disfunçāo do lobo frontal tem sido pouco estudada em crianças com epilepsia, em especial com epilepsia do lobo temporal. No único estudo sobre este assunto, demonstrouse que há um déficit executivo, sendo que as crianças com esclerose mesial têm maiores déficits de execução planejamento do que açuelas com lesōes neocorticais temporais ou frontais. A presença de uma disfunçāo do lobo frontal nos pacientes com epilepsia parcial e generalizada pode corroborar as evidencias de que epilepsia e transtorno psiquiátrico são epifenómenos e não fenómenos com relaçāo causa-efeito. Conclu-

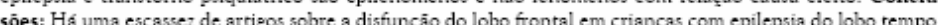
ral, sendo de interesse saber se esta ocorre e se pacientes com etiologias distintas apresentam diferentes graus de comprometimento destas funçōes.

Unitermos: epilepsia, crianças, lobo frontal, lobo temporal, transtornos psiquiátricos.

ABSTRACT

Frontal lobe disfunction in children and adolescents with temporal lobe epilepsy and possible correlation with psychiatric disorders

Introduction: There is evidence that individuals with certain types of epilepsy may present cognitive disorders, and that these disorders can be more debilitating than seizures proper. Frontal lobe disorders are reported in adults with temporal lobe epilepsy, carachterized by executive disfunction. Rationale: Literary revision of work concerning the occurence of frontal lobe dysfunction in children and adolescents with temporal lobe epilepsy. Methods: Systematic revision of published literature in PUBMED. Results: Frontal lobe dysfunction has been poorly studied in children with epilepsy, especially in temporal lobe epilepsy. In the only study on has been pootly studied in children with eptlepsy, espectally hin cemporal lobe epilepoy. The enly study on

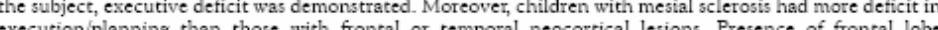
execution, dysfunction, in patienes with partial and generalized epilepsy, may corroborate evidence that epilepsy and psychiartic disorders are epiphenomena and not cause-effect related phenomena. Conclusion: There are few articles on frontal lobe dysfunction in children with temporal lobe epilepsy. It would be interesting to find out if, and how much this occurs, and if patients with distinct etiologies present different levels of functional disability.

Key words: epilepsy, children, frontal lobe, temporal lobe, psychiatric disorders.

* Unidade de Neuropticologia da Divisáo de Neurocirurgia Funcional do Inotituto de Ptiquiatria do HC.FMUSP. * Departame

*+4 Laboratório de Neurofiviologia - Projeto para Estudo dos Transtornos Poiquiátricos em Crianças e Adolevcentes com Epilepoia - Instituto e Departamento de Poiquiatria do Hoopital das Clínicas da Universidade de Sáo Paulo.

Received Feb 14, 2005; accepted Apr 25, 2005. 


\title{
Which factors may play a pivotal role on determining the type of psychiatric disorder in children and adolescents with epilepsy?
}

\author{
Sigride Thome-Souza ${ }^{a}$, Evelyn Kuczynski ${ }^{b}$, Francisco Assumpção Jr. ${ }^{b}$, Patricia Rzezak $^{c}$, \\ Daniel Fuentes, ${ }^{\mathrm{c}}$, Lia Fiore ${ }^{\mathrm{a}}$, Kette D. Valente ${ }^{\mathrm{a}, *}$ \\ ${ }^{2}$ Laboratory of Clinical Neurophysiology, Institute and Department of Psychiatry, Clinic's Hospital University of São Paulo (USP) \\ Medical School, São Paulo, Brazil \\ - Unit of Child Psychiatry, Institute and Department of Psychiatry. Clinic's Hospital University of Sío Paulo (USP) Medical Schaol Sĩo Paulo, Brazil \\ - Unit of Neuropsychology, Institute and Department of Psychiatry, Clonic's Hospital Univer suty of Sáo Paulo (USP) Medical School, Sáo Paulo, Brazil \\ Received 21 June 2004; revised 1 September 2004; accepted 4 September 2004
}

Abstract

Physicians have become aware of the high prevalence of psychiatric disorders (PDs) in children and adolescents with epilepsy; however, there are many controversies as to which factors may have an important role in the different types of PD. This study was designed to assess the main PD; verify the age of onset compared with the age of diagnosis of the PD; and determine which factors may be correlated with the type of PD described. For this purpose, a multidisciplinary team evaluated children and adolescents (4-18 years) with epilepsy and analyzed patient-related factors such as age (grouped according to Piaget's cognitive scale: $<6$ years, 7-13 years, >13 years), sex, family history of PDs, and cognitive status. With respect to epilepsy features, we considered age of onset, duration, seizure control at the time of psychiatric evaluation, refractoriness, antiepileptic drugs (mono- vs polytherapy), seizure type (generalized vs focal), and epilepsy type (idiopathic vs symptomatic/probably symptomatic). Depression occurred in $36.4 \%$ and attention-deficit hyperactivity disorder (ADHD) in $29.1 \%$, these being the most frequent PDs in this series. Focal epilepsy was significantly more frequent in children and adolescents with PDs. As to the type of PD, age was an important factor, with a predominance of ADHD in children and depression in adolescents $(P<0.0001)$. Family history was contributory for depression, but not for others PDs $(P<0,0001)$. Depression remained underdiagnosed and untreated for a longer period. Impact of early diagnosis and treatment remains unknown.

Q 2004 Elsevier Inc. All rights reserved.

Keywords: Epilepsy; Psychiatric disorders; Children; Adolescents; Behavior; Depression; Attention-deficit hyper activity disorder

\section{Introduction}

Interest in psychiatric disorders (PDs) in children with epilepsy is relatively new. On the other hand, psychosocial and behavioral consequences of epilepsy in childhood are extensively described [1-7].

Ounsted and Lindsay prospectively documented $[1,2]$ that children with epilepsy, although intellectually spared, have learning disabilities. Additionally, with re-

" Corresponding author. Fax: +55 1130795493.

E-mail address: kettevalente@msn.com (K.D. Valente). spect to psychosocial effects, children and adolescents with epilepsy have a tendency toward social isolation [1,4-7], which, according to Jensen and Vaernet [3], improves with seizure control after surgery, if this procedure is performed before adolescence.

In the past, PDs in epilepsy were considered a consequence of psychosocial disrupture and behavioral disorders, meaning an adaptive phenomenon to a chronic disease with an important stigma. Advances in the field of psychiatry have led to the belief that epilepsy and PDs are epiphenomena rather than cause-consequence factors [8-12]. The bilateral relationship between epilepsy

1525-5050/\$ - see front matter 2004 Elsevier Ine. All rights reserved. doi:10.1016j.yebeh.2004.09.001 


\section{Temporal Lobe Epilepsy in Childhood: Comprehensive Neuropsychological Assessment}

Catarina A. Guimarães, PhD, Li M. Li, MD, PhD, Patrícia Rzezak, BSc, Daniel Fuentes, PhD, Renata C. Franzon, MD, PhD, Maria Augusta Montenegro, MD, PhD, Fernando Cendes, MD, PhD, Sigride Thomé-Souza, MD, Kette Valente, MD, PhD, and Marilisa M. Guerreiro, MD, PhD

The neuropsychological features of children with temporal lobe epilepsy are not yet well defined. The aim of this study was to identify the neuropsychological deficits in children with temporal lobe epilepsy. We evaluated 25 patients and compared them with 25 normal children. All children underwent a comprehensive neuropsychological assessment. We found a significant difference in favor of the control group in the following measures IQ; forward digit; Trail Making Test for Children B; Wisconsin Card Sorting Test; block design; Boston naming test, verbal fluency; and Wide Range Assessment of Memory and Learning verbal learning, visual learning, verbal memory visual memory delayed recall of verbal learning, delayed recall of stories, and recognition of stories. Our findings show that children with temporal lobe epilepsy present with several neuropsychologica deficits, despite normal IQ. These findings point to a dysfunction of cerebral areas other than temporal lobe, particularly the frontal lobes.

Keywords: neuropsychology; epilepsy; temporal lobe epilepsy; memory; executive functions
A dults with temporal lobe epilepsy often present with cognitive deficits of memory and language. ${ }^{1,2}$ The classic model of material-specific memory supposes that a lesion in, or resection of, the hippocampus of the language-dominant hemisphere usually suggests a verbal memory disturbance, ${ }^{3,4}$ while damage of the nondominant hemisphere hippocampus may result in visual memory disturbance. ${ }^{5-9}$ More recent studies, however, have shown that memory deficits seem to be a common finding in patients with temporal lobe epilepsy, especially if the left temporal lobe or both temporal lobes are damaged. ${ }^{24,10.13}$ Those patients may also present with naming problems. ${ }^{1,2}$ In addition to memory and language deficits, executive dysfunction may be found in patients with temporal lobe epilepsy., ${ }^{4,1416}$

Temporal lobe epilepsy in childhood has a wide range of clinical-electroencephalographic presentation. ${ }^{17}$ In addi tion, the neuropsychological features in childhood tempora lobe epilepsy are not yet well defined. The relationship

From the Department of Neurology, State University of Campinas, Såo Paulo (CAG, LML, RCF, MAM, FC, MMG), and Institute of Psychiatry. University of Så Paulo (PR, DF, ST-S, KV), Brazil

Address corresponden ce to: Marilisa M. Guerreiro, MD, PhD, Department of Neurology-FCM-UNICAMP, PO Box 6111, 13083-970 Campinas, SP, Brazil; e-mail: mmg@fcm.unicamp.br.

Guimaraes CA, Li LM, Rzezak P, et al. Temporal lobe epilepsy in childhood: comprehensive neuropsychological assessment. J Child Neurol. $2007 ; 22: 836-840$ between the localization of the lesion and performance on memory tests is also not well established. ${ }^{18,19}$ Spectroscopy appears to provide a good correlation between unilateral temporal injury and specific cognitive verbal and nonverbal dysfunction. ${ }^{20}$ When compared with normal controls, children with temporal lobe epilepsy can show specific memory deficits according to the hemispheric specialization. ${ }^{21-24}$ This finding means that verbal memory is impaired in children with left temporal lobe epilepsy and visual memory is impaired in children with right temporal lobe epilepsy-a classic finding of memory dysfunction.

Other studies, however, found a poor visual memory performance when patients with right mesial temporal sclerosis were assessed, and no difference was detected when verbal tests were used on patients with left mesial temporal sclerosis. ${ }^{25,26}$ These findings are not in keeping with recent studies in adults, as higher sensitivity is found in verbal memory tests that usually assess left temporal lobe injury. ${ }^{2-4,10-12,27,28}$ Nevertheless, other studies found no deficit in specific memory. ${ }^{18,29-33}$

Language disturbance, IQ lower than controls, and deficits in executive functions have also been found in children with temporal lobe epilepsy. ${ }^{18,34,35}$ Considering the lack of clear-cut data about the neuropsychological profile of children with temporal lobe epilepsy, our aim was to identify the neuropsychological deficits in this population. 


\begin{tabular}{|l|}
\hline Journal of \\
Epilepsy and \\
Clinical \\
Neurophysiology
\end{tabular}

I Epilepsy Clin Neurophysiol 2006; 12(1 suppl. 1):22.25

\section{Memory Impairment in Children with Temporal Lobe Epilepsy: a Review}

Catarina A. Guimarães*, Li Li Min", Patrícia Rzezak"**, Daniel Fuentes"*, Renata C. Franzon*, Maria Augusta Montenegro*, Kette Valente*", Fernando Cendes*, Marilisa M. Guerreiro*

Depertment of Neurology, State University of Cempuneso - FCM/UNICAMP

\section{ABSTRACT}

Introduction: The authors present a review arcicle on memory aspects of temporal lobe epilepsy in childhood. Methods: We performed a search in the literature. Results: Temporal lobe epilepsy (TLE) in childhood present with great clinical, electroencephalographic and eriological diversity. The neuropsychological features in children with TLE are not well-defined yet. The relationship berween the laceralization of the lesion and performance on memory tests is not established. Conclusion: The studies performed in children with TLE show controversy data. This finding may be due to the etiological, clinical and electroencephalographic diversity seen in such group of children. Besides, most studies use different assessments. Therefore, it is clear that more studies are necessary to elucidace which neuropsychological deficits occur in children with TLE.

Key words childhood, temporal lobe epilepsy, memory, neuropsychological assessment.

\section{RESUMO}

Dano de memória em crianças cam epilepsia do lobo temporal: uma revisáo

Introduçăo: Os autores apresentam um artigo de revisāo sobre memória em epilepsia de lobo temporal na infância. Método: Realizou-se levantamento bibliográfico sobre $o$ assunto, acrescido de contribuiços pes soais. Resultados: Epilepsia de lobo temporal (ELT) na infância apresenta grande diversidade clínica, etiológica e eletrencefalográfica. As características neuropsicológicas de crianças com. ELT ainda nāo estáo claramente definidas. A relação entre lateralização da lesāo e desempenho na realização dos testes também näo está totalmente elucidada. Conclusão: Na infância, os resultados dos estudos em ELT em relaçâo aos déficits de memória são controversos. Isso pode estar relacionado à diversidade clínica, etiológica e elerrencefalográfica existente. Além disso, a forma de avaliaçāo entre os estudos é muito variảvel havendo diferenças quanto à natureza dos testes utilizados. Assim, fica claro que mais estudos sào necessários pars elucidar o perfil neuropsicológico das srianças com ELT.

Palavras-chave: infância, epilepsia de lobo temporal, memória, avaliação neuropsicológica.

\begin{abstract}
Neuropsychological deficits may occur in adulc patients with temporal lobe epilepsy (TLE), particularly when mesial strucrures are damaged. These patiencs usually have specific cognitive impairment, mainly related to memory. If damage involves the hippocampus of the dominant hemisphere for language, patients may present
\end{abstract}

with verbal memory impairment ${ }^{(1-2)}$, while damage to the hippocampus of the nondominant hemisphere may result in visual memory impairment ${ }^{(3.5)}$.

In adults, there is a clear-cut relationship between hippocampal injury and memory impaiment in patients with left TLE. In patients with right TLE, this relationship

- Department of Neurology - State University of Campinas - FCM/UNICAMP

*+ Institute of Povehiatry University of Säo Paulo - FMUSP

Received Nar. 28, 2005. accepted Dec. 16, 2005 
1. Adams CBT, Beardsworth ED, Oxbury SM, Oxbury JM, Fenwick PB. Temporal lobectomy in 44 children: outcome and neuropsychological follow-up. J Epilepsy 1990; 3 Suppl: 157-68.

2. Almeida Filho N. Epidemiologia social das epilepsias no Brasil. In: Sena PG, editor. Novas achegas sobre a epilepsia. Salvador: UFBA, Centro Editorial e Didático; 1980. p. 57-76.

3. Almeida Filho N. Epidemiologia das desordens mentais da infância no Brasil. Salvador: Centro Editorial e Didático da Universidade Federal da Bahia; 1985.

4. American Psychiatric Association. Diagnostic and statistical manual of mental disorders. 4th. ed. (DSM - IV-TR). Washington: American Psychiatric Association; 2002.

5. Akanuma N, Alarcón G, Lum F, Kissani N, Koutroumanidis M, Adachi N, et al. Lateralising value of neuropsychological protocols for presurgical assessment of temporal lobe epilepsy. Epilepsia. 2003;44:408-18.

6. Arzimanoglou A. Temporal lobe epilepsy in children and cognitive dysfunction: comprehensive methodologies for a comprehensive research and care. In: Arzimanoglou A, Aldenkamp A, Cross H, Schmitz B, Lassonde M, Moshé SL. Cognitive dysfunction in children with temporal lobe epilepsy. Montrouge: Editions John Libbey Eurotext; 2005. p. 275-89.

7. Arzimanoglou A, Guerrini R, Aicardi J. Aicardi's epilepsy in children. Philadelphia: Lippicott Williams \& Wilkins; 2004.

8. Babb TL e Brown WJ. Neuronal, dendritic, and vascular profiles of human temporal lobe epilepsy correlated with cellular physiology in vivo. Adv Neurol. $1986 ; 44: 949-66$.

9. Bachevalier J, Mishkin M. Visual recognition impairment follows ventromedial but not dorsolateral prefrontal lesions in monkeys. Behav Brain Res. 1986;20:249-61.

10. Baddeley AD. Working memory. Oxford: Oxford University Press; 1986.

11. Begley CE, Annegers JF, Lairson DR, Reynolds TF, Hauser WA. Cost of epilepsy in the United States: a model based on incidence and prognosis. Epilepsia. $1994 ; 35: 1230-43$ 
12. Begley CE, Famulari M, Annegers JF, Lairson DR, Reynolds TF, Coan S, et al. The cost of epilepsy in the United States: an estimate from population-based clinical and survey data. Epilepsia. 2000;41:342-51.

13. Bell BD, Davies KG. Anterior temporal lobectomy, hippocampal sclerosis, and memory: recent neuropsychological findings. Neuropsychol Rev. 1998; 8:25-41.

14. Bellgowan PS, Binder JR, Swason SJ, Hammeke TA, Springer JA, Frost JA, et al. Side of seizure focus predicts left medial temporal lobe activation during verbal encoding. Neurology. 1998; 51:479-84.

15. Bernasconi N, Bernasconi A, Caramanos Z, Antel SB, Andermann F, Arnold DL. Mesial temporal damage in temporal lobe epilepsy: a volumetric MRI study of the hippocampus, amygdala, and parahippocampal region. Brain. 2003; 126:462-9.

16. Bernasconi N, Duchesne S, Janke A, Lerch J, Collins DL, Bernasconi A. Wholebrain voxel-based statistical analysis of gray matter and white matter in temporal lobe epilepsy. Neuroimage. 2004;23: 717-23.

17. Blume WT, Girvin JP, McLachlan RS, Gilmore BE. Effective temporal lobectomy in childhood without invasive EEG. Epilepsia. 1997; 38: 164-7.

18. Blume WT. Diagnosis and management of epilepsy. CMAJ . 2003; 168:441-8.

19. Borges MA, Barros EP, Zanetta DM, Borges AP. Prevalência da epilepsia entre os índios bakairis do estado do Mato Grosso, Brasil. Arq Neuropsiquiatr. 2002;60:805.

20. Briellmann RS, Berkovic SF, Syngeniotis A, King MA, Jackson GD. Seizureassociated hippocampal volume loss: a longitudinal magnetic resonance study of temporal lobe epilepsy. Ann Neurol. 2002; 51:641-4.

21. Bryson G, Whelan HA, Bell M. Memory and executive function impairments in deficit syndrome schizophrenia. Psychiatry Res. 2001; 102:29-37.

22. Brockhaus A, Elger CE. Complex partial seizures of temporal lobe origin in children of different age groups. Epilepsia. 1995; 36:1173-81.

23. Burgerman RS, Sperling MR, French JA, Savkin AJ, O'Connor MJ. Comparison of mesial versus neocortical onset temporal lobe seizure: neurodiagnostic findings and surgical outcome. Epilepsia. 1995; 36:662-70. 
24. Cairns ED, Cammock J. Development of a more reliable version of Matching Familiar Figures Test. Dev Psychol. 1978; 13: 555-60.

25. Capilla A, Romero C, Maestu F, Campo P, Fernandez S, Gonzalez-Marques J, et al. Emergence and brain development of executive functions. Actas Esp Psiquiatr. $2004 ; 32: 377-86$.

26. Cendes F, Kobayashi E. Epilepsia do Lobo Temporal. In: Guerreiro CAM. Epilepsia. Campinas: Lemos Editorial; 2000. p. 201-13.

27. Cheung $\mathrm{M}$, Chang AS. Memory impairment in humans after bilateral damage to lateral temporal neocortex. Neuroreport. 2003; 14:371-4.

28. Cheung MC, Chan AS, Chan YL, Lam JM, Lam W. Effects of illness on memory processing of patients with TLE. Epilepsia. 2006;47: 1320-8.

29. Conboy JE. Algumas medidas típicas univariadas da magnitude do efeito. Aná Psicológica. 2003;2:145-58.

30. Clusmann H, Kral T, Fackeldey E, Blümcke I, Helmstaedter C, von Oertzen J, et al. Lesional mesial temporal lobe epilepsy and limited resections: prognostic factors and outcome. J Neurol Neurosurg Psychiatry. 2004; 75: 1589-96.

31. Corcoran R, Upton D. A role for the hippocampus in card sorting? Cortex. 1993;29:293-304.

32. Cormack F, Cross JH, Isaacs E, Harkness W, Wright I, Vargha-Khadem F, et al. The Development of Intellectual Abilities in Pediatric Temporal Lobe Epilepsy. Epilepsia. 2007;48:201-4.

33. Cronel-Ohayon S, Zesiger P, Davidoff V, Boni A, Roulet E, Deonna T. Deficit in memory consolidation (abnormal forgetting rate) in childhood temporal lobe epilepsy. Pre and postoperative long-term observation. Neuropediatrics. $2006 ; 37: 317-24$.

34. Culhane-Shelburne K, Chapieski L, Hiscock M, Glaze D. Executive functions in children with frontal and temporal lobe epilepsy. JINS. 2002;8:623-32.

35. Cunningham JM, Pliskin NH, Cassisi JE, Tsang B, Rao SM. Relationship between confabulation and measures of memory and executive function. J Clin Exp Neuropsychol. 1997; 19:867-77. 
36. Damasio A. O erro de Descartes. Emoção, razão e o cérebro humano. São Paulo: Companhia das Letras; 1996.

37. Davidson S, Falconer MA. Outcome of surgery in 40 children with temporal lobe epilepsy. Lancet. 1975; 1:1260-3.

38. Delazer M, Gasperi A, Bartha L, Trinka E, Benke T. Number processing in temporal lobe epilepsy. J Neurol Neurosurg Psychiatry. 2004; 75:901-3.

39. Delaney RC, Rosen AJ, Mattson RH, Novelly RA. Memory function in focal epilepsy: a comparison of non-surgical, unilateral temporal lobe and frontal lobe samples. Cortex. 1980; 16: 103-17.

40. Delgado-Escueta AV, Bacsal FE, Treiman DM. Complex partial seizures on closedcircuit television and EEG: a study of 691 attacks in 79 patients. Ann Neurol. $1982 ; 11: 292-300$.

41. Detre JA, Maccotta L, King D, Alsop DC, Glosser G, D'Esposito M, et al. Functional MRI lateralization of memory in temporal lobe epilepsy. Neurology. 1998;50:92632.

42. Devinsky O, Morrel MJ, Vogt BA. Contributions of anterior cingulated cortex to behavior. Brain. 1995; 118:279-306.

43. Doval O, Gavira M, Kanner AM. Frontal lobe dysfunction in epilepsy. In: Ettinger $A B$, Kanner AM. Psychiatric issues in epilepsy - a practical guide to diagnosis and treatment. Filadélfia: Lippicott Williams \& Wilkins; 2001. p. 261-71.

44. Duchowny M, Levin B, Jayakar P, Resnick T, Alvarez L, Morrison G, et al. Temporal lobectomy in early childhood. Epilepsia. 1992; 33:298-303.

45. Duchowny M, Jayakar P, Resnick T, Harvey AS, Alvarez L, Dean P, et al. Epilepsy surgery in the first three years of life. Epilepsia. 1998; 39: 737-43.

46. Dupont S, Semah F, Boon P, Saint-Hilaire JM, Adam C, Broglin G, et al. Association of ipsilateral motor automatisms and contralateral dystonic posturing: a clinical feature differentiating medial from neocortical temporal lobe epilepsy. Arch Neurol. 1999; 56:927-32.

47. Dupont S, Van de Moortele PF, Samson S, Hasboun D, Poline JB, Adam C, et al. Episodic memory in left temporal lobe epilepsy: a functional MRI study. Brain 2000; 123: 1722-32. 
48. Duvernoy HM. The human hippocampus. Berlin: Springer; 1998.

49. Elger CE, Helmstaedter C, Kurthen M. Epilepsy and cognition. Lancet Neurol. $2004 ; 3: 663-72$.

50. Engel J. Introduction to temporal lobe epilepsy. Epilepsy Res. 1996;26: 141-50.

51. ____-_. Mesial temporal lobe epilepsy: what have we learned? Neuroscientist. $2001 ; 7: 340-52$.

52. Erickson JC, Clapp LE, Ford G, Jabbari B. Somatosensory auras in refractory temporal lobe epilepsy. Epilepsia. 2006;47:202-6.

53. Fastenau PS, Shen J, Dunn DW, Perkins SM, Hermann BP, Austin JK. Neuropsychological predictors of academic underachievement in pediatric epilepsy: moderating roles of demographic, seizure, and psychosocial variables. Epilepsia. 2004; 45: 1261-72.

54. Fernandes JG, Schimidt MI, Monte TL, Tozzi S, Sander JW. Prevalence of epilepsy: the Por to Alegre study. Epilepsia. 1992; 33(Suppl 3):S132.

55. Fish DR. The role of scalp electroencephalography in presurgical evaluation. In: Shorvon S et al. The treatment of epilepsy. London: Blackwell Science; 1996. p. 542-61.

56. Fossati P, Amar G, Raoux N, Ergis AM, Allilaire JF. Executive functioning and verbal memory in young patients with unipolar depression and schizophrenia. Psychiatry Res. 1999;89:171-87.

57. Fuerst D, Shah J, Shah A, Watson C. Hippocampal sclerosis is a progressive disorder: a longitudinal volumetric MRI study. Ann Neurol. 2003;53:413-6.

58. Gazzaniga MS, Ivry RB, Mangun GR. As funções executivas e os lobos frontais. In: Rosat RM. Neurociência cognitiva. 2 ed. São Paulo: Artmed; 2008. p. 517-54.

59. Gil R. Distúrbios de Memória. In: Gil R. Neuropsicologia. São Paulo: Livraria Santos Editora Ltda.; 2003. p. 171-96.

60. Gioia GA, Isquith PK, Retzlaff PD, Espy KA. Confirmatory factor analysis of Behavior Rating Inventory of Executive Function (BRIEF) in a clinical sample. Child Neuropsychol. 2002; 8:249-57. 
61. Gohier B, Ferracci L, Surguladze SA, Lawrence E, El Hage W, Kefi MZ, et al. Cognitive inhibition and working memory in unipolar depression. J Affect Disord. 2009; 116: 100-5.

62. Golby AJ, Poldrack RA, Illes J, Chen D, Desmond JE, Gabrieli JD. Memory lateralization in medial temporal lobe epilepsy assessed by functional MRI. Epilepsia. 2002; 43:855-63.

63. Goldberg E. The executive brain. Frontal lobes and the civilized mind. New York: Oxford University Press; 2001.

64. Golden CJ. The Luria-Nebraska children's battery: theory and formulation. In: Hynd GW and Obrzut JE. Neuropsychological assessment and the school-age children. New York: Grune \& Stratton; 1981. p.277-302.

65. Goldstein B, Obrzut JE, John C, Ledakis G, Armstrong CL. The impact of frontal and non-frontal brain tumor lesions on Wisconsin Card Sorting Test performance. Brain Cogn. 2004; 54: 110-6.

66. Goldman PS. An alternative to developmental plasticity: heterology of CNS in infants and adults. In: Stein D, Rosen J, Butters N. Plasticity and recovery of function in the central nervous system. New York: Academic Press; 1974. p. 14974.

67. Gomes MM. Epidemiologia: distribuição, fatores de risco e considerações prognósticas. In: Guerreiro CAM, Guerreiro MM, Cendes F, Cendes IL, editors. Epilepsia. São Paulo: Editora Lemos; 2000. p. 11-21.

68. Gonzalez LM, Anderson VA, Wood SJ, Mitchell LA, Harvey AS. The localization and lateralization of memory deficits in children with temporal lobe epilepsy. Epilepsia. $2007 ; 48: 124-32$.

69. Guimarães CA, Li LM, Rzezak P, Fuentes D, Franzon RC, Augusta Montenegro M, et al. Temporal lobe epilepsy in childhood: comprehensive neuropsychological assessment. J Child Neurol. 2007; 22:836-40.

70. Guimarães CA, Rzezak P, Fuentes D, Franzon RC, Montenegro MA, Cendes F, et al. Memory in Children with Temporal Lobe Epilepsy. J Child Neurol. submitted 
71. Grammaldo LG, Giampà T, Quarato PP, Picardi A, Mascia A, Sparano A, et al. Lateralizing value of memory tests in drug-resistant temporal lobe epilepsy. Eur J Neurol. 2006; 13:371-6.

72. Grattan LM e Eslinger PL. Frontal lobe damage in children and adults: a comparative review. Dev Neuropsychol. 1991; 7:283-326.

73. Heaton RK, Chelune GJ, Talley JL, Kay G, Curtiss G. Wisconsin card sorting Test Manual - revised and expanded. Psychological Assessment Resource. São Paulo: Casa do Psicólogo; 1993.

74. Helmstaedter C, Kurthen M. Memory and epilepsy: characteristics, course, and influence of drugs and surgery. Curr Opin Neurol. 2001;14:211-6.

75. Helmstaedter C. Effects of chronic epilepsy on declarative memory systems. Prog Brain Res. 2002; 135:439-53.

76. _-_-_-_ Effects of chronic temporal lobe epilepsy on memory functions. In: Arzimanoglou A, Aldenkamp A, Cross $\mathrm{H}$ et al. Cognitive dysfunction in children with temporal lobe epilepsy. Montrouge: Editions John Libbey Eurotext;2005. p. 13-30.

77. Helmstaedter C e Kockelmann E. Cognitive outcomes in patients with chronic TLE. Epilepsia. 2006; 47:96-8.

78. Hessen E, Lossius MI, Reinvang I, Gjerstad L. Predictors of neuropsychological impairment in seizure-free epilepsy patients. Epilepsia. 2006;47:1870-8.

79. Hermann BP, Wyler AR, Ritchie ET. Wisconsin Card Sorting Test performance in patients with complex partial seizures of temporal lobe origin. J Clin Neuropsychol. $1988 ; 10: 467-76$.

80. Hermann BP, Seidenberg M. Executive system dysfunction in temporal lobe epilepsy: effects of nociferous cortex versus hippocampal pathology. J Clin Exp Neuropsychol. 1995; 17:809-19.

81. Hermann B, Seidenberg M, Bell B, Rutecki P, Sheth RD, Wendt G, et al. Extratemporal quantitative MRI volumetrics and neuropsychological function in temporal lobe epilepsy. JINS. 2003; 9:353-62. 
82. Hermann B, Seidenberg M, Bell B, Rutecki P, Sheth R, Ruggles K, et al. The neurodevelopment impact of childhood onset Temporal Lobe Epilepsy on brain structure and function. Epilepsia. 2002;43: 1062-71.

83. Hermann B, Seidenberg M, Lee EJ, Chan F, Rutecki P. Cognitive phenotypes in temporal lobe epilepsy. JINS. 2007; 13:12-20.

84. Hernandez MT, Sauerwein HC, Jambaqué I, De Guise E, Lussier F, Lortie A, et al. Deficits in executive functions and motor coordination in children with frontal lobe epilepsy. Neuropsychologia. 2002; 40: 384- 400.

85. Hopkins IJ, Klug GL. Temporal lobectomy for the treatment of intractable complex partial seizures of temporal lobe origin in early childhood. Dev Med Child Neurol. $1991 ; 33: 26-31$.

86. Horner MD, Flashman LA, Freides D. Focal epilepsy and the Wisconsin Card Sorting Test. J Clin Exp Neuropsychol. 1989;11:74.

87. Igarashi $\mathrm{K}$ e Kato $\mathrm{M}$. Developmental change in working memory. In: Osaka $\mathrm{N}$. Brain and working memory. Kyoto: Kyoto University Press; 2000. p. 299-308.

88. Igarashi K, Oguni H, Osawa M, Awaya Y, Kato M, Mimura M, et al. Wisconsin Card Sorting Test in children with Temporal Lobe Epilepsy. Brain Develop. $2002 ; 24: 174-8$.

89. ILAE - Commission on Classification and Terminology of the International League Against Epilepsy. Proposal for Revised Classification of Epilepsy and Epileptic Syndrome. Epilepsia. 1989; 30: 389-99.

90. ILAE- Diagnosis. Clinical Neuropsychology: Cognitive Function in Epilepsy. Epilepsia. 2003; 44:29-30.

91. Jackspn GD, Berkovic SF, Duncan JS, Connelly A. Optimizing diagnosis of hippocampal sclerosis using MR imaging. AJ NR. 1993;14: 753-62.

92. Jambaqué I, Dellatolas G, Dulac O, Ponsot G, Signoret JL. Verbal and visual memory impairment in children with epilepsy. Neuropsychologia. 1993; 31:132137.

93. Janszky J, Rásonyi G, Clemens Z, Schulz R, Hoppe M, Barsi P, et al. Clinical differences in patients with unilateral hippocampal sclerosis and unitemporal or bitemporal epileptiform discharges. Seizure. 2003; 12: 550-4. 
94. Jokeit H, Ebner A. Effects of chronic epilepsy on intellectual functions. Prog Brain Res. 2002; 135: 455-63.

95. Jorge CL. Epilepsia com esclerose mesial temporal: aspectos clínicos e fisiopatológicos. BJECN 1996;2:215-27.

96. Kahane P, Arzimanoglou A, Bureau M, Toger J. Non-idiophatic focal epilepsies in children. In: Roger J, Bureau M, Dravet C et al. Epileptic syndromes in childhood and adolescence. 4th ed. Paris: John Libbey Eurotext; 2005.

97. Keiski M, Fuerst D, Shah A, Shah J, Watson G. Executive functions in temporal lobe epilepsy: relationship to disease variables. Poster apresentado no $60^{\text {th }}$ American Epilepsy Society Meeting - San Diego, CA em Dezembro de 2006.

98. Kim H, Yi S, Son El, Kim J. Material- Specific Memory in Temporal Lobe Epilepsy: Effects of seizure Laterality and Language Dominance. Neuropsychology. 2003; 17:59-68.

99. Kotagal P. Psychomotor seizures: clinical and EEG findings. In: Wyllie E. The treatment of Epilepsy: principles and practices. Philadelphia: Lea \& Febiger; 1993. p. $378-92$.

100. Lagae L. Cognitive side effects of anti-epileptic drugs. The relevance in childhood epilepsy. Seizure. 2006;15:235-41.

101. Lah S, Grayson S, Lee T, Miller L. Memory for the past after temporal lobectomy: impact of epilepsy and cognitive variables. Neuropsychologia. 2004;42:1666-79.

102. Lassonde M, Sauerwein HC, Jambaqué I, Smith ML, Helmstaedter C. Neuropsychology of childhood epilepsy: pre- and postsurgical assessment. Epileptic Disord. 2000;2:3-13.

103. Laurent A e Arzimanoglou A. Cognitive Impairments in Children with Nonidiopathic Temporal Lobe Epilepsy. Epilepsia. 2006;47: 99-102.

104. Leite JP, Neder L, Arisi GM, Carlotti CG, Assirati JA, Moreira JE. Plasticity, synaptic strength, and epilepsy: what can we learn from ultrastructural data? Epilepsia. 2005; 46: 134-41.

105. Lendt M, Helmstaedter C, Elger CE. Pre- and postoperative neuropsychological profiles in children and adolescents with temporal lobe epilepsy. Epilepsia. 1999; 40: 1543-50. 
106. Lezak MD. Neuropsychological Assessment. 7 ed. Nova York: Oxford University Press; 1995.

107. Lespinet V, Bresson C, N'Kaoua B, Rougier A, Claverie B. Effect of age of onset of temporal lobe epilepsy on the severity and the nature of preoperative memory deficits. Neuropsychologia. 2002;40: 1591-1600.

108. Lieb J P, Dasheiff RM, Engel J. Role of the frontal lobes in the propagation of mesial temporal lobes seizures. Epilepsia. 1991;32:822-37.

109. Li SC, Schoenberg BS, Wang CC, Cheng XM, Zhou SS, Bolis CL. Epidemiology of epilepsy in urban areas of the People's Republic of China. Epilepsia. 1985;26:3914.

110. Lieb JP, Walsh GO, Babb TL. A comparison of EEG seizure patterns recorded with surface and depth electrodes in patients with temporal lobe epilepsy. Epilepsia. $1976 ; 12: 137-60$.

111. Lindsay J, Glaser G, Richards P, Ounsted C. Developmental aspects of focal epilepsies of childhood treated by neurosurgery. Dev Med Child Neurol. $1984 ; 26: 574-87$.

112. Liu RS, Lemieux L, Bell GS, Hammers A, Sisodiya SM, Bartlett PA, et al. Progressive neocortical damage in epilepsy. Ann Neurol. 2003;53:312-24.

113. López-Góngora M, Martínez-Domeño A, García C, Escartín A. Effect of levetiracetam on cognitive functions and quality of life: a one-year follow-up study. Epileptic Disord. 2008; 10:297-305.

114. Loring DW, Strauss E, Hermann BP, Barr WB, Perrine K, Trenerry MR, et al. Differential neuropsychological test sensitivity to left temporal lobe epilepsy. JINS. $2008 ; 14: 394-400$.

115. Luria AR. Fundamentos da Neuropsicologia. Rio de Janeiro: Editora da USP; 1984.

116. Manford M, Fish DR, Shorvon SD. An analysis of clinical seizure patterns and their localizing value in frontal and temporal lobe epilepsies. Brain. 1996; 119(Pt 1):1740.

117. Mangels JA, Craik FIM, Levine B, Schwartz ML, Stuss DT. Effects of divided attention on episodic memory in chronic traumatic brain injury: a function of severity and strategy. Neuropsychologia. 2002;40:2369-85. 
118. Marino Jr. R, Cukiert A, Pinho E. Aspectos epidemiológicos da epilepsia em São Paulo. Um estudo da prevalência. Arq Neuropsiquiatr. 1986;44:243-54.

119. Marsh L, Morrell MJ, Shear PK, et al. Cortical and hippocampal volume deficits in temporal lobe epilepsy. Epilepsia. 1997;38: 576-87.

120. Martin JH. Neuroanatomy - text and atlas. 3rd. ed. New York: McGraw-Hill; 2003.

121. Martin RC, Sawrie SM, Gilliam FG, Palmer CA, Faught E, Morawetz RB, et al. Wisconsin Card Sorting performance in patients with Temporal Lobe Epilepsy: clinical and neuroanatomical correlates. Epilepsia. 2000;41:1626-32.

122. Maton B, Jayakar P, Resnick T, Morrison G, Ragheb J, Duchowny M. Surgery for medically intractable temporal lobe epilepsy during early life. Epilepsia. 2008; 49:80-7.

123. Meador KM. Cognitive and memory effects of the new antiepileptic drugs. Epilepsy Res. 2006;68:63-6.

124. Meletti S, Benuzzi F, Rubboli G, Cantalupo G, Stanzani Maserati M, Nichelli P, et al. Impaired facial emotion recognition in early-onset right mesial temporal lobe epilepsy. Neurology. 2003;60:426-31.

125. Meyer SE, Carlson GA, Wiggs EA. A prospective study of the association among impaired executive functioning, childhood attentional problems, and development of bipolar disorder. Dev Psychopathol. 2004; 16:461-76.

126. Mitchell WG, Chavez JM, Lee H, Guzman BL. Academic underachievement in children with epilepsy. J Child Neurol. 1991;6:65-72.

127. Minotti L, Kahane P, Tassi L, Lo Russo G, Sivelle G, Joannard A, et al. Peut-on simplifier les investigations préchirurgicales chez l'enfant? In: Bureau M, Kahane P, Munari C. Epilepsies partielles graves pharmaco-résistantes de l'enfant: stratégies diagnostiques et traitements chirurgicaux. Montrouge: Johm Libbey Eurotext; 1998. p. 181-94.

128. Mizrahi EM, Kellaway P, Grossman RG, Rutecki PA, Armstrong D, Retting G, et al. Anterior temporal lobectomy and medically refractory temporal lobe epilepsy of childhood. Epilepsia. 1990; 3:302-12. 
129. Mohamed A, Wyllie E, Ruggieri P, Kotagal P, Babb T, Hilbig A, et al. Temporal lobe epilepsy due to hippocampal sclerosis in pediatric candidates for epilepsy surgery. Neurology. 2001;56:1643-9.

130. Moscovitch M. A neuropsychological model of memory and consciousness. In: Squire LR e Butters N. Neuropsychological of memory. 2nd ed. New York: Guilford Press; 1992.

131. Mueller SG, Laxer K, Cashdollar N, Buckley, Paul C, Weiner MW. Voxel-based Optimized Morphometry (VBM) of Gray and White Matter in Temporal Lobe Epilepsy (TLE) with and without Mesial Temporal Sclerosis. Epilepsia. 2006; 47:900-7.

132. Nelissen N, Van Paesschen W, Baete K, Van Laere K, Palmini A, Van Billoen H, et al. Correlations of interictal FDF-PET metabolism and octal SPECT perfusion changes in human temporal lobe epilepsy with hippocampal sclerosis. Neuroimage. 2006; 32:684-95.

133. Nolan MA, Redoblado MA, Lah S, Sabaz M, Lawson JA, Cunningham AM, et al. Memory function in childhood epilepsy syndromes. J Paediatr Child Health. 2004; 40:20-7.

134. Noronha AL, Borges MA, Marques LH, Zanetta DM, Fernandes PT, de Boer H, Espíndola J, Miranda CT, Prilipko L, Bell GS, Sander JW, Li LM. Prevalence and pattern of epilepsy treatment in different socioeconomic classes in Brazil. Epilepsia. 2007;48:880-5.

135. O’Brien TJ, Kilpatrick C, Murrie V, Vogrin S, Morris K, Cook MJ. Temporal lobe epilepsy caused by mesial temporal sclerosis and temporal neocortical lesions. Brain. 1996; 119:133-41.

136. Orozco-Giménez C, Verdejo-García A, Sánchez-Alvarez JC, Altuzarra-Corral A, Pérez-García M. Clinical neuropsychology of the surgery of temporal lobe epilepsy. Rev Neuro. 2002; 35: 1116-35.

137. Ottman R, Winawer MR, Kalachikov S, Barker-Cummings, C, Gilliam TC, Pedley TA, et al. LGI1 mutations in autossomal dominant partial epilepsy with auditory features. Neurology. 2004; 62: 1120-6. 
138. Oyegbile TO, Dow C, Jones J, Bell B, Rutecki P, Sheth R, et al. The nature and course of neuropsychological morbidity in chronic Temporal Lobe Epilepsy. Neurology. 2004;62:1736-42.

139. Pacia SV, Devinsky O, Perrine K, Raydin L, Luciano D, Vazquez B, et al. Clinical features of neocortical temporal lobe epilepsy. Ann Neurol. 1996;40:724-30.

140. Placencia M, Shorvon SD, Paredes V, Bimos C, Sander JW, Suarez J, et al. Epileptic seizures in an Andean region of Ecuador. Incidence and prevalence and regional variation. Brain. 1992;115(Pt3):771-82.

141. Powell HW, Koepp MJ, Richardson MP, Symms MR, Thompson PJ, Duncan JS. The application of functional MRI of memory in temporal lobe epilepsy: a clinical review. Epilepsia. 2004; 45: 855-63.

142. Raffard S, Bayard S, Gely-Nargeot MC, Capdevielle D, Maggi M, Barbotte E, et al. Insight and executive functioning in schizophrenia: a multidimensional approach. Psychiatry Res. 2009;167:239-50.

143. Richardson MP, Strange BA, Duncan JS, Dolan RJ. Preserved verbal memory function in left medial temporal pathology involves reorganization of function to right medial temporal lobe. Neuroimage. 2003;20:S112-S119.

144. Riva D, et al. Memory disturbance in early hippocampal pathology. In: Avanzini G et al. Limbic seizures in Children. Milão: John Libbey; 2001. p. 167-74.

145. Romine CB, Lee D, Wolfe ME, Homack S, George C, Riccio CA. Wisconsin Card Sorting Test with children: a meta-analytic study of sensitivity and specificity. Arch Clin Neuropsychol. 2004; 19: 1027-41.

146. Rosene DL, Van Hoesen GW. Hippocampal efferents reach widespread areas of cerebral cortex and amygdala in the rhesus monkey. Science. 1977;198:315-7.

147. Rzezak P, Fuentes D, Guimarães CA, Thome-Souza S, Kuczynski E, Li LM, et al. Frontal lobe dysfunction in children with temporal lobe epilepsy. Pediatr Neurol. 2007; 37: 176-85.

148. Rzezak P, Fuentes D, Guimarães CA, Thome-Souza S, Kuczynski E, Guerreiro M, et al. Executive Dysfunction in Children and Adolescents with Temporal Lobe Epilepsy: Is Wisconsin Card Sorting Test Enough? Epilepsy Behav. 2009 May 10. [Epub ahead of print]. 
149. Sauerwein HC, Gallagher A, Lassonde M. Neuropsychological deficits in children with temporal lobe epilepsy. In: Arzimanoglou A, Aldenkamp A, Cross $\mathrm{H}$ et al. Cognitive dysfunction in children with temporal lobe epilepsy. Montrouge: Éditions John Libbey Eurotext; 2005. p. 1-12.

150. Saygi S, Spencer SS, Schever R, Katz A, Mattson R, Spencer DD. Differentiation of temporal lobe ictal behavior associated with hippocampal sclerosis and tumors of temporal lobe. Epilepsia. 1994; 35:737-42.

151. Schouten A, Oostrom KJ, Pestman WR, Peters AC, Jennekens-Schinkel A, Dutch Study Group of Epilepsy in Childhood. Learning and memory of school children with epilepsy: a prospective controlled longitudinal study. Dev Med Child Neurol. 2002; 44:803-11.

152. Shamim S, Hasler G, Liew C, Sato S, Theodore WH. Temporal lobe epilepsy, depression, and hippocampal volume. Epilepsia. 2008. [Epub ahead of print]

153. Sheibel AB. Are complex partial seizures a sequela of temporal lobe digenesis? In: Smith D, et al. Advances in Neurology. New York: Raven Press; 1991. p. 59-77.

154. Schmidt D, Baumgartner C, Loscher W. The chance of cure following surgery for drug-resistant temporal lobe epilepsy. What do we know and do we need to revise our expectations? Epilepsy Res. 2004; 60: 187-201.

155. Schwarcz R, Scharfman HE, Bertram EH. Temporal lobe epilepsy: renewed emphasis on extrahippocampal areas. In: Davis KL, Charney D, Coyle JT, Nemeroff C. Neuropsychopharmacology: the fifth generation of progress. Philadelphia: Lippincott Williams \& Wilkins; 2002. p. 1843-55.

156. Scott RA, Lhatoo SD, Sander JW. The treatment of epilepsy in developing countries: where do we go from here? Bull World Health Organ. 2001;79:344-51.

157. Senanayake N, Roman GC. Epidemiology of epilepsy in developing countries. Bull World Health Organ. 1993; 71(2):247-58.

158. Simard S, Rouleau I, Brosseau J, Laframboise M, Bojanowsky M. Impact of executive dysfunctions on episodic memory abilities in patients with ruptured aneurysm of the anterior communicating artery. Brain Cogn 2003;53:354-8.

159. Sheslow D, Adams W. Wide Range Assessment of Memory and Learning Administration Manual. Willmington: Wide Range Inc.; 1990. 
160. Spencer SS, et al.. Mesial temporal sclerosis: eletroclinical and pathological correlations and applications to limbic epilepsy in childhood. In: Avanzini G et al. Limbic seizures in Children. Milão: John Libbey; 2001. p. 41-54.

161. Stafstrom CE. Epilepsy: a review of selected clinical syndromes and advances in basic science. J Cereb Blood Flow Metab. 2006; 26:983-1004.

162. Strauss E, Loring D, Chelune G, Hunter M, Hermann B, Perrine K, et al. Predicting cognitive impairment in epilepsy: findings from the Bozeman epilepsy consortium. J Clin Exp Neuropsychol. 1995; 17: 909-17.

163. Strauss E, Sherman EMS, Spreen O. A compendium of neuropsychological tests Administrations, normas and commentary. 3rd ed. Oxford: Oxford University Press; 2006.

164. Szabó CA, Wyllie E, Stanford LD, Geckler C, Kotagal P, Comair YG, et al. Neuropsychological effect of temporal lobe resection in preadolescent children with epilepsy. Epilepsia 1998; 39:814-9.

165. Takaya S, Hanakawa T, Hashikawa K, Ikeda A, Sawamoto N, Nagamine T, et al. Prefrontal hypofunction in patients with intractable mesial temporal lobe epilepsy. Neurology. 2006;61:1674-6.

166. Thompson PJ, Duncan JS. Cognitive decline in severe intractable epilepsy. Epilepsia. 2005; 46:1780-7.

167. Thompson JM, Gray JM, Crawford JR, Hughes JH, Young AH, Ferrier IN. Differential deficit in executive control in euthymic bipolar disorder. J Abnorm Psychol. 2009; 118: 146-60.

168. Tremont G, Halpert S, Javorsky DJ, Stern RA. Differential impact of executive dysfunction on verbal list learning and story recall. Clin Neuropsychol. 2000; 14: 295- 302.

169. Uijl SG, Uiterwaal CS, Aldenkamp AP, Carpay JA, Doelman JC, Keizer K, et al. A cross-sectional study of subjective complaints in patients with epilepsy who seem to be well-controlled with anti-epileptic drugs. Seizure. 2006; 15:242-8. .

170. Vanderploeg RD, Schinka JA, Retzlaff P. Relationships between measures of auditory verbal learning and executive functioning. J Clin Exp Neuropsychol. 1994; 16: 243- 52. 
171. Vargha-Khadem F, Gadian DG, Watkins KE, Connelly A, Van Paesschen W, Mishkin M. Differential effects of early hippocampal pathology on episodic and semantic memory. Science. 1997;277:376-80.

172. Vargha-Khadem F, Gadian DG, Mishkin M. Dissociations in cognitive memory: the syndrome of developmental amnesia. Philos Trans R Soc Lond B Biol Sci. $2001 ; 356: 1435-40$.

173. Volcy Gómez M. Mesial temporal lobe epilepsy: its physiopathology, clinical characteristics, treatment and prognosis. Rev Neurol. 2004;38:663-7.

174. Villanueva V, Serratosa JM. Temporal lobe epilepsy: clinical semiology and age at onset. Epileptic Disord. 2005; 7:83-90.

175. Wechsler D. Wechsler Intelligence Scale for Children (WISC-III). 3rd. ed. São Paulo: Casa do Psicólogo; 1991.

176. Wieser HG. Differentiating frontal lobe seizures from temporal lobe seizures. Adv Neurol. 1992; 57:267-85.

177. Williams J. Learning and behavior in children with epilepsy. Epilepsy Behav. 2003; 4: 107-11.

178. Wyllie E, Chee M, Granström ML, DelGiudice E, Estes M, Comair Y, et al .Temporal lobe epilepsy in early childhood. Epilepsia. 1993; 34:859-68.

179. Wyllie E. Surgical treatment of epilepsy in children. Pediatr Neurol. 1998; 19:17988.

129. Wyllie E. Surgical treatment of epilepsy in pediatric patients. Can J Neurol Sci. 2000; $27: 106-10$. 